\title{
MAJOR LIFE-CHANGING EVENTS AND PREFERRED RETIREMENT \\ TIME AMONG OLDER ADULTS: EVIDENCE FROM THE 1992 TO 2014 \\ HEALTH AND RETIREMENT STUDY
}

A Dissertation
presented to
the Faculty of Personal Financial Planning
at the University of Missouri-Columbia
In Partial Fulfillment
of the Requirements for the Degree
Doctor of Philosophy
bU by
Dr. Rui Yao, Dissertation Supervisor
JULY 2019


(C) Copyright by Guopeng Cheng 2019

All Rights Reserved 
The undersigned, appointed by the dean of the Graduate School, have examined the dissertation entitled

\section{MAJOR LIFE-CHANGING EVENTS AND PREFERRED RETIREMENT TIME AMONG OLDER ADULTS: EVIDENCE FROM THE 1992 TO 2014 HEALTH AND RETIREMENT STUDY}

presented by Guopeng Cheng,

a candidate for the degree of doctor of philosophy, and hereby certify that, in their opinion, it is worthy of acceptance.

Dr. Rui Yao

Dr. Frances Cogle Lawrence

Dr. Abed G. Rabbani

Dr. Phil Deming 


\section{ACKNOWLEDGMENTS}

I would like to express my deepest appreciation and sincere gratitude to my advisor and committee chair, Dr. Rui Yao, for her continuous support of my PhD study. Dr. Yao has taught me more than I could ever give her credit for here. I first got to know Dr. Yao in my junior year; she has become my role model since then. Dr. Yao has guided me through my master and $\mathrm{PhD}$ studies. She has imparted to me advanced knowledge of

conducting research and given me precious opportunities and honest advice, thus building my confidence in my academic and career pursuits. Dr. Yao has inspired me by her hardworking manner, attention to detail, and professional attitude. I give Dr. Yao credit for a great deal of the success I have achieved today. Her endless support played a significant role in enabling me to research and write this dissertation. Without her guidance and persistent help, this dissertation would not have been possible.

Besides my advisor, I would like to thank the rest of my dissertation committee members, Dr. Abed G. Rabbani and Dr. Phil Deming, for their great support and valuable comments. I am thankful to Dr. Rabbani for supporting my job search and letting me teach his risk management class as a guest lecturer. I thank Dr. Deming for serving as the committee member from outside my program, for always inspiring me, for encouraging my thinking on the development of this dissertation, and for supporting my job search.

Finally, I would like to express my appreciation for my parents, who have helped, loved, and encouraged me throughout my life. I have always known that they believe in me and want the best for me. Studying abroad has changed my life and opened my eyes to the world; it could not have happened without their financial and emotional support. I 
would like to thank both of them for giving me the strength to reach for the stars and chase my dreams. 


\section{TABLE OF CONTENTS}

ACKNOWLEDGMENTS ii

LIST OF ILLUSTRATIONS ................................................................................. vii

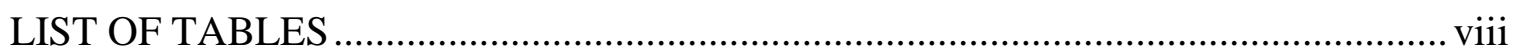

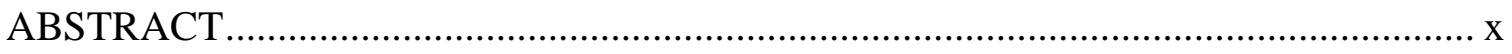

CHAPTER 1: INTRODUCTION TO THE STUDY …………………................... 1

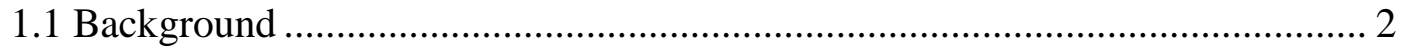

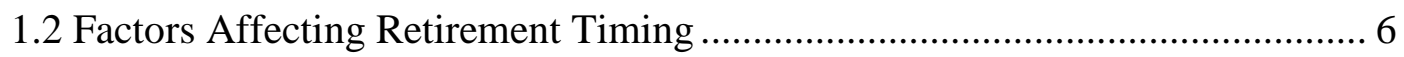

1.3 The Emergence of Empirically Tested Life-Changing Events .......................... 9

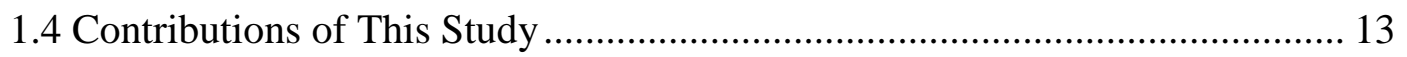

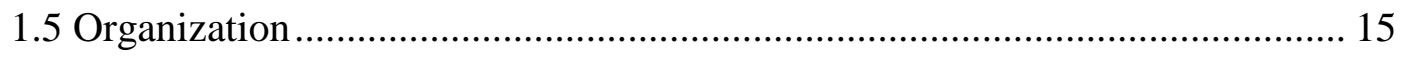

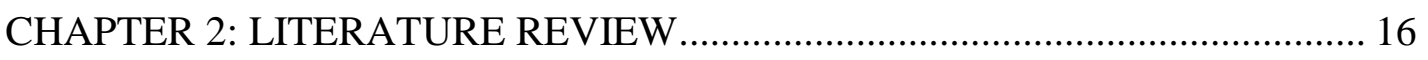

2.1 Effects of Life-Changing Events.............................................................. 16

2.1.1 Change in Marital Status......................................................................... 17

2.1.2 Change in Financial Status................................................................ 18

2.1.3 Change in Health Condition....................................................................... 21

2.2 Other Considerations Besides Life-Changing Events ...................................... 22

2.2.1 Effects of Demographic Characteristics …………………………….... 23

2.2.2 Effects of Economic Factors .............................................................. 29

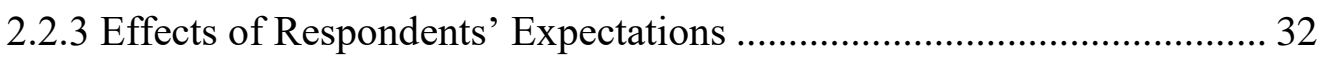

CHAPTER 3: CONCEPTUAL FRAMEWORK ………………………................ 38

3.1 An Explanation of Each Life-Changing Event Affecting Retirement Timing 39

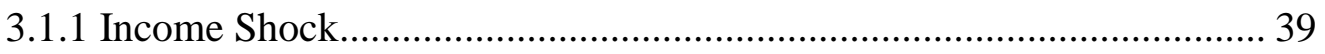

3.1.2 Wealth Change ...................................................................................... 40

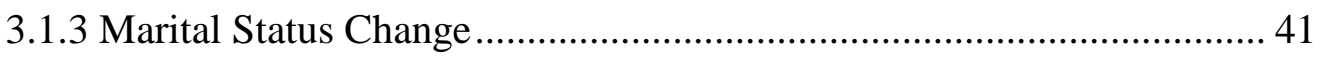




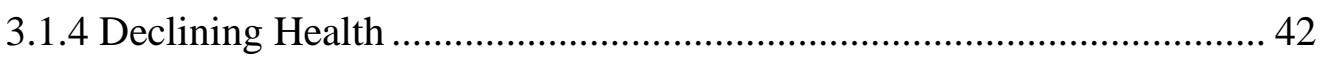

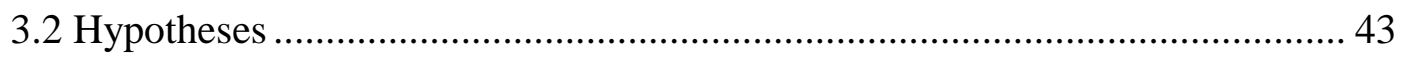

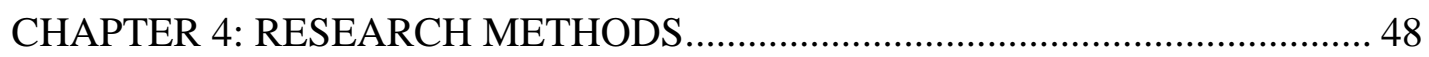

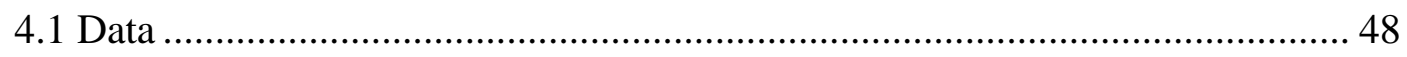

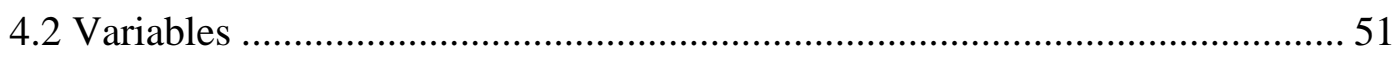

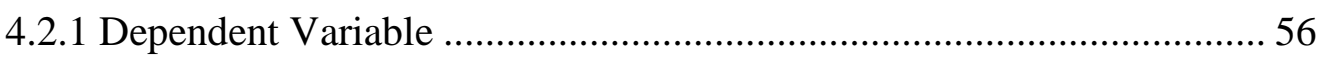

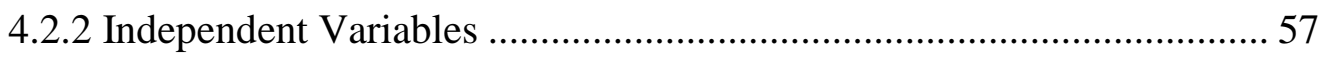

4.2.2.1 Major life-changing events ...................................................... 57

4.2.2.2 Demographic characteristics ..................................................... 61

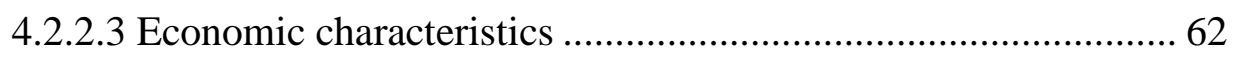

4.2.2.4 Respondents' expectations and preferences .............................. 63

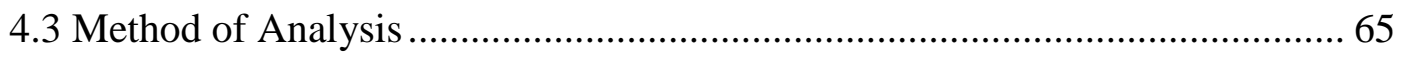

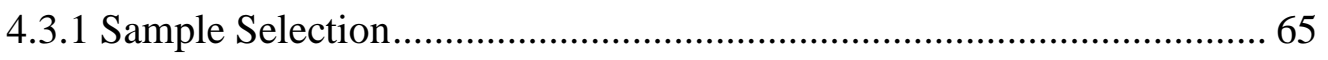

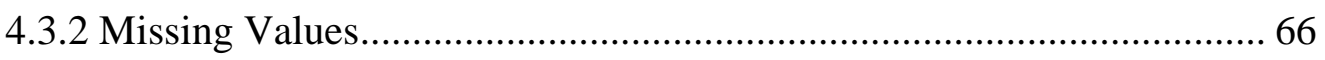

4.3.3 Descriptive Analysis and Linear Regression Analysis ........................... 66

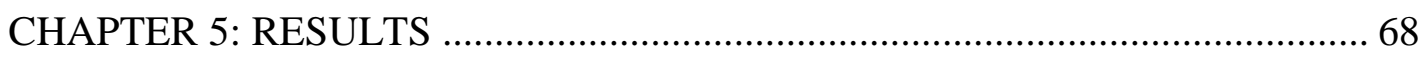

5.1 Sample Characteristics Concerning Retirement Years ...................................... 68

5.2 Sample Characteristics Concerning Major Life-Changing Events ................... 69

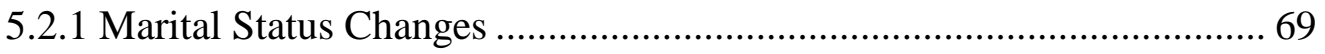

5.2.2 Health Status Changes ........................................................................ 76

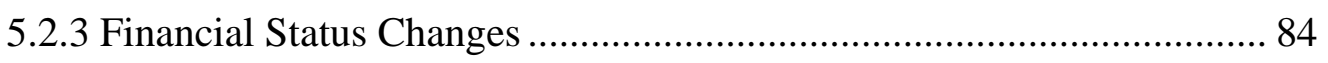

5.3 Sample Characteristics Concerning Demographics, Economics, and

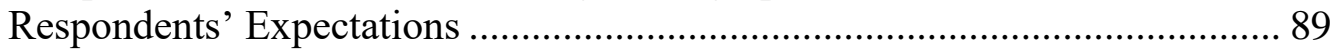

5.4 Summary of Retirement Timing by Sample Characteristics............................. 99

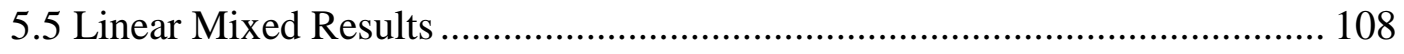

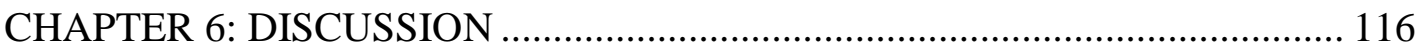




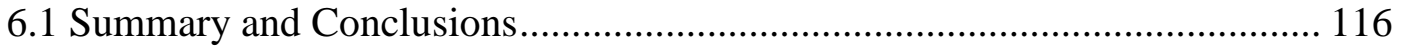

6.1.2 Life-Changing Events ............................................................ 116

6.1.2 Non-Life-Changing Characteristics ............................................ 121

6.2 Limitation and Implications ............................................................. 129

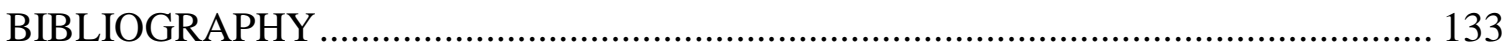

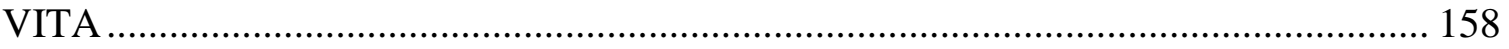




\section{LIST OF ILLUSTRATIONS}

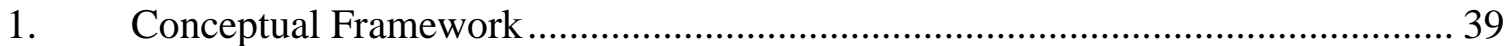




\section{LIST OF TABLES}

1. A Definition of the RAND HRS Waves, Their Years, and Number of Observations

2. Summary of the Variables Used in the Empirical Model in This Dissertation .... 52

3. Sample Characteristics Concerning Retirement Timing. 69

4. Summary of Marital Status Changes - Not Married to Married Before Retirement 73

5. Summary of Marital Status Changes - Married to Divorced Before Retirement . 73

6. Summary of Marital Status Changes - Married to Widowed Before Retirement. 74

7. Summary of Marital Status Changes - Remained Married Before Retirement .... 74

8. Summary of Marital Status Changes - Never Married Before Retirement........... 75

9. Summary of Health Status Changes - Diagnosed with Diabetes Before Retirement 79

10. Summary of Health Status Changes - Diagnosed with Cancer Before Retirement

11. Summary of Health Status Changes - Diagnosed with Lung Disease Before Retirement 80

12. Summary of Health Status Changes - Diagnosed with a Stroke Before Retirement 81

13. Summary of Health Status Changes - Diagnosed with Heart Disease Before Retirement. 81

14. Summary of Health Status Changes - Reported Depressed Before Retirement ... 82

15. Summary of Health Status Changes - Diagnosed with a Psychiatric Problem Before Retirement 83

16. Summary of Financial Status Changes - Positive Income Shock Before Retirement 86

17. Summary of Financial Status Changes - Negative Income Shock Before Retirement 86

18. Summary of Financial Status Changes - Wealth (Mean and Median). 87 
19. Summary of Respondents' Characteristics Besides Life-Changing Events (Demographics, Economics, and Expectations) ................................................... 91

20. Summary of Retirement Timing by Sample Characteristics .............................. 100 


\begin{abstract}
This study evaluated the way life-changing events affect older adults' preferred and actual retirement age using the 1992/1993, 1994/1995, 1996, 1998, 2000, 2002, 2004, 2006, 2008, 2010, 2012, and 2014 surveys of the Health and Retirement Study (HRS). In this dissertation, retirement timing was measured by the gap between a person's actual retirement year and planned retirement year. The study focused on three categories of major life-changing events - marital, health, and financial status changes - and how they were associated with individuals' retirement timing. The study compared characteristics of individuals who retired earlier than their preferred retirement time to those who delayed retirement and retired on time. The findings provide insights into the way lifechanging events and other factors influence the time people exit the workforce. The discussion section offers recommendations for researchers as well as financial educators and practitioners working with older adults to increase awareness of life-changing events' effects on retirement time. After controlling for other factors, the findings lend empirical support to the belief that some major life-changing events are significantly associated with individuals' retirement time. The results showed consistent positive correlations between retirement timing and whether a person was widowed, experienced a positive income shock, or had diabetes, cancer, or heart disease. Other life-changing events were found to have statistically significant negative correlations. Negative associations existed with mental health status changes; people who reported they were depressed or received a diagnosis of a psychiatric problem retired earlier than planned.
\end{abstract}

Keywords: major life-changing events, planned retirement time 


\section{Chapter 1: Introduction to the Study}

Even the best planners cannot anticipate and account for every variable that the future holds. People who carefully plan might have reserve funds set aside for an unexpected cost, or they might keep themselves in good shape with the expectation that doing so will minimize their future healthcare expenses and help to ensure a good quality of life in their golden years. On the other hand, many people are gamblers by nature. Rather than plan, they live in the now, saving very little and hoping that the future will provide for itself. Regardless of whether a person is a planner, a gambler, or somewhere in between, some events are so momentous that they completely confound expectations. These are the life-changing events. They vary and are usually deeply personal, but often, the results are the same: Life-changing events reshape people's future. A person has little choice other than to be reactive, rather than proactive, in the face of such a redefining experience.

Whether it is a marriage or a divorce, a drastic improvement in health or a sudden injury, or an unexpected windfall or unemployment, a life-changing event rewrites a person's autobiography. Perhaps the most common financial aftereffects concern retirement planning. People often change their plans for retirement, especially the age at which they retire, after experiencing life-changing events. This study examines how these events affect people's preferred retirement time, empirically comparing the characteristics of individuals who retired early to those who delayed retirement. The aim is to gain a better understanding of how to maintain financial health when life-changing events are on the horizon and to endure, even thrive, with as little upheaval as possible after such events occur. 


\subsection{Background}

Many previous studies have defined retirement as the time at which a person ceases to work completely or withdraws from the waged work life (Denton \& Spencer, 2009; Fisher, Chaffee, \& Sonnega, 2016). The Oxford English Dictionary's definition of "retirement" corresponds to what previous researchers have provided: "The action or fact of leaving one's job and ceasing to work." For many people, retirement means working hard all their lives to reach a point sometime in the future, usually in their 60s (Anspach, 2019), when they can begin to live the good life because they have sufficient assets, investment income, and capital set aside that they can cease to trade their time for the dollars that their jobs or professions provided for their technical skills and abilities.

Prior to 1900, there was no systematic research on retirement. From 1900 to 1950 , a minimal amount of research focused on household financial issues, but from 1950 to 1980, researchers began to examine multiple aspects of households, including their retirement (Shultz \& Wang, 2011). Researchers started to merge longitudinal studies of retirement between 1980 and 2000. The retirement landscape has been in flux for the past two decades, and because of that uncertainty, more and more researchers since 2000 have begun to investigate the process of retirement (Shultz \& Wang, 2011).

The traditional models of earning indicate that people set aside a small amount of retirement savings every year and invest it in stocks, bonds, or annuities. However, today's world is very different, and many reasons contribute to the differences in retirement behavior identified in the past 20 years. This background section will explore each reason in turn. First, Social Security's future payouts have become unpredictable, making for a challenging climate for retirement savings (Social Security Board of 
Trustees, 2017). People are attempting to plan for a future while the United States' financial policies are constantly changing, the Social Security earnings test has been eliminated for individuals who have reached full retirement age, and the eligibility age for full benefits has increased. Workers' average retirement age has increased over time in response to such social and economic demands (Zickar, 2013). By 2018, approximately $40.1 \%$ of individuals who were 55 years and older actively participated in the workforce. This participation rate increased steadily, up from 32.4\% in 2000 (U.S. Department of Labor, 2018). Workers in the past 20 years have delayed their retirement significantly to receive full Social Security benefits.

Second, most employers are no longer offering healthcare benefits for retirees. In $2010,17.7 \%$ of employees worked for an employer that offered health coverage to early retirees, down from $28.9 \%$ in 1997, and in the same period, the percentage of nonworking retirees over age 65 with employer-provided health benefits dropped from $20 \%$ to $16 \%$ (Fronstin \& Adams, 2012). Therefore, more retirees now try to rely on Medicare, which is a less generous program for covering the medical expenses typically associated with older age. In a study of annual healthcare costs in the year 2011, researchers estimated that the average spending on Medicare-covered services for a 65-year-old or older individual was $\$ 14,890$ (McArdle, Stark, Levinson, \& Neuman, 2012). Of that total, Medicare covered an average of $\$ 11,930$ (80\%) while two comparison plans—one a typical plan for people who had retired from the federal government and the other a typical preferred-provider plan offered by large private employers-covered $\$ 12,260(82 \%)$ and $\$ 12,800(86 \%)$, respectively. Couple this change with the fact that healthcare costs increase faster than other sectors of the economy. Healthcare spending in 
the United States nearly doubled from 2000 to 2010, and though the rate of growth has slowed since, it is expected to be higher than the growth of the economy for the near future (Pritchard et al., 2016). In short, more workers anticipate covering substantial portions of future healthcare expenses and struggle to predict just how big those expenses will be. These changes and uncertainties in the healthcare market have affected people's retirement decision-making.

The money available to afford healthcare costs in retirement is a real concern, but the money to be able to afford anything and everything — every living expense — is, of course, an even more significant factor influencing people's retirement times. Therefore, a person's anticipated retirement income is arguably the biggest consideration when thinking about when to retire. The third reason for changes in retirement behavior over the past two decades is that the number of pension plans available in both the private and public sectors has declined in the past 20 years (Butrica, Iams, Smith, \& Toder, 2009). The decline in private pensions began in the 1980s and has continued into the $21 \mathrm{st}$ century (Zickar, 2013). Compared with 292 Fortune 500 companies that offered defined benefit (DB) plans in 1998, only 99 provided such plans in 2015 (Geisel, 2016). Upon retirement, retirees with a DB plan receive, for the rest of their lives, a fixed amount of money based on their previous salary and number of years of service. With defined contribution (DC) plans, participants bear $100 \%$ of the investment risks and must take an active role in making uncertain investment choices (Yao \& Cheng, 2017). Payouts vary based on the investment decisions the employee makes. In the meantime, the federal government has created a variety of financial tools that help employees to save for their retirement and at least partly replace companies' vanishing DB plans. For example, Roth 
individual retirement accounts (IRAs) permit employees to contribute after-tax income into accounts that allow tax-free withdrawals, subject to restrictions. 401(k) plans allow workers to contribute pre-tax dollars to a savings account, to both save for retirement in the long term and reduce taxable income in the short term.

In an analysis of the U.S. Census Bureau's Current Population Survey, the results illustrated that access to employer-sponsored DB or DC plans in the private sector has declined, dropping from $60.4 \%$ in 1999 to $50.9 \%$ in 2014 among employees aged 21 to 64 years (Brown, Saad-Lessler, \& Oakley, 2018). The researchers defined "access" as the employer sponsoring one or more retirement plans, regardless of whether an employee qualifies or contributes. Access dropped sharply in the 2001 recession and then again after the 2008 financial crisis and has remained low, with only $50.9 \%$ of employees having access in 2014. Small firms tend to offer less access to employer-sponsored retirement plans. On the contrary, large firms offer more access and benefits to their employees (Pew Charitable Trust, 2016). Moreover, Brown et al. (2018) noted that declining access over the past decade has mirrored employees' declining participation rates in the United States. There has been a noticeable decrease in the percentage of employees participating in employer-provided retirement plans, from $47.4 \%$ in 2001 to $40.1 \%$ in 2014.

Thus far in this section, the flux in the retirement landscape over the past 20 years has been attributed to three types of changes — namely, those in Medicare policies, in access to retiree healthcare, and in access to employer-sponsored retirement plans. There is a fourth factor: Demographic changes are a major force behind discussions of individuals' retirement timing. The United States is currently going through what is often 
called an age revolution. This change will continue through the first half of this century.

Based on the U.S. Census Bureau's projection (U.S. Department of Commerce, 2009), the percentage of the population that is age 65 and older has been increasing significantly, from 3.1 million which counted as $1.2 \%$ in 1900 to 40.2 million which counted as $13.0 \%$ in 2010 , and will continue to grow rapidly, reaching 88.5 million which counted as $20.2 \%$ in 2050 . Because of these demographic shifts, along with changes in people's tools for and habits of saving for retirement, the study of retirement has grown substantially in the past decade and had included the factors associated with retirement timing. For all of the reasons listed in this section, adults in the United States no longer fit into the traditional models of planning for and taking retirement. There have been too many changes since the turn of the 21 st century. This study seeks to update the traditional notions of retirement by focusing on life-changing factors that impact the decision of when to retire.

\subsection{Factors Affecting Retirement Timing}

The previous section focused on what might be thought of population-wide factors, meaning the elements of retirement decision-making that affect the entire population of American workers. In contrast, this section hones in on an individual's decision factors, which are unique and more personal to each worker. Besides changes in the country's social and economic atmosphere, workers' characteristics are directly associated with retirement timing. Income and wealth are two significant inputs for retirement timing decisions. Some researchers have found that workers with fewer financial assets may remain in their jobs longer. On the other hand, those with greater financial assets can afford to retire at an early age (Kim \& DeVaney, 2005). Changes in 
earnings before retirement age have a strong influence on retirement patterns. However, it is important to note that the inputs that impact low-income workers' retirement decisions are different than those of middle- to high-income individuals. While Kim \& DeVaney (2005) found that greater financial assets motivate people to retire early, Mitchell and Fields (1984) found that base wealth was associated with earlier retirement whereas higher income was associated with later retirement. Because Social Security benefits are progressive, when low-income workers retire, they receive a higher proportion of their before-retirement income. Therefore, Butrica, Iams, and Smith (2007) concluded that a high replacement of pre-retirement income induces low-income workers to retire early. Workers who have high incomes or limited workforce participation have lower probabilities of retiring early (Butrica et al., 2007). High-income earners are less likely to claim Social Security before their full retirement age; they continue to work to maintain the standard of living to which they are accustomed. Workers with limited labor participation continue to work because they gain relatively more from doing so since their contributions over time to the Social Security fund have not yet ensured a high payout.

In addition to income and wealth, researchers have examined how marital status affects the decision to retire and have found that retirement is not a decision a married individual makes alone but, rather, a decision that spouses make jointly (Smith \& Moen, 1998). Married workers are more likely to continue working if their partners also do so (Gustman \& Steinmeier, 2000) and typically choose similar retirement times (Henretta, O’Rand, \& Chan, 1993; Johnson \& Favreault, 2001). One study found that nearly a quarter of sample married couples retired within 1 year of each other (Hurd, 1990). 
Spouses also factor in how much time they want to spend with one another when planning their retirement times, basing retirement dates on how much leisure time they want with each other (An, Christensen, \& Gupta, 2004; Shaw, 1984).

It is difficult to predict the degree to which health affects labor force participation among older employees, but it is clear that good health motivates people to some degree to continue working and postpone retirement (Wheaton \& Crimmins, 2013). Individuals' retirement times are related closely not only to retirement income but also to physical health (Calvo, Sarkisian, \& Tamborini, 2012). Health's effects on retirement time have been examined in several previous studies (e.g., Calvo et al., 2012). Some of these have found that good health postponed individuals' retirement (Dave, Rashad, \& Spasojevic, 2008; Jaeger \& Holm, 2004) while others have found that it led individuals to retire early (Jokela et al., 2010). Between 1982 and 1993, there was a dramatic increase in the number of workers who continued to work beyond their 60s. This phenomenon could be explained by increases in healthy behaviors, better health conditions over people's lifespans, and declines in critical diseases such as cardiovascular disease and arthritis (Crimmins, Reynolds, \& Saito, 1999). Bound, Stinebrickner, and Waidmann (2010) confirmed that poor health leads to labor force withdrawal among older males. They found the probability of exiting the workforce before the age of 62 was 5 times greater for those individuals in poor health than for those who were in average health. Moreover, individuals aged 47 to 64 who were suffering from lung disease and cancer were 13.1 and 4.8 times more likely, respectively, to retire early within an 8-year period than those who were in good health. Workers who had diabetes and arthritis were 3.4 and 1.9 times more likely to retire than to remain working (Shultz \& Wang, 2007). 
Financial status (income and wealth), marital status, and health—all three seem to affect retirement decisions, and a major upheaval to any of these decision factors might alter when a person chooses to retire. Understanding the effects of life-changing events on individuals' retirement timing highlights the importance and benefit of financial education for pre-retirees as well as for financial professionals, who need to work closely with clients dealing with life-changing events to make suitable adjustments to their retirement decisions. This study uses data from the 1992 to 2014 Health and Retirement Study (HRS) to investigate whether life-changing events have significant effects on individuals' retirement timing. This dissertation examines three types of life-changing events: changes in marital status, financial status, and health condition. Other factors affecting individuals' retirement timing are also analyzed. The results of the current study have extensive implications not only for pre-retired workers but for everyone related to the financial planning industry.

\subsection{The Emergence of Empirically Tested Life-Changing Events}

To know which life-changing events warrant examination in this dissertation, one must understand which events have been identified in the research literature as the most profoundly life-altering. This section explores researchers' findings concerning life events over the last half-century and which ones have been empirically ranked as the most life-changing.

Adolf Meyer originally devised the life chart to keep records about people's major life events (Rahe, 1992). Adolf Meyers' (1951) research on the life chart as a tool in medical diagnoses was first recognized at the 1949 Conference on Life Stress and Bodily Disease sponsored by the Association for Research in Nervous and Mental Diseases. 
Starting in 1908, during the time Meyer worked at the Henry Phipps Psychiatric Clinic, he sought a way to record a patient's history, present condition, the condition of each organ and its function, and the development and condition of the patient's integrated personality (Meyer, 1951). The goal was to investigate the relationship between a patient's life events and symptoms. His team created a unique way to graphically record patient information by using a life chart, reporting on both physical illnesses, which were also referred to as disorders of the various organs, and mental status, which included a patient's current living situation and reactions to certain life changes. Each of his patients had different life experiences, a different life than the other patients. Meyer noted marital status changes and health condition changes, both physical and mental, in his life charts.

Based on the life chart invented by Meyer, 15 years later, Holmes and Rahe (1967) worked on quantifying the extent of social adjustments required by select events. Also, these researchers sought to specify the qualities of events that were related to later illnesses. They collected data from 394 subjects who completed the researchers' test, which included 43 life events empirically derived from clinical experience. Each item was designed to contain life events that were either indicative of or required a significant change in an individual's ongoing life pattern. Subjects were asked to rate a series of such events as to their relative degrees of necessary readjustment. Subjects needed to use all of their personal experiences to arrive at their answers.

Holmes and Rahe (1967) developed the Social Readjustment Rating Scale based on the sample's estimations of the amount of social readjustment an average person would experience when an event occurs. As defined by the researchers, social readjustment refers to the degree and duration of a person's accommodation to a life 
event, regardless of the event's desirability. When using the Social Readjustment Rating Scale, a score for a period of time denotes the total readjustment a subject makes by summarizing the estimated social readjustment values of those life events that happened during that time frame. These adjustments are always stressful to some degree, and the accumulation of a substantial number of changes and the adjustments they require often place significant stress on physical or mental health. Even though different subjects assigned a different order and magnitude to the life-changing events tested, Holmes and Rahe (1967) explained that variation is normal and based on the subject population's histories. Where they found a high degree of consensus, the findings suggested agreement among individuals that these particular life events were significant in altering the course of a person's life.

Among all the 43 life events—which concerned marriage, occupation, economics, residence, group and peer relationships, education, religion, recreation, and healthmarital status changes, financial changes, and health changes were ranked at the top as priorities above the other life events concerning education, religion, recreation, and group and peer relationships (Holmes \& Rahe, 1967). For example, the change that the researchers labeled as Death of Spouse was ranked first as the most profoundly lifechanging event. Divorce was ranked in second place, followed by Marital Separation in third, Personal Injury or Illness in sixth, Marriage in seventh, and Change in Financial State in sixteenth. As Holmes and Rahe (1967) mentioned, these events connect to major areas of dynamic significance in the social structure of the American way of life. Many of them are socially recognized and consonant with American values. 
Rabkin and Struening (1976) stated that the purpose of life-events research is to demonstrate an association between the onset of illness and the number of life events that require individuals to make changes and socially adaptive responses. In their study, they also mentioned that most investigators working in this field had adopted Holmes and Rahe's (1967) Social Readjustment Rating Scale for ranking the same 43 life events. Rabkin and Struening (1976) concluded that using this life events approach to measure stress and illness was an attractive, directive, and simple way to conduct research because of the ease of data collection; it made common sense to participants as well. However, Rabkin and Struening (1976) also noted that other studies that examine life events must develop and implement a germane domain of life events that is strictly relevant to the topic and population being studied, thus suggesting that Holmes and Rahe's (1967) list of 43 events might not always be the best.

Later studies have also raised questions about the generalizability of Holmes and Rahe's Social Readjustment Rating Scale. Redfield and Stone (1979) collected survey questionnaires from 85 participants and crafted a list of life events based on the number of occurrences across participant responses. Each participant received a questionnaire that included 44 life events with instructions attached. The researchers (Redfield \& Stone, 1979) controlled the order of events listed in the questionnaire, introducing an independent random order because Hough, Fairbank, and Garcia (1976) had found that the order of the events influenced social adjustment ratings. Redfield and Stone (1979) grouped the 44 life events into three categories: Personal Catastrophe, Achievement, and Domesticity. The life events included in the Personal Catastrophe classification, such as Death of Spouse and Illness or Injury to Family Members, can cause great and sudden 
damage or suffering. Life events related to Achievement reflected personal success and the improvement of interpersonal relations and financial conditions. They included Improved Finances and Promotion at Work. The third event category, Domesticity, included Pregnancy and Birth of Child.

Over 40 years ago, the research into 43 life events conducted by Holmes and Rahe (1967) as well as into 44 life events by Redfield and Stone (1979) identified changes in financial, marital, and health status as three categories of events that significantly impact individuals' lives. As Rabkin and Struening (1976) noted, future studies on life-changing events should narrow the focus to those events directly and strictly related to the research topic. Therefore, this dissertation includes the three categories of major life events that have been proven by the previous studies to be lifechanging and that are directly associated with individuals' retirement times. Indeed, this study goes one step further by breaking apart one of the three categories, financial status, into (a) changes in income and (b) changes in wealth since the retirement-related research literature distinguishes between how these two factors affect retirement decisions, as explained in Chapter 2.

\subsection{Contributions of This Study}

This dissertation investigates how major life-changing events, including changes in financial status (income and wealth), marital status, and health condition, are associated with people's retirement times. Previous studies that have examined retirement consider it a stressful yet critical decision (Bossé, Aldwin, Levenson, \& WorkmanDaniels, 1991; Matthews, Brown, Davis, \& Denton, 1982; Singh, Kaur, \& Kaur, 1984). However, very few studies have focused on analyzing the way life-changing events are 
associated with individuals' preferred retirement times (Atchley, 1982; Matthews \& Brown, 1987). When they have, past studies have generally focused only on financial status or the retiree's own health (Banks, Breeze, Lessof, \& Nazroo, 2006; Lumsdaine \& Mitchell, 1999; Shanas, 1970). Previous retirement research has spent very little time examining the impacts of other notable events, such as marital status changes or the development of serious health problems among family members.

Studies have shown that the comparative timing and buildup of life events are key predictors in whether the events will become truly life-changing and require adjustments to a person's life course (Feeney, Dooley, Finucane, \& Kenny, 2015; Palmer, Bhargava, $\&$ Hong, 2006). This dissertation is the first to evaluate and seek to understand the effect of this particular range and accumulation of life-changing events on an individual's retirement time. Specifically, it examines change effects over time by examining individuals' data in the HRS, a nationally panel study of older adults. It contributes to the current literature on retirement time by investigating the relationship between the occurrence of major life-changing events and individuals' elective decisions of when to retire using 12 waves of the HRS from 1992/1993, 1994/1995, 1996, 1998, 2000, 2002, 2004, 2006, 2008, 2010, 2012, and 2014. Major life events may trigger individuals to take significant actions, such as early or late retirement. Understanding life-changing events' effects on the time at which people retire helps individuals and their financial advisors to communicate about and plan for these changes, even if the events themselves are usually unexpected. Consequently, this study's findings have the potential to contribute to the future education of scholars in the field of retirement research and, indeed, any individuals planning for retirement. 


\subsection{Organization}

This dissertation is organized into six chapters. The next chapter reviews the relevant literature on the relationship between retirement time and major life events, including marital status change, financial status change, and health condition change. It delves into the relationships between the time at which individuals retire and demographic and economic characteristics as well as people's expectations and preferences concerning retirement. Chapter 3 introduces the conceptual framework for this dissertation, which has been built upon several existing theories: substitution effect, income effect, life-cycle model, life course theory, continuity theory, and role theory. The chapter also presents this dissertation's hypotheses, which are based on the conceptual framework. Chapter 4 introduces the data and variables used for the analysis and also justifies the empirical methodologies adopted in examining the factors related to HRS survey respondents' retirement timing. Chapter 5 discusses the research results, describing the sample's characteristics, the observed relationships between major lifechanging events and the time at which individuals retire, and the robustness check using the income risk aversion variable. The final chapter summarizes the findings and discusses their implications for individuals, financial professionals, and future research. 


\section{Chapter 2: Literature Review}

Life-changing events and other factors have been found to be associated closely with older individuals' retirement timing (Feeney et al., 2015; Szinovacz \& Washo, 1992). For example, a change in marital status can be a stressful event for people, both emotionally and financially, particularly with respect to retirement timing. One study found that divorced female respondents were more likely to retire later than were married female respondents (Finch, 2014). Financial changes, including income and wealth changes, also affect people's retirement timing together with the rising cost of living, particularly for medical expenses. Older workers must estimate whether they can afford to retire and live a financially independent life, and some must continue to work until they reach that point (Miller, 2018; Neuman, Cubanski, Huang, \& Damico, 2015; Szinovacz, 2003).

This chapter explores the existing body of research to uncover the factors commonly attributed to why people choose to retire when they do. Many previous studies have focused on the factors that affect retirement timing. The factors can be grouped into life-changing events and more static, non-life-changing characteristics that define a person: demographic variables, economic variables, and occupational variables. The following sections of this chapter adhere to these same categories.

\subsection{Effects of Life-Changing Events}

When compared to demographics and economics, few studies have focused on the association between life-changing events and individuals' preferred retirement time. That said, some studies do exist that provide a guide for how to formulate the current study's conceptual framework. The next three sections describe the research concerning the 
associations between retirement timing and three life-changing events: marital status changes, financial status changes, and health condition changes. It is necessary to understand this research to establish a foundation for formulating the hypotheses presented in Chapter 3.

\subsubsection{Change in Marital Status}

Empirical work has examined the way in which marital status can affect the decision to retire. Researchers have found that retirement is not a decision that an individual makes; rather, it is a decision that spouses make jointly (Smith \& Moen, 1998). One study found that married workers were more likely to continue to work if their partners decided to do so (Gustman \& Steinmeier, 2000). Husbands were less likely to retire before their working wives when race and other household characteristics were controlled (Henretta et al., 1993). Later empirical studies confirmed that respondents were more likely to retire if their spouse had retired already (Johnson \& Favreault, 2001). Leisure is an important factor in a household's planned retirement time because it determines how much time spouses are willing to spend with each other (An et al., 2004; Shaw, 1984). In an analysis of the 1982 Social Security New Beneficiary Survey, Hurd (1990) found that nearly a quarter of married couples retired within 1 year of each other. These findings demonstrate that retirement timing is influenced by marriage. Is retirement timing also influenced by divorce or having never married at all?

Hall and Johnson (1980) confirmed that married individuals were more likely to retire later than single individuals. Also, in a sample from the first 14 waves of the British Household Panel Survey, Finch (2014) found that divorced and single women were significantly more likely to retire later compared to married women. One contribution 
that the current study intends to make is to add to these findings, explaining how changes marital status — single, married, widowed, or divorced — affects people's retirement decision-making.

\subsubsection{Change in Financial Status}

Previous studies have shown that income has a mixed association with retirement time. In their analysis of 5,000 male respondents from the 1966-1983 National Longitudinal Surveys of Older Men, Bartel and Sicherman (1993) found that individuals' income had a negative and significant correlation with the time at which they retiredmeaning that the age at which a person retires goes down when income goes up. Other empirical studies also have confirmed that earned income has a negative correlation with the time of retirement (Damman, Henkens, \& Kalmijn, 2011). One explanation of this fact is that retirement becomes more attractive to individuals who have increased income or have received large amounts of unexpected money (Farnham \& Sevak, 2007). For example, an analysis of data on 496 lottery winners in Massachusetts showed that the winners were more likely to quit their jobs or work fewer hours (Imbens, Rubin, \& Sacerdote, 2001). Studies also have found that individuals who received a large inheritance tended to exit the labor force early (Holtz-Eakin, Joulfaian, \& Rosen, 1993).

Individuals suffer a significant decrease in their income during periods of job displacement. Significant income loss is associated directly with postponing individuals' retirement time. Chan and Stevens (1999a) analyzed 1992, 1994, and 1996 waves of HRS and found that respondent who experienced significant percentages (20\%) of wage loss were more likely to delay their retirement. Anderson, Burkhauser, and Quinn (1986) showed that men who suffered significant income loss were more likely to delay 
retirement than women. Job displacement occurs when an employer removes a current position that is held by an employee. Quintini and Venn (2013) defined job displacement as involuntary job loss due to economic factors, such as economic downturns and company restructuring. By investigating how wages were affected by job displacement, Ruhm (1991) analyzed 3,813 workers who suffered job displacement from 1969 to 1982 waves of the Michigan Panel Study of Income Dynamics. Results showed displaced workers experienced $25 \%$ income loss when comparing their post-displacement wage to unemployment income. Topel (1990) confirmed this result. Specifically, he found substantial and long-lasting effects of job loss on annual earnings and wages. He discovered that annual earnings during the year following displacement were nearly $40 \%$ below their previous level. The majority of this impact was caused by unemployment. Moreover, workers whose employers were shut down suffered a very large (12\%) wage reduction (Stevens, 1997).

While the research described at the beginning of this section demonstrated negative correlations between income and retirement timing, other studies have found that income was associated positively with the time at which people retired. Increased wages reduce leisure because they raise the opportunity costs and provide an incentive to work more hours; therefore, people delay retirement when their income goes up (Pozzebon \& Mitchell, 1989). A net wage increase results in higher leisure costs and prompts individuals to relocate their demand from leisure to consumption, creating a substitution effect that causes individuals to postpone retirement (Pozzebon \& Mitchell, 1989). Interestingly, early retirement induced by the substitution effect is more common 
among low-income individuals than high-income individuals (Conde-Ruiz, Galasso, \& Profeta, 2013) because leisure costs are lower for low-income individuals.

Other studies have also suggested that the associations between income and the time at which people retire are different for low-income earners. In an analysis of a sample of Danish husbands and wives, An et al. (2004) found that low-income individuals in poor health were more likely to retire early. The An et al. study focused on low-income earners, a population that may respond differently to an increase in income than high-income earners.

While it seems obvious on the surface, many people are confused about the fact that income is different than wealth. As Hoffower (2019) wrote, "Wealth isn't about how much money you make or spend—it's about how much money you keep.” As with income, wealth is a good predictor of the time at which individuals retire. For many people, the value of one's home is a large part of their accumulated wealth. By using the HRS data, Szinovacz, Martin, and Davey (2013) found that a decrease in the value of the respondent's primary residence was associated with continuing to work after age 62 . Farnham and Sevak (2007) confirmed this result. Specifically, they found that a $10 \%$ increase in housing value was associated with a 5-month decrease in retirement age. People are generally more likely to leave the workforce if they can financially afford to retire than if they cannot (Taylor \& Shore, 1995). However, some researchers' studies have yielded different results. For example, Gorodnichenko, Song, and Stolyarov (2013) and Disney, Ratcliffe, and Smith (2010) found that housing prices had no significant effect on retirement time. 
Like home values, market returns have been associated directly with the accumulation of wealth in individuals' retirement accounts. Yao and Park (2012) found that market returns had a significant negative correlation with retirement timingmeaning that, as market returns go up, the age at which a person retires goes down. Also, increasing an individual's Social Security wealth (SSW) induces him or her to retire early (Pellechio, 1979). SSW is the present value of future benefits discounted at the market interest rate.

\subsubsection{Change in Health Condition}

Previous studies have examined the effects of individuals' changing health on the time at which they retire. Many studies have found that a decrease in health conditioneither mental or physical - is correlated with a decrease in the age at which a person retires. First, in an analysis of the 1992 through 2006 HRS data, Dave et al. (2008) found that individuals who had difficulties associated with mobility and daily activities, or individuals who experienced declines in mental health, retired an average of 6 years earlier than did their counterparts without such conditions. Second, Calvo et al. (2012) tested four theory-based hypotheses about the way health is associated with individuals' "on time" retirement (defined in the study as age 62); they found that physical and emotional health conditions were associated positively with individuals' retirement age when they controlled unobserved factors. Third, Jokela et al. (2010) conducted a study on British government employees over 15 years, and the results showed that mental health and physical function predicted retirement age. Applying time survival analysis, they found that poor mental health increased the likelihood that individuals would retire early. Fourth, McGarry (2004) discovered that poor health was a significant factor for early 
retirement. She also found that changes in health condition affected individuals' retirement expectation to a greater extent than did changes in income or wealth. Fifth and finally, Damman et al. (2011) confirmed that people intended to retire early if they were diagnosed with health problems during their midlife.

Additional studies have focused specifically on mental health and found that it is closely associated with early retirement. Using data that included 20,655 participants from Australia, researchers (Paradise, Naismith, Davenport, Hickie, \& Glozier, 2012) found that mental illness increased the risk of women's early retirement. Also, Rice, Lang, Henley, and Melzer (2011) revealed that depression is a significant predictor of leaving the workforce early by using the symptomatic depression scale, which was developed by the Centre for Epidemiological Studies. Moreover, Olesen, Butterworth, and Rodger (2012) stated that men and women with poor mental health had a higher rate of early retirement.

Based on the findings described in this section, this paper puts forth the hypothesis that individuals confronted with declining health are more likely to retire early than individuals in good health. Chapter 3 provides more details.

\subsection{Other Considerations Besides Life-Changing Events}

This paper focuses on those life-changing events that are decision factors influencing a person's choice of retirement time. However, it is clear that other factors also affect retirement timing. Previous research has proven that demographic characteristics, economic factors, and expectations and preferences come into play in retirement decision-making. While it is not the purpose of this paper to focus on these 
factors, they are described in the next three sections, respectively, to provide a comprehensive review of the literature.

\subsubsection{Effects of Demographic Characteristics}

Demographic characteristics have been found to be associated with retirement timing. This section describes, in turn, the research related to age, gender, race, education, number of children, and occupation.

Often, the effect of age is examined in research on retirement time. Jex and Grosch (2013) stated that age is one of the most important factors in people's consideration of the time at which they will retire. According to Settersten and Hagestad (1996), the question of when to retire exerts more pressure on older employees in the workforce, especially those who are in positions with lower pay than they expected and those with very little hope of promotion. Numerous studies have found that older workers were more likely to anticipate retiring sooner than younger workers (e.g., Jex \& Grosch, 2013; Kim \& Feldman, 2000). In addition, older workers also have more limited time to work because of declining physical and mental health (Moen, 1996).

Some studies have found that increasing age also causes people to increase the age at which they plan to retire: Zappalà, Depolo, Fraccaroli, Guglielmi, and Sarchielli (2008) found that older employees were more likely to prefer to postpone their expected retirement age than were younger workers. Their explanation for this finding was that older workers who were close to retirement had a better understanding of whether their actual financial situation was adequate for retirement.

Gender is also a common factor examined in studies on retirement time. However, researchers have found mixed results concerning the effects of gender on retirement, 
often concluding that the effects are attributable to other household factors. For example, women are more likely to extend their employment time than are men. On average, women choose to retire later because they have insufficient funds in their retirement accounts (Bardasi \& Jenkins, 2002; Yabiku, 2000) due to the following characteristics that are common to many women's career paths: childbearing interferes with women's careers, women tend to have a history of part-time jobs (Yabiku, 2000), and they tend to have lower incomes than men in older age (Bardasi \& Jenkins, 2002). In addition, Hank (2004) found that, for financial reasons, single mothers with children tend to retire later than do divorced men with no children.

However, some researchers have found that women retire earlier than men for a variety of reasons. One study found that married female respondents in England were more likely to retire before their normal retirement years (Finch, 2014). In their analysis of a panel study, Rice et al. (2011) showed that female workers were more likely to retire early than were male workers when health issues were controlled. Further, previous researchers have found that married women were more likely to be the household caregiver, which led them to stop working early to fulfill household healthcare responsibilities (Dentinger \& Clarkberg, 2002; Moen, 1996). For example, Dentinger and Clarkberg (2002) noted that women respondents were more likely to retire early when their disabled husbands needed physical care. On the other hand, men respondents were more likely to delay retirement when their disabled wives needed physical care. These results can be interpreted by approaching them from a sex-role perspective; men are more likely to have more responsibility for providing financial support and shoulder more 
financial burden during their wives' illness periods, while women more frequently assume the caregiving role.

Race, as well as other demographic characteristics, also has been found to be related closely to retirement age. One study found that Blacks were more likely to retire early when health conditions affected their ability to work (McNamara \& Williamson, 2004). Evidence has shown that Black workers were more likely to report poor health conditions regardless of their actual abilities because of their working environment (Aaron \& Callan, 2011; Bound, Schoenbaum, \& Waidmann, 1996). Gibson (1987) found that Black female workers tended to retire early because of low income and workforce discrimination. Moreover, Gibson (1991) found similar results after analyzing 305 Blacks aged 55 and older in the National Survey of Black Americans. Compared to Whites, researchers have found that Blacks and other minorities are less likely to plan to delay their retirement (McNamara \& Williamson, 2004).

Education is another demographic characteristic reviewed in this section. Educational attainment has been examined frequently in research on retirement timing. Several previous studies have found that education is related positively to individuals' retirement age. By analyzing the 2008 HRS, Szinovacz et al. (2013) found that people with 13 to 15 years of education were more likely to work after age 65 than were those who had equal or less than 12 years of education. Aaron and Callan (2011) also found that lower educational attainment was related to early retirement and higher educational attainment to later retirement (Rice et al., 2011). Higher education can delay retirement because of the extra years more highly educated people spend working to offset their years of schooling. Another explanation for the positive correlation between high levels 
of educational attainment and older retirement ages is that people with a high level of education make more money and have a better working environment, so they tend to work longer than do people with lower levels of education (Mein et al., 2000). However, Blekesaune and Skirbekk (2012) analyzed the Norwegian Ageing and Generation Survey and found that some people with a high level of education and more wealth chose to retire early.

Having children is also a factor which affects the time that people decide to retire. Moen (1996) explained how having children affected people's retirement based on the life course perspective theory. Moen stated that, often, women who have children in earlier life adjust their later-life retirement time. Finch (2014) tried to explain this phenomenon by analyzing participants from the United Kingdom and found that childbearing and the caregiving provided to newborns demanded a lot of time that could not then be dedicated to working outside of the home, resulting in less time spent in the paid workforce. These women caregivers were more likely to continue to work additional years beyond normal retirement age to compensate for the missed work time that they experienced earlier in their lives. Besides spending time taking care of newborns in earlier life, caregiving for older children in later life also influences retirement decisions (Matthews \& Fisher, 2013). Retizes et al. (1998) proposed that providing financial support to children is the main reason women enter the workforce initially. As economic pressure builds over the years of caregiving and the costs for education and living expenses increase, these factors may encourage women to continue to perform a full-time job longer than they had intended when they first entered the workforce. Some may even work beyond full retirement age to ensure their children are supported. 
Other researchers have examined the role that child care plays in parents' retirement processes, whether the parents are male or female. For example, Reitzes, Mutran, and Ferandez (1996) tested how the number of children affected people's decisions to retire. They found that having more children was related to greater delays in retirement. These delays were associated with both parents but more strongly with mothers. Another study showed that individuals who are financially responsible for children are less likely to retire (Szinovacz, DeViney, \& Davey, 2001). The researchers analyzed data from the first two waves of the National Survey of Families and Households, with a sample size of 897 individuals who were employed and aged between 55 and 75 years. They found women who had less frequent contact with their children were more likely to retire at a later time, possibly because this barrier helped them to avoid leaving the workforce to deal with child-related concerns. Pienta and Hayward's study (2002) found a somewhat opposite result compared to Szinovacz et al. (2001). By analyzing data from the 1992 HRS, they found the presence of children delayed retirement for male respondents but not for females. They explained that males typically shoulder more responsibilities as the major income sources to provide financial support to their households when compared to females. Providing additional financial support for children is considered a main function of male individuals acting in the role of father (Dentinger \& Clarkberg, 2002).

The type of occupation a person holds affects the time that people decide to retire. In a study published in 1974, Parnes and Nestel found evidence that differences in retirement timing were related to male workers' occupations. Male professionals tend to delay retirement so that they can remain at their jobs longer than men in other 
occupations, such as blue-collar or clerical jobs. White-collar workers, who generally work in less physically demanding jobs and more pleasant working environments, are more willing to continue their careers and retire later; however, blue-collar workers tend to retire early because of their diminishing competence in performing their physically demanding jobs and their high-pressure work environments (Streib \& Schneider, 1971). Relatedly, another study conducted almost two decades later found that male workers in clerical and service positions had higher probabilities of leaving the workforce because of disability (Hayward, Hardy, \& Grady, 1989). Male professionals with high education levels are more likely to delay retirement as a result of their higher accumulated retirement wealth and other financial rewards (Hayward \& Grady, 1990). House et al. (1990) found that this high risk of death prompted manual laborers to retire earlier than managerial or professional workers. In 1990, House, Kessler, and Herzog found that male workers who were manual laborers were more likely to die at a younger age than male workers who were in managerial and professional jobs. They proved that those workers who changed from manual jobs to managerial jobs had lower levels of mortality risk.

The second occupational characteristic to consider is job access based on race. It affects the types of occupations that individuals have access to and, consequently, their feelings of financial security as they plan for retirement. Black men tend to have servicetype occupations, such as food preparation, building cleaning, and maintenance, when compared to men of other races (Jackson, Chatters, \& Tayler, 1993). Because of working in low-income jobs, which lessens the ability to save toward retirement, these Black workers more often equate retirement with financial insecurity (Jackson, Chatters, \& 
Tayler, 1993). In addition, research has found that Black men and married men are more likely to retire later than White men and single men (Hayward, Hardy, \& Grady, 1989).

Third, the nature of career changes can have long-term impacts on retirement timing. Moore and Hayward (1990) found that a person's longest and last occupations have significant effects on retirement time. Furthermore, working in a series of unrelated jobs is associated with a higher probability of retiring early. Pavalko, Elder, and Clipp (1993) found that men who held a series of unrelated jobs had a higher likelihood of early mortality than those with more stable patterns of employment, suggesting that career patterns are significant factors in determining health and well-being, including longevity. Relatedly, the researchers found that men with a series of unrelated jobs tended to plan for and choose an earlier retirement date because of the toll the jobs took on their health and well-being.

\subsubsection{Effects of Economic Factors}

As with demographic characteristics, a number of researchers have investigated how economic factors impact retirement timing. This section explores their findings.

Sevak (2002) stated that individuals who plan to retire early need to have more money saved in their retirement accounts. Studies also have found that people accelerated their retirement when retirement benefits rose by $20 \%$. According to Hurd and Boskin (1984), a large number of people retired between 1969 and 1972 because of increases in Social Security benefits. Further, Chan and Stevens (1999b) confirmed that changes in a retirement account's value have a direct effect on an individual's planned retirement age. While some researchers have argued that changes in people's retirement savings have no significant effect on the age at which they retire (Burtless, 1986), the preponderance of 
the existing research points to a clear association: increases in retirement benefits result in decreases in people's retirement timing. For example, by analyzing male respondents from the 1992, 1994, 1996, and 1998 HRS, Coile and Gruber (2000) found that SSW affected their retirement time significantly in that each $\$ 10,000$ increase in SSW increased the retirement probability by $0.07 \%$ above the baseline retirement rates.

Moreover, researchers have specifically explored the impacts of DB and DC pension plans on retirement timing. One study found that DB plans are a significant determinant of retirement age (Stock \& Wise, 1990). Using the 1992 to 1998 HRS, Sevek (2002) found that a decrease in male respondents' DC plan balances made them delay their retirement. One reason for this is that retirees considered funds in their DC plans as their major source of retirement income, and accordingly, they felt financially insecure when decreases in these DC balances occurred because they would have an insufficient amount of money to live on at the time of retirement (Lusardi \& Mitchell, 2007). Goodstein (2008) confirmed that wealth has a significant effect on older male respondents and that every $\$ 100,000$ increase in wealth reduced labor force participation by $0.08 \%$ points.

In addition to retirement benefits, health benefits have a significant influence on retirement decision-making. One set of researchers found that individuals who have access to health insurance retire earlier than those who do not have insurance (Blau \& Gilleskie, 2006). Yao and Park (2012) found health insurance coverage in retirement increased the probability of retirement by $63.6 \%$ for those who did not have any investment assets. Based on the results from analyzing the HRS dataset, studies have found that the availability of employer-provided retiree health insurance for older 
employees is associated with their early retirement (Johnson, Davidoff, \& Perese, 2003; Karoly \& Jeannette, 1998). The ability to purchase health insurance after retirement plays an important role in retirement decisions for couples. For example, Szinovacz et al. (2013) found that couples had a high probability of retiring on time if at least one of them was covered by health insurance other than Medicare. Also, Kapur and Rogowski (2006) confirmed that the probability of a husband and wife retiring at the same time increased dramatically if one spouse had employer-provided health insurance after retirement.

Like having health benefits, having a home has been studied by several researchers and found to be an important factor influencing retirement timing. By analyzing the 2006 and 2008 HRS, researchers found that the decreasing value of a person's primary residence was positively associated with delaying planned retirement until after age 62 (Szinovacz, Martin, \& Davey, 2013). Similarly, by using the 1992 to 2002 HRS data, Farnham and Sevak (2007) confirmed that increasing housing values were positively associated with retirement timing. Specifically, a 10\% increase in housing value decreased the expected retirement age by 3.5 to 5 months. Other researchers have found contrary results; other studies have found little evidence of an association between housing values and retirement timing both in and outside of the United States. By using the 1997 to 2007 British Panel Household Survey (BHPS), which is a national survey including more than 5,000 households and contains complete information on their demographics and economic status, Gorodnichenko et al. (2013) found that housing value did not have a significant impact on participants' retirement timing. In a similar study conducted in Great Britain, where the wealth effect in the last 
20 years was examined, there was little evidence to indicate that housing values influenced retirement timing (Disney et al., 2010).

Several studies have tested for correlations between retirement timing changes and housing price changes in response to the Great Recession of the late 2000s (e.g., Scopelliti, 2014). For example, one study that used data from the HRS found that stock prices and housing values dropped in synchronization and caused fluctuations in retirement expectations (Goda, Shoven, \& Slavov, 2012). Taking housing value changes into consideration, Hurd and Rohwedder (2010) analyzed HRS 2009 Internet survey data to investigate the probability that people would continue to work after age 65 , examining respondents who were over age 55 and had working status in 2009 . They found that the probability of continuing to work significantly increased when compared to 2008 baseline data, by nearly $10 \%$ from $39.6 \%$ to $49.5 \%$, and the researchers concluded that a decreasing housing price is a significant factor for delaying retirement and continuing to work.

This section has focused on the following economic factors that affect retirement timing: (a) the value of retirement accounts (Social Security as well as DB and DC plans), (b) the availability of health benefits, and (c) home values. All of these factors are important influencers that affect the age at which people choose to retire. Therefore, all of them must be accounted for when investigating the distinct effects that life-changing events have on retirement time.

\subsubsection{Effects of Respondents' Expectations}

As with demographic and economic factors, an individual's expectations play an important role in retirement timing because expectations concerning inheritances or 
bequests, as well as individual's retirement preferences, shape a person's view of retirement in a broader opportunity structure.

The strain imposed by a job can affect retirement. Stress related to an individual's work-related tasks has been negatively associated with a person's retirement time. Researchers have offered the following rationale for the relationship between job expectations (such as stress level) and retirement behavior: Desirable job characteristics encourage workers to continue to work while undesirable characteristics push workers to retire early (Mein et al., 2000). This study (Mein et al., 2000), involving a British longitudinal study on civil servants, showed that female workers who experienced higher job demands were more likely to take early retirement, but the same relationship did not exist in the study's male participants. The researchers posited that the female employees suffered more pressure when working in high-demand jobs. The psychological impact of retirement appeared to depend both on gender and on the stress levels of the jobs the workers were leaving, with men who were leaving high-stress jobs experiencing a reduction in distress symptoms and men from low-stress jobs reporting an increase in distress symptoms. Low job satisfaction was a significant indicator of early retirement for both men and women (Mein et al., 2000). Moreover, Grosch and Pransky (2009) confirmed that employees working physically demanding jobs were linked to early retirement. They stated that physically demanding jobs tended to become less favorable to older employees; the stress of the workload caused both physical and emotional pressure.

Jobs characterized as having limited opportunities cause stress as well, leading employees to retire early (Beehr, Glazer, Nielson, \& Farmer, 2000). When studying the 
rate at which employees leave a workforce and are replaced, Hanisch and Hulin (1991) found that the planned age of retirement was significantly positively associated with workforce satisfaction. Schmitt \& McCune (1981) suggested that job dissatisfaction, as well as workers' awareness that they were unable to meet the demands placed on them, discouraged individuals from continuing to work and negatively related to their retirement decisions. On the other hand, job holders with more independence or the ability to use a variety of skills were less likely to decide in favor of early retirement. By analyzing 197 older, male state-government employees who were getting ready to retire, as well as their spouses, the researchers found that respondents who received higher social support at work felt less stress and had a lower probability of early retirement (Schmitt \& McCune, 1981). Moreover, the same research found that workers who participated in jobs with more growth opportunities tended to work longer.

A more recent study examining European subjects (De Preter, Van Looy, \& Mortelmans, 2014) found that work expectations greatly influenced female workers' retirement timing, more so than male workers, and female workers were especially influenced by the working environment and stress from their jobs. Workers feel less pressure if they have more workforce flexibility, and it delays retirement for older workers (Earl \& Taylor, 2015). In a study comparing planned retirement years and actual retirement years among a group of Dutch participants, both the pressure and challenge of a participant's job were related to an expected earlier retirement age, while growth opportunities in a participant's job were related to a higher actual retirement age (van Solinge and Henkens, 2014). 
Inheritance has been found to be a significant factor in people's retirement timing as well. Researchers have found that individuals who were lottery winners or received a large amount of inheritance tend to retire early (Holtz-Eakin et al., 1993; Imbens et al., 2001). More than a century ago, Carnegie (1891) wrote about the effect of receiving inheritances on people's decisions to continue participating in the labor force. He said that stopping work and choosing to retire was negatively associated with the amounts of inheritance workers received, which means that the greater the amounts of inheritance that workers receive, the lower attachment they feel to the labor force. Holtz-Eakin et al. (1993) reviewed a sample of personal federal tax returns from the years 1982 and 1985 and focused on a group of 8,500 study participants who received inheritances in 1982 and 1983. The researchers found that a single person who received an approximately $\$ 150,000$ inheritance was roughly 4 times more likely to leave the workforce and retire early than a person who received a $\$ 15,000$ inheritance. Their findings confirmed Carnegie's 1891 results, demonstrating that a large inheritance decreases a person's labor force participation.

The desire and ability to leave bequests to children, family members, or others can further influence people's decisions concerning their desired asset accumulation, thus also affecting their retirement time (Smith, 1995). By studying the 1994 HRS, Smith (1995) found that respondents who believed that leaving a bequest was important accumulated $\$ 86,000$ more in assets than those who placed no importance on bequests, thus they tended to delay retirement to accumulate more wealth. The decisions made by people who intended to make voluntary bequests were associated with other factors too. For example, researchers (De Nardi \& Yang, 2014) found that people who wanted to 
leave luxury goods for their household members increased their savings rates throughout their life spans and continued to work beyond full retirement age. Additionally, they found that, when compared to individuals without an interest in making a bequest, people who intended to make luxury voluntary bequests were either receiving high incomes for their labor or had accumulated more wealth with stronger bequest motives (De Nardi, French, \& Jones, 2010). Similarly, Lusardi (2002) reported that respondents who might save to leave a bequest to future generations tended to retire at a later time.

One last factor has been explored in the relevant literature and found to affect the decision of when to retire. Previous researchers have identified an individual's preference for their financial planning horizon as a significant factor influencing retirement timing. The financial planning horizon is defined as the number of years that a person wants his or her financial assets to last. The importance of planning during the retirement process and prior to actual retirement was reviewed by Taylor and Doverspike (2003). The researchers found that deciding on the appropriate financial planning horizon was related to retirement timing insofar as sound realistic horizons made it possible for people to adhere to their chosen retirement times and avoid unexpected delays. The financial planning horizon helps an individual financially prepare for the transition from full-time or part-time working status to retirement, as well as get ready to retire at an earlier time (Reitzes, Mutran, \& Fernandez, 1996). An effective financial planning horizon relates closely to an individual's retirement goals and expectations. Taylor and Doverspike (2003) pointed out that horizons based on unrealistic expectations and unfillable goals were less likely to help people achieve satisfying retirements. In a later study, Taylor and Schaffer (2013) investigated the relationship between retirement planning and people's 
adaptions to personal characteristics and retirement environments. Notably, they found that environmental changes - including changes to work content, organizational context, and the balance of work and leisure — could cause people to adjust their retirement plans and their retirement timing so that they either retired at a later or earlier time.

People's financial planning horizon is related to the efficiency of retirement planning and timing. After comparing 429 American and 988 Dutch working adults, aged 25 to 64 years, Hershey, Henkens, and Van Dalen (2007) found that American participants were more involved in retirement planning activities and had more realistic retirement goals than Dutch participants did. Their results indicated that Americans had stronger goals and realistic financial planning horizons earlier in their professions. Americans were also more proficient at directly relating retirement planning to the financial resources they currently had, their financial planning horizons, and their financial knowledge, adequacy of saving, and frequency of retirement planning activities. This research highlights the importance of the financial planning horizon in retirement planning and associated retirement time.

This chapter has extensively reviewed the literature regarding factors that impact retirement timing, covering life-changing events as well as demographic, economic, and expectations factors. Chapter 3 uses the knowledge gleaned from this literature to build a conceptual framework for the current study. 


\section{Chapter 3: Conceptual Framework}

Individuals' retirement timing is largely determined by their economic position and personal preferences. Researchers have studied how a change in income and wealth can affect retirement timing using three economic theories: the substitution effect (Kalemli-Ozcan \& Weil, 2010), income effect (Coile, 2004), and life-cycle model (Biggs, 2016). Meanwhile, other scholars have adopted different theories, such as the continuity theory (Wang, 2007), life course perspective theory (Elder, 1995; Quick \& Moen, 1998; Wang, Zhan, Liu, \& Shultz, 2008), and role theory (Ashforth, 2001; Carter \& Cook, 1995), to explain the effects of individual preferences on retirement times. These theories provide the foundation for a wide range of studies on retirement decisions and a complete outline for understanding behavior choices. These theories also form the conceptual framework for the current study's examination of retirement timing, as illustrated in Figure 1. This figure demonstrates that an individual's preferred retirement time, when examined by the relevant extant theories, is primarily dictated by the three major lifechanging events that are the focus of this study and act as retirement decision factors: financial status change (which is divided into income shock and wealth change in Figure 1), marital status change, and the declining health of the individual. 


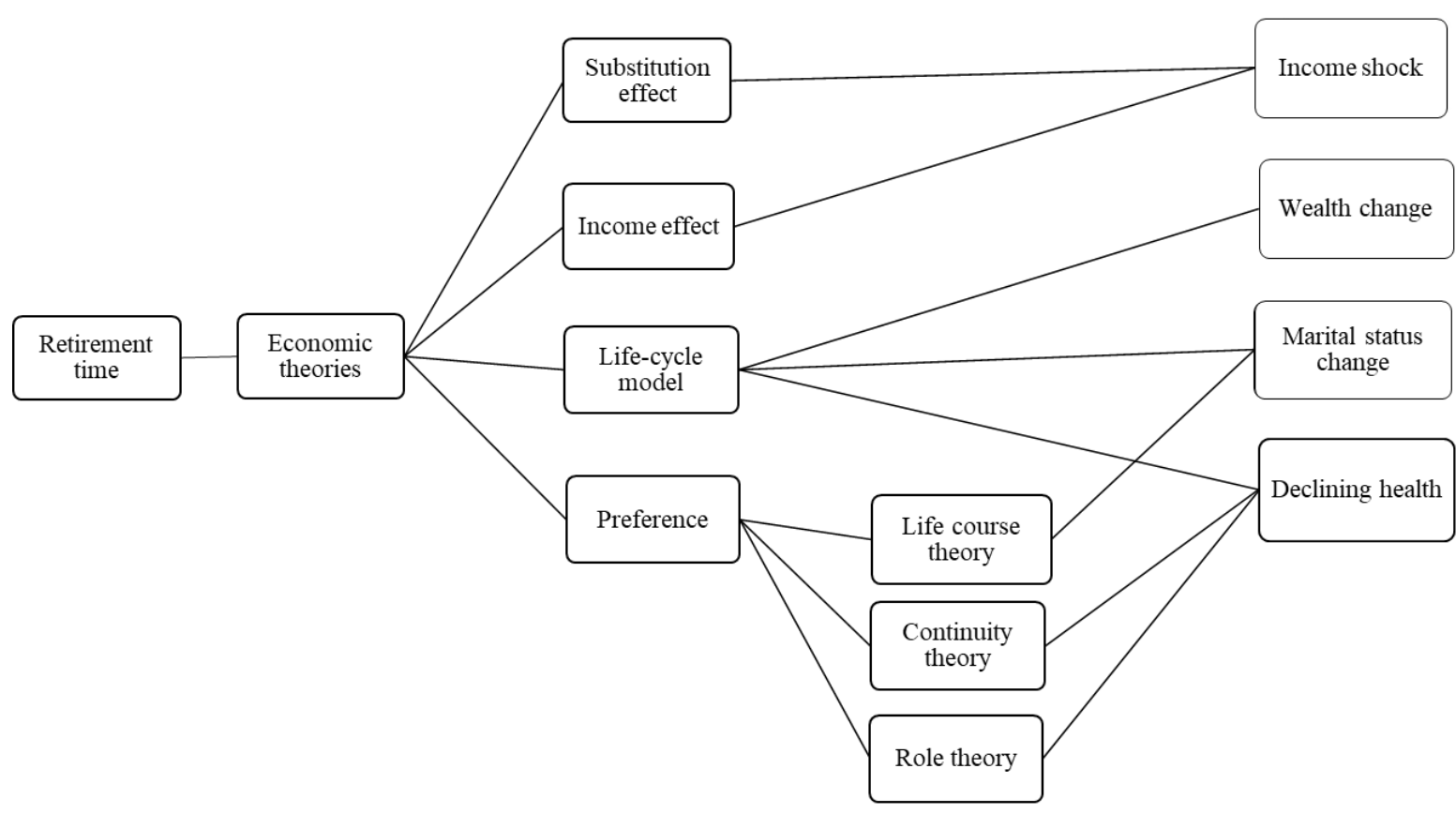

\section{Figure 1. Conceptual Framework}

This chapter begins by examining the six theories (substitution effect, income effect, life-cycle model, life course theory, continuity theory, and role theory) that form the midsection of Figure 1; they can be thought of the links that connect the four decision factors (income shock, wealth change, marital status, and declining health) to retirement timing. After exploring the factors and theories, this chapter ends by presenting the hypotheses that will be tested in this study.

\subsection{An Explanation of Each Life-Changing Event Affecting Retirement Timing}

\subsubsection{Income Shock}

As the words imply, the term income shock is defined as an abrupt change in income. Economically, the retirement decision-making process revolves around a choice between the number of hours a person devotes to work versus leisure time. Whether transitory or permanent, an income shock necessarily affects how a person thinks about 
retirement. The substitution effect (Kalemli-Ozcan \& Weil, 2010) and income effect (Coile, 2004) theories explain how a change in income influences retirement. For example, an increase in income results in dueling effects: an income effect of earlier retirement and a substitution effect of delayed retirement (Burbidge \& Robb, 1980), both of which are directly associated with retirement decision-making.

When wages increase, the income effect leads individuals to purchase more normal goods, including leisure. Previous studies have confirmed that higher income encourages people to retire earlier when they treat leisure as a normal good (Coile, 2004; Damman et al., 2011; Farnham \& Sevak, 2007). On the other hand, increased wages reduce leisure because they raise the opportunity costs and provide an incentive to work more hours and delay retirement (Pozzebon \& Mitchell, 1989). Furthermore, a net wage increase results in higher leisure costs, which encourages individuals to relocate their demand from leisure to consumption. This reallocation of resources has a substitution effect that causes individuals to postpone retirement (Pozzebon \& Mitchell, 1989). As a result, wage changes have income and substitution effects on the demand for leisure.

\subsubsection{Wealth Change}

Just as an income shock is a change in income, a wealth change means just that: a change in a person's wealth, or the value of the person's assets. The life-cycle model is a fundamental framework that economists have used to study retirement planning and savings (Biggs, 2016). The model predicts that people plan their consumption over a longer time frame in order to produce a specific standard of living during retirement that does not vary greatly from year to year. The model highlights how individuals make retirement decisions. Using the life-cycle model, Ando and Modigliani (1963) suggested 
that people accumulate wealth during their work lives to support their lives during retirement, when they no longer have earned income. Retirement preparedness requires having adequate wealth to draw a retirement income that maintains one's standard of living during retirement so that it is close to the pre-retirement level (Schulz, 1992). Therefore, changes in wealth before retirement significantly affect individuals' retirement times.

\subsubsection{Marital Status Change}

The previous two decision factors-income shock and wealth change-focused on the changes to financial status that play into a person's decision of when to retire. The next two factors focus on non-financial events, which, of course, indirectly affect finances. In this section, changes in marital status are discussed.

As Figure 1 shows, the life-cycle model (Biggs, 2016) helps to demonstrate the linkage between wealth change and retirement timing. It also explains how marital status changes affect retirement timing. A divorce, for instance, changes the accumulated wealth that each spouse can rely upon. For example, because of the limited capacity to build retirement wealth, women tend to accumulate less wealth on their own and receive lower incomes during older age (Bardasi \& Jenkins, 2002; Sefton, Evandrou, \& Falkingham, 2011). Because women among the older generations typically relied on the wealth accumulated by their husbands' jobs, they find themselves with a drastically different standard of retirement living should they divorce and, therefore, may choose to delay their retirement.

Life course theory also shows how marital status change is a factor in retirement decision-making. Researchers (Kim \& Feldman, 2000) have argued that retirement is an 
opportunity to participate in activities that people value outside of work. Retirement is viewed as a life transition in a continuous trajectory; transition is a key concept in life course theory (Wang, 2007). According to this theory, previous life events significantly affect retirement timing and experiences (Elder, 1995). Timing and interdependence are two crucial elements in this theory. Timing denotes historical time, or the timing of a transition in an individual's life while social interdependence refers to collaborative social worlds and connections that link individuals and their life experiences to broader changes in society (Elder, 1995). According to Wang et al. (2008), life course theory emphasizes job and family-related variables, including changes in jobs and marital status and the effects of individual characteristics on retirement decisions.

\subsubsection{Declining Health}

Just as life-cycle theory (Biggs, 2016) helps to link wealth change and marital status change to retirement timing, it also links declining health to retirement timing. As explained earlier, people plan their consumption over a long period to produce a specific standard of living during retirement. Retirement preparedness requires having adequate wealth to maintain that standard of living (Schulz, 1992). Declining health changes the plan. An individual must delay retirement and work longer to achieve what, in his or her mind, is the ideal amount of wealth-because the person can no longer work at the same pace to earn the same income, because the person must pay greater healthcare costs, or both.

A second theory also links declining health and retirement timing: One of the theories used most often in retirement research is continuity theory (Wang, 2007), which is used to interpret and understand the factors that play into employees' decisions to retire 
(Gobeski \& Beehr, 2009). This theory explains the importance of past life events and experiences and their effects on the decision to retire among middle-aged and older adults (Atchley, 1999). According to Atchley (1989), individuals might make decisions based on past life events rather than considering alternative options. When confronted with one's own declining health, one's leisure time decreases. As a result, a person may choose to trade work hours for healthcare hours rather than sacrifice leisure time. In other words, because the person's past life experiences and events dictated a specific amount of leisure, the person will not consider an alternative when faced with declining health but will, instead, give up work to maintain the "leisure status quo." This theory views retirement as an opportunity to maintain a familiar lifestyle and social contracts (Quick \& Moen, 1998).

One final theory connecting declining health and retirement timing is role theory. It emphasizes the importance of retirement because the experience of transitioning from employment to nonemployment can be viewed as losing one's role in society (Merton, 1957; Moen, Dempster-McClain, \& Williams, 1992) and as a worker (Merton, 1957). Researchers have argued that worry and depression occur when a role is lost, as well as feelings of dissatisfaction during retirement (Rosow, 1967). This is particularly true for people who have invested a tremendous amount of time and effort in their careers (Burke, 1991; Wheaton, 1990). In contrast, the transition from employment to retirement can be a relief for those who have experienced a stressful work environment (Wheaton, 1990).

\subsection{Hypotheses}

The theories illustrated in Figure 1 and defined up to this point in Chapter 3 have led to the following hypotheses that were tested in this study. First, income shock is 
linked to retirement timing, as demonstrated by the substitution effect (Kalemli-Ozcan \& Weil, 2010) and income effect (Coile, 2004). These two theories compete with one another when describing how income shock affects a person's preferred retirement timing (Burbidge \& Robb, 1980). The substitution effect says that there is a positive correlation between income and retirement timing: If income goes up, the age at which a person retires goes up because a higher-income earner focuses on the bigger opportunity cost of missing out on the earnings from a high-paying job (Pozzebon \& Mitchell, 1989). The aversion to a loss of income implies a lower demand for leisure, which means a delay in the actual retirement age (Lacomba \& Lagos, 2006). Related research found that, when income decreased dramatically, a negative income shock led workers to postpone retirement (Munnell, Muldoon, \& Saas, 2009).

Contrary to the substitution effect, the income effect says there is a negative correlation between the two variables: If income goes up, the preferred retirement time goes down because people treat leisure as a normal good (Coile, 2004; Damman et al., 2011; Farnham \& Sevak, 2007). Researchers have found that individuals who were lottery winners or received a large amount of inheritance tended to retire early (HoltzEakin et al., 1993; Imbens et al., 2001). In addition, Kim and Feldman (2000) found individuals chose to completely quit work and retire early if they received sweepstakes that would pay their current annual income for their entire lives. Previous researchers measured income shock differently: Stevens (1997) defined it as a $12 \%$ income loss compared to a person's post-displacement wage, Ruhm (1991) measured it as a $25 \%$ change, and Topel (1990) measured it as a 40\% change. For this study, income shock was 
defined as either a positive or negative $12 \%$ or more change from a person's previous yearly income.

Both the substitution effect and income effect theories agree that income affects retirement age (though they disagree about the nature of the correlation), which leads to the first set of hypotheses.

Hypothesis 1a: Positive income shock will induce early retirement.

Hypothesis 1b: Negative income shock will induce retirement delay.

The next hypothesis focuses on wealth. Change in wealth has been shown to be related to retirement time, as explained by the life-cycle model (Biggs, 2016). Coronado and Perozek (2003) found that people who held corporate equities prior to a bull market retired 7 months earlier than other respondents. Likewise, the higher their accumulated pension wealth, the earlier individuals tended to leave the workforce (Butler, Huguenin, $\&$ Teppa, 2005). These earlier researchers informed the following hypothesis:

Hypothesis 2: Individuals who have positive wealth changes will be more likely to retire early.

The life-cycle model (Biggs, 2016) explains that wealth for supporting retirement consumption is accumulated during a person's entire working life. Evidence shows that divorced women remain in the workplace longer while married women retire early (McDonald, 1996; Smeaton \& McKay, 2003). Extending one's working years is the only option for people who have divorced to increase their retirement income, whereas sharing a spouse's pension is a feasible and desirable option for married people (Smeaton \& McKay, 2003). Levinson (1986) suggested that people who subscribe to the life course theory assign a greater priority to leisure activities and retirement, focusing on the life- 
course transition that leads to less responsibility for others and more dedication to what one values most. Compared to unmarried pre-retirees, married pre-retirees are more likely to retire early so that they can spend more time enjoying life with their families and friends (Shultz, Morton, \& Weckerle, 1998). These findings have led to the next hypothesis.

Hypothesis 3: Changing marital status from married to divorced or widowed will induce retirement delay.

As a life event, changes in a worker's health status can decrease productivity, resulting in less accumulated wealth (Dwyer \& Mitchell, 1999). The life-cycle theory (Biggs, 2016) argues that individuals in poor health choose to work longer so that they can maintain their expected standard of retirement living, as defined by their long-term plans, which provides them an ideal amount of income and also covers their healthcare costs. On the other hand, continuity theory (Wang, 2007) says that people will retire earlier when confronted with declining health; it focuses on a consistency of patterns over the retirement transition period, and it also contributes to the retirement adjustment process. In order to maintain their predictable life patterns, individuals rely on their resources that include multiple individual attributes, such as education level and health they have accumulated (Kim \& Feldman, 2000). As a result, individuals in poor health require more free time for healthcare and are likely to retire early (Dwyer \& Mitchell, 1999). Role theory treats retirement as the absence of a work identity. Depending on the specific requirements and working conditions of the job, poor health can make work more difficult and less rewarding, resulting in a shorter work life (Dwyer \& Mitchell, 
1999). While the theories contradict one another somewhat, the balance suggests that declining health leads to earlier retirement, and thus the final hypothesis:

Hypothesis 4: Individuals confronted with declining health will retire early compared to individuals in good health. 


\section{Chapter 4: Research Methods}

The majority of this chapter describes the data and variables used in this dissertation's research to examine major life-changing events and their effects on people's retirement times. The end of the chapter reviews the process of sample selection, a concern about missing values, and the types of analyses employed. First is a description of the data.

\subsection{Data}

This study needed a dataset that included sufficient information to review the retirement intentions and actions of numerous individuals near retirement age or in retirement. The HRS was selected for its abundant data concerning retirement, its large number of participants, and the number of years it has been performed. The HRS is a detailed longitudinal survey of American retirees and those approaching retirement age conducted by the University of Michigan. It offers ongoing countrywide data of U.S. adults older than 50 years. Its core purpose is to provide longitudinal data that permit researchers to make analyses and provide support to policy makers on retirement, health insurance, saving, and economic well-being. The National Institute of Aging sponsors this study through a special Congressional appropriation, currently conducting the survey every 2 years. The HRS consists of seven birth cohorts: the initial cohort (born 19311941), the Study of Assets and Health Dynamics cohort (AHEAD, born before 1924), the Children of Depression cohort (CODA, born 1924-1930), the War Baby cohort (WB, born 1942-1947), the Early Baby Boomer cohort (EBB, born 1948-1953), the Mid Baby Boomer cohort (MBB, born 1954-1959), and the Late Baby Boomer cohort (LBB, born 
1960-1965). The current study concerns itself only with the first six cohorts; LBB was not included in this study's data.

The HRS provides an opportunity for researchers to investigate a variety of subject areas related to population aging in the United States. Because it is a very rich and complex dataset, in order to make the data more accessible to researchers, the RAND Center for the Study of Aging, with funding and support from the National Institute of Aging and the Social Security Administration, created a researcher-friendly, cleaned, and streamlined version of the HRS core interviews. The RAND HRS variables cover an extensive range of measures, including demographics, health, health insurance, income, Social Security, pensions, wealth, family structure, expectations, and employment history. Variables are named and derived consistently across waves, and any cross-wave differences are documented by the RAND Center.

This study used twelve waves of the HRS survey obtained from 1992 through 2014 to examine whether major life-changing events significantly affect individuals’ planned retirement ages. The data was plentiful; thousands of observations were reported in each of the years. Each year of the HRS is referred to as a wave, and the waves are numbered sequentially. This paper uses the same terminology, which is defined in Table 1, along with the number of observations for each wave-12,652 sample observations included in the $1992 / 1993$ wave, 19,642 in the $1994 / 1995$ wave, 17,991 in the 1996 wave, and so on.

\section{Table 1.}

A Definition of the RAND HRS Waves, Their Years, and Number of Observations

\begin{tabular}{ccc}
\hline Wave & Year of survey & No. of observations \\
\hline Wave 1 & 1992 and 1993 & 12,652 \\
Wave 2 & 1994 and 1995 & 19,642 \\
Wave 3 & 1996 & 17,991
\end{tabular}




\begin{tabular}{ccc}
\hline Wave & Year of survey & No. of observations \\
\hline Wave 4 & 1998 & 21,384 \\
Wave 5 & 2000 & 19,579 \\
Wave 6 & 2002 & 18,165 \\
Wave 7 & 2004 & 20,129 \\
Wave 8 & 2006 & 18,469 \\
Wave 9 & 2008 & 17,217 \\
Wave 10 & 2010 & 22,034 \\
Wave 11 & 2012 & 20,554 \\
Wave 12 & 2014 & 18,747 \\
\hline
\end{tabular}

To hone in on responses concerning retirement time, the research focused on the HRS survey questions that elicited information about respondents' retirement plans and actions. In the original HRS survey, the employment section asked respondents about their retirement plans. First, the survey stated: "Now I have a few questions about work and retirement." Next, respondents were asked about their retirement plans: "Now I want to ask about your retirement plans. Do you plan to stop working altogether or work fewer hours at a particular date or age, have you not given it much thought, or what?" This question was formatted slightly differently in the first two waves than in those thereafter, but the RAND Center's harmonization across waves has made it possible to compare relevant responses in all twelve waves under study.

The RAND Center also harmonized another difference in the waves' data, which concerns the year in which a respondent intends to retire. In Wave 1, the age at which the respondent wanted to stop working was noted, but the year when the respondent believed he or she would exit the workforce was not recorded. On the other hand, both age and year were recorded in other waves. The RAND Center added the planned retirement year for Wave 1 responses using two other data points that were collected in Wave 1: (a) the respondent's birth year and (b) the age at which the respondent wanted to stop working. 
The year the respondent intended to exit the workforce was calculated as the respondent's birth year plus the "exit age" given.

Because of these discrepancies, this research used the RAND HRS. Critically for this dissertation's research, the RAND HRS includes a retirement year variable that combines the answers to a two-part set of questions. For ease of discussion here, the first question will be called Question 1, and the second pair of questions will be called Questions 2a and 2b. First, a respondent was asked to answer Question 1, which asked whether the respondent was planning to stop work altogether. Second, if the answer to Question 1 was yes, the respondent was asked Question 2a: "At what age do you plan to stop working?" If the respondent answered no to Question 1, then he or she progressed to Question 2b: “At what age do you think you will stop working?” In all waves, multiple answers could be given, including "stop work altogether," "never stop work," "haven't given it much thought," "no current plans — continue as is," "work fewer hours," "change kind of work," "work for myself," and "other." The retirement year variable was used in this dissertation for sample selection, which will be described in more detail at the end of the chapter, when the method of analysis is described.

\subsection{Variables}

Table 2 summarizes the attributes of the dependent variable and independent variables included in this dissertation, and each is further explained in later sections after the table. 
in Table 2.

Summary of the Variables Used in the Empirical Model in This Dissertation

\begin{tabular}{llcccc}
\hline $\begin{array}{l}\text { Variable } \\
\text { number }\end{array}$ & Variable name & Variable type & $\begin{array}{c}\text { Measure type } \\
\text { in HRS }\end{array}$ & $\begin{array}{c}\text { Measure type in this } \\
\text { dissertation }\end{array}$ & Variable description \\
\hline
\end{tabular}

Dependent variable

Gap between actual

1 retirement year and planned retirement year
Continuous variable

\section{Independent} variable

\section{Categorical}

2 Marital status changes

3 Positive income shock

Independent variable

$4 \quad$ Negative income shock

$5 \quad$ Wealth change
Independent variable

Independent variable $\mathrm{n} / \mathrm{a}$

$\mathrm{n} / \mathrm{a}$

Continuous
Categorical

Continuous

Categorical

Binary

Binary

Continuous
A positive number means delayed retirement; zero means retirement exactly as planned; a negative number means retirement earlier than planned

Not married to married, married to divorced, married to widowed, remained married (reference), never married

Yes $=1 ;$ no $=0$

Yes=1; no=0

Percentage change of wealth 


\begin{tabular}{|c|c|c|c|c|c|}
\hline $\begin{array}{l}\text { Variable } \\
\text { number }\end{array}$ & Variable name & Variable type & $\begin{array}{c}\text { Measure type } \\
\text { in HRS }\end{array}$ & $\begin{array}{c}\text { Measure type in this } \\
\text { dissertation }\end{array}$ & Variable description \\
\hline 6 & $\begin{array}{l}\text { Whether diagnosed with } \\
\text { diabetes before retirement }\end{array}$ & $\begin{array}{l}\text { Independent } \\
\text { variable }\end{array}$ & Binary & Binary & Yes $=1 ;$ no=0 \\
\hline 7 & $\begin{array}{l}\text { Whether diagnosed with } \\
\text { cancer before retirement }\end{array}$ & $\begin{array}{l}\text { Independent } \\
\text { variable }\end{array}$ & Binary & Binary & Yes $=1 ;$ no $=0$ \\
\hline 8 & $\begin{array}{l}\text { Whether diagnosed with } \\
\text { lung disease before } \\
\text { retirement }\end{array}$ & $\begin{array}{l}\text { Independent } \\
\text { variable }\end{array}$ & Binary & Binary & Yes $=1 ;$ no $=0$ \\
\hline 9 & $\begin{array}{l}\text { Whether diagnosed with a } \\
\text { stroke before retirement }\end{array}$ & $\begin{array}{l}\text { Independent } \\
\text { variable }\end{array}$ & Binary & Binary & Yes $=1 ;$ no $=0$ \\
\hline 10 & $\begin{array}{l}\text { Whether diagnosed with } \\
\text { heart disease before } \\
\text { retirement }\end{array}$ & $\begin{array}{l}\text { Independent } \\
\text { variable }\end{array}$ & Binary & Binary & Yes $=1 ;$ no $=0$ \\
\hline 11 & $\begin{array}{l}\text { Reported depressed before } \\
\text { retirement }\end{array}$ & $\begin{array}{l}\text { Independent } \\
\text { variable }\end{array}$ & Binary & Binary & Yes $=1 ;$ no $=0$ \\
\hline 12 & $\begin{array}{l}\text { Whether diagnosed with a } \\
\text { psychiatric problem before } \\
\text { retirement }\end{array}$ & $\begin{array}{l}\text { Independent } \\
\text { variable }\end{array}$ & Binary & Binary & Yes $=1 ;$ no $=0$ \\
\hline
\end{tabular}

Independent variables - Demographic characteristics

$13 \quad$ Age

$14 \quad$ Gender

15 Race/ethnicity
Independent variable

Independent variable

Independent variable

\section{Continuous Continuous}

Binary

Categorical
Binary

3-level categorical
Measured as a continuous variable

Female $=1 ;$ male $=0$

White (reference), Black, other 


\begin{tabular}{|c|c|c|c|c|c|}
\hline $\begin{array}{l}\text { Variable } \\
\text { number }\end{array}$ & Variable name & Variable type & $\begin{array}{c}\text { Measure type } \\
\text { in HRS }\end{array}$ & $\begin{array}{l}\text { Measure type in this } \\
\text { dissertation }\end{array}$ & Variable description \\
\hline 16 & Education & $\begin{array}{l}\text { Independent } \\
\text { variable }\end{array}$ & Categorical & 5-level categorical & $\begin{array}{l}\text { Less than high school } \\
\text { (reference), high } \\
\text { school/GED, some } \\
\text { college, college and } \\
\text { graduate or professional }\end{array}$ \\
\hline 17 & Number of children & $\begin{array}{l}\text { Independent } \\
\text { variable }\end{array}$ & Discrete & Discrete & $\begin{array}{l}\text { Number of children } \\
\text { reported }\end{array}$ \\
\hline 18 & Occupation & $\begin{array}{l}\text { Independent } \\
\text { variable }\end{array}$ & Categorical & 5-level categorical & $\begin{array}{l}\text { Managerial (reference), } \\
\text { professional, sales, } \\
\text { service, other }\end{array}$ \\
\hline
\end{tabular}

Independent variables - Economic characteristics

$\begin{array}{lllll}19 & \text { Income } & \begin{array}{l}\text { Independent } \\ \text { variable } \\ \text { Independent }\end{array} & \text { Continuous } & \text { 4-level categorical } \\ \text { variable } & \text { Continuous } & \text { 4-level categorical } \\ 21 & \text { Pealth } & \begin{array}{l}\text { Independent } \\ \text { variable }\end{array} & \text { Categorical } & \text { 4-level categorical } \\ 22 & \text { Homeownership } & \begin{array}{l}\text { Independent } \\ \text { variable }\end{array} & \text { Binary } & \text { Binary } \\ 23 & \begin{array}{l}\text { Health insurance coverage in } \\ \text { retirement }\end{array} & \begin{array}{l}\text { Independent } \\ \text { variable }\end{array} & \text { Binary } & \text { Binary }\end{array}$

\section{Categorized into quartiles}

Categorized into quartiles

No pension (reference),

DB only, DC only, DB

and DC

Own home $=1$;

do not own home $=0$

Yes $=1 ;$ no=0

Independent variables - Respondents' expectations and preferences 


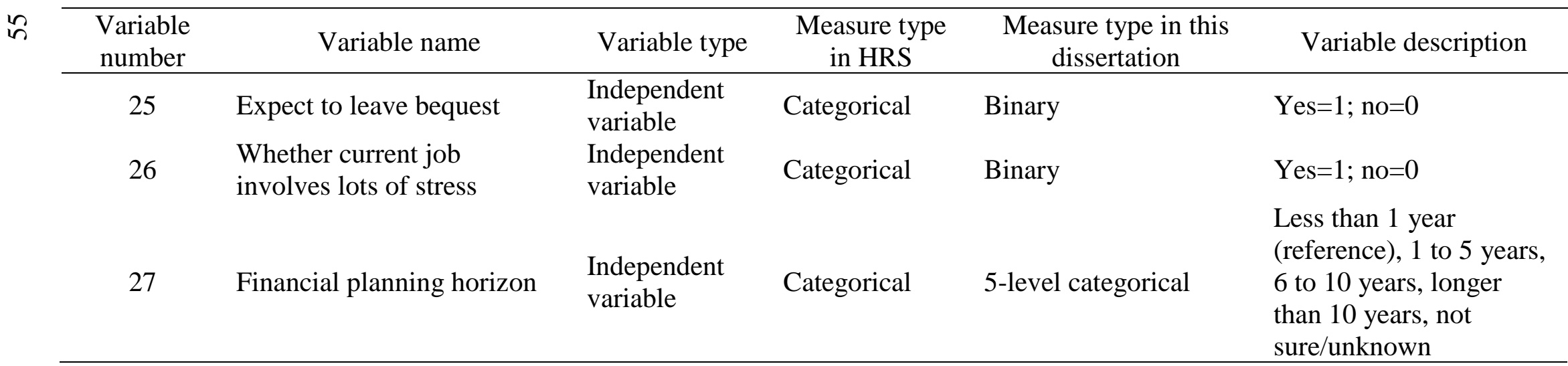




\subsubsection{Dependent Variable}

The dependent variable—gap between actual retirement year and planned retirement year-is a continuous variable that is the difference between the actual retirement year and planned retirement year, as shown in the following formula:

DV $($ continuous variable $)=$ Actual retirement year - Planned retirement year

- If DV > 0, it indicates the respondent delayed retirement;

- if DV $=0$, it indicates the respondent retired at exactly the year planned;

- if DV $<0$, it indicates the respondent retired earlier than planned.

The planned retirement year reports when a respondent is planning to stop work or retire. If multiple responses were given during the respondent's HRS survey participation period, then the most recently reported planned year was counted as the respondent's planned retirement year, for the reason that the respondent must have made adjustments and changes based on changes in the respondent's own personal, financial, or health conditions or situations. The actual retirement year is self-explanatory for those respondents who gave only 1 year consistently across their survey participation periods. It is a little less obvious when a respondent gave different retirement years during different HRS waves. In such cases, a respondent's last-reported retirement year was counted.

Obviously, the formula shown in the previous paragraph can yield positive or negative numbers. The further away the result is from zero, either in a positive or negative direction, the greater the difference between what the respondent planned and what the respondent actually did. A large negative difference can be interpreted as the respondent's early retirement well before the date intended; a large positive difference 
signals retirement delayed to a time that is well out of the range the respondent planned originally. In contrast, a small difference indicates that the respondent's actual retirement age was similar to what the respondent expected it to be. This dissertation focused on determining which independent variables affect gap between actual retirement year and planned retirement year — meaning, factors that affect individuals' decisions to retire when they planned or to deviate.

\subsubsection{Independent Variables}

The independent variables for this study were selected based on the previous literature concerning this field of research and the conceptual model described in Chapters 2 and 3, respectively. The independent variables were grouped into four categories: (1) major life-changing events, including changes in marital status, health status, and financial status; (2) respondents' demographic characteristics of age, gender, race/ethnicity, education, number of children, and occupation; (3) economic characteristics of pension-plan ownership, homeownership, and health insurance coverage in retirement; and (4) respondents' expectations and preferences-specifically, whether they expected to receive an inheritance, whether they expected to leave any bequests to loved ones, whether their current jobs involved lots of stress, and what their preferences were for their financial planning horizons.

4.2.2.1 Major life-changing events. This dissertation's research included three types of major life-changing events: (1) marital status change; (2) health condition change; and (3) financial change. Each of these independent variables is discussed in turn in this section. 
First, the marital status variable is a category variable in the HRS with values ranging from 1 to 8 , representing different marital statuses: $1=$ married; 2 = married, spouse absent; $3=$ partnered; $4=$ separated $; 5=$ divorced; $6=$ separated $/$ divorced 7 = widowed; and $8=$ never married. Combining household marital status into more concise categories enabled more straightforward and easier interpretation of the results. Respondents' marital statuses may change over their participation periods; as a result, this dissertation treated marital status as a changing variable and categorized the marital statuses changes into five categories: (1) changed from not married (i.e., separated, divorced, separated/divorced, widowed, or never married) to married (i.e., married, married with spouse absent, or partnered); (2) changed from married to divorced (i.e., divorced, separated, or separated/divorced); (3) changed from married to widowed; (4) remained married (reference); and (5) never married.

The second of the three categories of major life-changing events is financial status change. This dissertation included income shocks and wealth changes as variables in this category. Income shock included both positive income shock and negative income shock. Positive income shock was defined as a greater than $12 \%$ positive change of household income between two consecutive waves. It was a dummy variable equal to " 1 " for respondents who had at least one positive income shock and " 0 " for those who did not have any positive income shocks. Likewise, negative income shock was defined as a greater than $12 \%$ negative change of household income between two consecutive waves. Similar to positive income shock, negative income shock was also a dummy variable equal to " 1 " for respondents who had at least one negative income shock and " 0 " for those who did not have any negative income shocks. The wealth change variable was 
defined as the percentage of total household wealth change between two consecutive waves and was measured as a continuous variable.

Of the three categories of major life-changing events, the third is health status change. Two sections of the HRS data were included in the health status change variable; they concern life-threatening diseases and mental health changes. Included in this dissertation were diagnoses relating to five life-threatening diseases according to the World Health Organization: diabetes, cancer, lung disease, stroke, and heart disease. Two mental health changes were included in this study. The first was whether the respondents reported that they were depressed, and the second was whether the respondents recorded that they were diagnosed with a psychiatric condition.

Respondents were asked to state whether their doctors diagnosed each of the five life-threatening diseases at each wave. In this dissertation, these diseases were treated as dichotomous variables: (1) In reporting whether the respondent was diagnosed with diabetes or high blood sugar, " 0 " indicated no diabetes diagnosed and " 1 " indicated diagnosed with diabetes for the variable whether diagnosed with diabetes before retirement. (2) In reporting whether the respondent was diagnosed with cancer or a malignant tumor of any kind, except skin cancer, " 0 " indicated no cancer diagnosed and " 1 " indicated diagnosed with cancer for the variable whether diagnosed with cancer before retirement. (3) For chronic lung disease, except asthma, such as chronic bronchitis or emphysema, " 0 " indicated no lung disease diagnosed and " 1 " indicated diagnosed with lung disease for the variable whether diagnosed with lung disease before retirement.

(4) For a stroke or transient ischemic attack, " 0 " indicated no stroke diagnosed and "1" indicated diagnosed with a stroke for the variable whether diagnosed with a stroke 
before retirement. (5) For a heart attack, coronary heart disease, angina, congestive heart failure, or other heart problems, " 0 " indicated no heart disease and " 1 " indicated diagnosed with heart disease for the variable whether diagnosed with heart disease before retirement.

As explained earlier, the study included two mental health change variables, which were whether the respondents reported they were depressed and whether they were diagnosed with a psychiatric condition. In this dissertation, these two mental health change variables were dichotomous variables. RAND HRS formatted whether respondents reported that they were depressed as a binary variable from Wave 2 to Wave 12. In Wave 1, the response concerning depression was treated as a categorical variable, with the categories including all or almost all of the time, most of the time, some of the time, and none or almost none of the time. Thus, for this study's reported depressed before retirement variable, all or almost all, most of the time, and some of the time were grouped as "reported depressed," and none or almost none were grouped as "not reported depressed" to create responses that were consistent with later waves. Reported depressed was a dummy variable equal to " 1 " for respondents who reported experiencing some depression, and "0" was a dummy variable for respondents who reported having experienced no or very little depression. The second mental health change variablewhether diagnosed with a psychiatric problem before retirement-was a dummy variable similar to the depression variable. In this dissertation, the dummy variable was equal to " 1 " for respondents diagnosed with a psychiatric condition and " 0 " for those not diagnosed with a psychiatric condition. 
4.2.2.2 Demographic characteristics. For demographic characteristics, this dissertation included the following variables in the analysis: age, gender, race/ethnicity, education, number of children, and occupation.

A respondent's age was utilized as a continuous variable in the same way it appeared in the original HRS data. The variable represented age in months during the first wave of participation. This variable was converted to age in years for ease of interpretation. Treating age as a continuous variable, rather than identifying the age range or age group (e.g., 60 to 65 years) of individuals, maintained each respondent's actual variance in age. The continuous-variable approach was expected to increase the likelihood that age would be seen as a predictor of the dependent variable. Age was centered at the mean age (54.2) in the regression analysis. Centering the age variable at its mean can help make the results more meaningful and easier to interpret.

Gender was a dummy variable equal to "0" for male respondents and "1" for female respondents. Male respondents were considered the reference group in the regression analysis.

The racelethnicity of the respondent was categorized into three groups: (1) White, (2) Black, and (3) other race, which included American Indian, Alaskan Native, Asian, Native Hawaiian, and Pacific Islander. The RAND HRS dataset does not provide detailed information regarding the subgroups in the "other" category. White respondents were treated as the reference group in the regression analysis.

The education of the respondent was categorized into four groups: (1) less than high school, (2) GED/high school, (3) some college, (4) college and above (i.e., 
bachelor's degree and graduate or professional degree). In the regression analysis, respondents with less than a high school education served as the reference category.

Number of children was a discrete variable, with "0" indicating that the respondent had no children, " 1 " indicating that the respondent had one child, "2" indicating two children, etc.

The occupation of the respondent was categorized into five categories: (1) managerial; (2) professional; (3) sales; (4) service, including cleaning, protection, food preparation, etc.; and (5) other, including farmers, members of the armed forces, and machine operators. Managerial was treated as the reference group in the regression analysis.

4.2.2.3 Economic characteristics. This dissertation included in its analysis the following variables regarding respondents' economic characteristics: pension-plan ownership, homeownership, and health insurance coverage.

Income was categorized into quartiles. The first quartile represented the lowest income and the fourth quartile represented the highest income. The first quartile was treated as the reference group in the regression analysis. Wealth was categorized into quartiles on a similar pattern as income. The first quartile represented the lowest wealth as the reference group in the regression analysis.

The variable pension ownership included DC plans only, DB plans only, both DB and DC plans, and no pension (reference). Homeownership served as a dummy variable, with " 0 " indicating that the respondent owned no primary residence and " 1 " indicating that the respondent did indeed own a primary residence. 
Health insurance coverage in retirement was a dichotomous variable that indicated whether the respondent reported having an employer-provided health insurance plan that would cover the respondent's healthcare expenses in retirement. The value "0" indicated that the respondent had no employer-provided retiree health insurance while " 1 " indicated that the respondent had employer-provided health insurance coverage in retirement.

4.2.2.4 Respondents' expectations and preferences. This dissertation included in the analysis the following variables regarding respondents' expectations and preferences concerning retirement: whether the respondents expected to receive an inheritance, whether the respondents preferred to leave any bequests, whether their current jobs involved lots of stress, and what their preferences were for their financial planning horizons.

In the HRS, the respondents were asked to report the probability of receiving an inheritance during the next 10 years using a 0 to100 scale. Respondents who had a less than $50 \%$ probability of receiving an inheritance were treated as not expecting to receive any inheritance. Respondents who had a greater or equal to $50 \%$ probability were treated as expecting to receive an inheritance. As a result, this study's variable called whether receive an inheritance was coded as a dummy variable equal to " 0 " for not expecting to receive any inheritance and "1" for expecting to receive an inheritance.

Whether leave any bequest was a binary variable. Respondents were asked to report the probability of leaving any bequest using a 0 to 100 scale. Respondents who had a less than 50\% probability of leaving any bequest were treated as not expecting to leave any bequest. Respondents who had a greater or equal to $50 \%$ probability were treated as 
expecting to leave a bequest. As a result, this study's variable called whether leave any bequest was coded as a dummy variable equal to "0" for not expecting to leave any bequest and " 1 " for expecting to leave a bequest.

Whether current job involves lots of stress was a binary variable. The respondents were asked if they agreed with the statement, "My job involves lots of stress." It was a categorical variable including strongly agree, agree, disagree, and strongly disagree in the RAND HRS data. In this dissertation, strongly agree and agree were grouped as having lots of stress in the current job, and the variable was equal to "1." Disagree and strongly disagree were grouped as not having lots of stress in the current job, and the variable was equal to "0."

Financial planning horizon is a variable that reports on what respondents consider their most important time period for family savings and spending. Respondents were not asked about this question in Waves 2, 3, 9 and 10. In Wave 4, one in the ten of the HRS cohort respondents were randomly selected to answer this question. In Wave 5, all cohort respondents were eligible for selection. In Waves 6,11 , and 12, this question was skipped for respondents who were age 65 or older and those who already answered the question in Wave 11. Responses were grouped into several categories in the RAND HRS, including the next few months, next year, next few years, next 5 to 10 years, longer than 10 years, and not sure/unknown. The same data was simplified for this study, grouping the next few months and next year together as one category. As a result, the financial planning horizon variable in this dissertation was categorized into (1) less than 1 year (reference), (2) 1 to 5 years, (3) 5 to 10 years, (4) longer than 10 years, and (5) not sure/unknown. 


\subsection{Method of Analysis}

This section describes the sample selection criteria, missing values, and ordinal linear regression analysis applied in this dissertation.

\subsubsection{Sample Selection}

The purpose of this study was to investigate the factors that affect the time at which people retire. The research focused on studying the respondents from all six cohorts. The total original sample size was 37,495 . Three scenarios were also treated specially. First, only pre-retired respondents from all cohorts were included. Sample size was 32,263 after applying the first scenario. Second, respondents with missing planned retirement year and actual retirement year were excluded from this study. In this dissertation, it is essential to select respondents who were retired within their participation period. Sample size was 19,646 after applying the second scenario. Third, for those survey participants who dropped out of the study and never returned, this study included their data up until the time they stopped participating. For those who stopped responding for a period of time and then reentered the study, this study included only their data during the first period in which they participated. If a respondent's demographic information was missing in the respondent's first interview, then the respondent was asked the same demographic questions again in later waves until the responses were collected. Respondents with missing values in the outcome and independent variables were therefore excluded from waves in which there were missing values. Only respondent was selected for a married household with a respondent and his/her spouse. After all of the exclusions due to these special scenarios, the final sample size was 8,247, with 5,796 respondents from the initial HRS cohort, 154 from the 
AHEAD cohort, 72 from the CODA cohort, 1,154 from the WB cohort, 864 from the EBB cohort, and 207 from the MBB cohort.

\subsubsection{Missing Values}

Some data of certain respondents are missing in some waves of the HRS due to data collection circumstances, such as a respondent's refusal to answer a survey question, voluntary withdrawal from the study, or death. Missing data leads to an unbalanced dataset in which not all respondents' data are present in every wave of the survey, and not all variables contain meaningful data from all respondents. Due to missing responses, not all variables used in this dissertation's research had complete data from all respondents across all waves in the HRS panel survey. It must be acknowledged that the unbalanced data may have introduced bias to this study because data selection might have been present if the missing data were not random. Reducing the number of observations to get a balanced panel could have been a solution to overcoming the potential for bias, but it, in itself, could have produced other selection problems. Ultimately, the decision was made to trust that the data was missing due to random circumstances concerning random participants, and the unbalanced panel was used in this dissertation because it allowed richer information to be included. The restricted maximum likelihood estimation (RMLE) method was applied in regression analysis. The RMLE method allows some approximation over some missing values.

\subsubsection{Descriptive Analysis and Linear Regression Analysis}

Descriptive analyses were conducted to show the sample characteristics among different waves and cohorts. A multivariate analysis was also conducted to examine the factors affecting the gap between actual retirement year and planned retirement year, 
especially the effects of experiencing major life-changing events. Since the gap between a respondent's actual retirement year and planned retirement year is a continuous variable in this dissertation, the regression model used was the linear mixed model. A linear relationship existed between the dependent and independent variables collectively, based on an examination of scatterplots of studentized residuals plotted against the unstandardized predicted values. The dependent variable displayed a normal distribution. A robustness check was used to examine how core regression coefficient estimates behaved when the regression model was modified by removing the financial planning horizon variable. If the coefficients are robust, this is commonly interpreted as evidence of model validity (Lu \& White, 2014). 


\section{Chapter 5: Results}

This chapter summarizes the study's data and describes the analyses performed to assess how major life-changing events affect people's retirement times. It reports findings concerning whether changes in marital, health, or financial status prompt people to retire earlier than their preferred retirement date, later than preferred, or on time. This chapter has five main sections. The first three sections summarize the characteristics of the RAND HRS participants, with the first section (5.1) focusing on the general characteristics of the sample's retirement timing, the second (5.2) reporting on the characteristics concerning major life-changing events, and the third section (5.3) describing considerations besides life-changing events that affect retirement timing. The fourth section describes how the characteristics from Sections 5.2 and 5.3 match up to retirement timing. The fifth and final section describes the results of the mixed linear regression analysis.

\subsection{Sample Characteristics Concerning Retirement Years}

The characteristics of the sample respondents' retirement timing are reported in Table 3. There were 3,801 respondents who retired early, 3,264 who delayed retirement, and 1,182 who retired on time. For those who retired early, they retired an average of 5.1 years earlier than their planned retirement years. For respondents who delayed retirement, they retired an average of 4.6 years later than their planned retirement years. Early retirees left work when they were an average of 60.4 years old even though they had expected to retire at age 65.5. Respondents who delayed their departure retired at an average of 67.0 years old, while they had planned to retire at 62.4. Finally, on-time retirement respondents planned to and did indeed retire at 62.8 years old. 
Table 3.

Sample Characteristics Concerning Retirement Timing

\begin{tabular}{|c|c|c|c|}
\hline & Early retirement & Delayed retirement & On-time retirement \\
\hline Number of respondents & 3,801 & 3,264 & 1,182 \\
\hline $\begin{array}{l}\text { Average actual } \\
\text { retirement year - }\end{array}$ & & & \\
\hline $\begin{array}{l}\text { Average planned } \\
\text { retirement year, } \\
\text { mean and (SD) }\end{array}$ & $-5.08(4.47)$ & $4.56(3.73)$ & 0 \\
\hline $\begin{array}{l}\text { Age at actual retirement } \\
\text { year, mean and (SD) }\end{array}$ & $60.41(5.28)$ & $67.00(5.71)$ & $62.84(4.50)$ \\
\hline $\begin{array}{l}\text { Age at planned } \\
\text { retirement year, } \\
\text { mean and }(\mathrm{SD})\end{array}$ & $65.49(5.47)$ & $62.44(4.81)$ & $62.83(4.50)$ \\
\hline
\end{tabular}

\subsection{Sample Characteristics Concerning Major Life-Changing Events}

As mentioned in Chapter 4, several participants in the RAND HRS panel survey were excluded from this study for differing reasons but primarily to ensure continuity and completeness among the data examined across the HRS waves. The final sample size for the current study was 8,247, with 5,796 respondents from the initial HRS cohort, 154 from the AHEAD cohort, 72 from the CODA cohort, 1,154 from the WB cohort, 864 from the EBB cohort, and 207 from the MBB cohort. The following three subsections describe this sample's characteristics as they pertain to marital, health, and financial status changes.

\subsubsection{Marital Status Changes}

Sample characteristics of the RAND HRS respondents' marital status changes are reported in Table 4 through Table 8 . These five tables list the percentages of individuals who made specific changes in their marital status before retirement—changing from not married to married, married to divorced, or married to widowed, or making no change at 
all by remaining married or never marrying. As a reminder, Section 4.2.2.1 of this dissertation provides detailed definitions of these changes. For example, "not married to married" means changes from not married (i.e., separated, divorced, separated/divorced, widowed, or never married) to married (i.e., married, married with spouse absent, or partnered).

Beginning with the first of the tables, Table 4 makes it clear that the total percentage of unmarried respondents who got married before retirement changed slightly over time from Wave 2 to Wave 12 (e.g., $2.9 \%$ in Wave 2 and 2.6\% in Wave 12). When looking at the changes in percentages over time for each of the six cohorts and when comparing them to the percentages of the sample, the rate of changing marital status from not married to married was very steady throughout the waves and across all six cohorts. The trend can be observed clearly in the initial HRS cohort from Wave 2 at $3.0 \%$, Wave 6 at $3.2 \%$, Wave 10 at $2.8 \%$, and Wave 12 at $2.5 \%$. The CODA cohort includes the second-oldest participants in the HRS, exceeded in age only by the AHEAD cohort; CODA had the overall lowest percentage change from married to not married before retirement at Wave 12 - only $1.4 \%$ — when compared to younger cohorts, such as WB (2.6\%), $\operatorname{EBB}(2.8 \%)$, and $\mathrm{MBB}(6.8 \%)$.

Based on Table 5's data, on average, approximately $2.0 \%$ of the total respondents got divorced before retirement during each of their survey participation periods. The highest rate of change was in the EBB cohort at Wave 10, with a 3.6\% divorce rate, and the lowest rate of change was in the AHEAD cohort, with only $0.6 \%$ of the cohort getting divorced before retirement. The initial HRS cohort had the second-lowest overall divorce rate (the lowest was AHEAD). The initial cohort's percentage started at $2.0 \%$ in Wave 2 
and remained at that same percentage through Wave 7. It then declined, reaching the cohort's lowest rate of change, which was $1.4 \%$, in Wave 12.

From Table 6, one can see that the total number of respondents who became widowed decreased over the years, with $8.8 \%$ widowed before retirement in Wave 2, $7.5 \%$ in Wave 7, and a return to $6.4 \%$ in Wave 12. For AHEAD, the percentage of people widowed was higher than the other five cohorts in this study. More than one-fifth of respondents from the AHEAD cohort were widowed in Wave 2 to Wave 10 (e.g., 23.4\% in Wave 2, 22.1\% in Wave 6, and 20.1\% in Wave 10). The CODA cohort had a similar trend as AHEAD, with more than $15 \%$ of the cohort's respondents widowed in Wave 4 through Wave 11.

Table 7 shows that more than half of the respondents from all of the waves remained married in the sample for this study. The total percentage of married respondents fluctuated, with $77.7 \%$ remaining married before retirement in Wave 1, 72.7\% in Wave 7, and 59.5\% in Wave 12. Of the six cohorts, the WB cohort had the largest percentages of respondents remaining married before retirement, with the WB's highest percentage in Wave $6(83.7 \%)$ and the WB's lowest percentage in Wave 12 (75.5\%). In terms of the total sample, Wave 7 had $72.7 \%$ of respondents who remained married, including $71.1 \%$ of the respondents from the initial HRS cohort, $56.5 \%$ from AHEAD, $66.7 \%$ from CODA, $83.6 \%$ from $\mathrm{WB}$, and $72.5 \%$ from EBB.

Finally, Table 8 reports the percentages of respondents who were never married before retirement. The results showed that the proportions were slightly changed across all 12 waves with the lowest percentages Wave $12(2.1 \%)$. Younger cohorts had lower starting percentages than older cohorts did (e.g., $3.0 \%$ of the EBB cohort and $1.9 \%$ of the 
MBB cohort never married before retirement, but $3.1 \%$ of the initial HRS cohort, $7.1 \%$ of the AHEAD cohort, and $4.2 \%$ of the CODA cohort never married). 
$\stackrel{2}{2}$ Table 4.

Summary of Marital Status Changes - Not Married to Married Before Retirement

\begin{tabular}{|c|c|c|c|c|c|c|c|}
\hline Wave & HRS & AHEAD & CODA & WB & EBB & MBB & Total \\
\hline Wave 2 & $3.0 \%$ & $1.9 \%$ & 0 & 0 & 0 & 0 & $2.9 \%$ \\
\hline Wave 3 & $3.0 \%$ & $1.9 \%$ & 0 & 0 & 0 & 0 & $2.9 \%$ \\
\hline Wave 4 & $3.1 \%$ & $2.6 \%$ & 0 & $2.5 \%$ & 0 & 0 & $3.0 \%$ \\
\hline Wave 5 & $3.2 \%$ & $2.6 \%$ & $1.4 \%$ & $2.4 \%$ & 0 & 0 & $3.1 \%$ \\
\hline Wave 6 & $3.2 \%$ & $2.6 \%$ & $1.4 \%$ & $2.4 \%$ & 0 & 0 & $3.0 \%$ \\
\hline Wave 7 & $3.1 \%$ & $2.6 \%$ & $1.4 \%$ & $2.8 \%$ & $3.0 \%$ & 0 & $3.0 \%$ \\
\hline Wave 8 & $2.9 \%$ & $2.6 \%$ & $1.4 \%$ & $2.9 \%$ & $2.8 \%$ & 0 & $2.8 \%$ \\
\hline Wave 9 & $2.9 \%$ & $1.9 \%$ & $1.4 \%$ & $2.9 \%$ & $2.9 \%$ & 0 & $2.9 \%$ \\
\hline Wave 10 & $2.8 \%$ & $1.3 \%$ & $1.4 \%$ & $2.7 \%$ & $3.1 \%$ & $6.8 \%$ & $2.9 \%$ \\
\hline Wave 11 & $2.6 \%$ & $1.3 \%$ & $1.4 \%$ & $2.7 \%$ & $3.0 \%$ & $6.3 \%$ & $2.7 \%$ \\
\hline Wave 12 & $2.5 \%$ & $1.3 \%$ & $1.4 \%$ & $2.6 \%$ & $2.8 \%$ & $6.8 \%$ & $2.6 \%$ \\
\hline
\end{tabular}

Note. Analysis of the 1992 through 2014 HRS. Sample size $=8,247$.

Table 5.

Summary of Marital Status Changes - Married to Divorced Before Retirement

\begin{tabular}{|c|c|c|c|c|c|c|c|}
\hline Wave & HRS & AHEAD & CODA & WB & EBB & MBB & Total \\
\hline Wave 2 & $2.0 \%$ & $0.6 \%$ & 0 & 0 & 0 & 0 & $2.0 \%$ \\
\hline Wave 3 & $2.0 \%$ & $0.6 \%$ & 0 & 0 & 0 & 0 & $2.0 \%$ \\
\hline Wave 4 & $2.0 \%$ & $0.6 \%$ & 0 & $2.8 \%$ & 0 & 0 & $2.1 \%$ \\
\hline Wave 5 & $2.0 \%$ & $0.6 \%$ & 0 & $2.6 \%$ & 0 & 0 & $2.0 \%$ \\
\hline Wave 6 & $2.0 \%$ & $0.6 \%$ & 0 & $2.7 \%$ & 0 & 0 & $2.1 \%$ \\
\hline Wave 7 & $2.0 \%$ & $0.6 \%$ & 0 & $2.7 \%$ & $3.2 \%$ & 0 & $2.2 \%$ \\
\hline Wave 8 & $1.9 \%$ & 0 & 0 & $2.7 \%$ & $3.2 \%$ & 0 & $2.1 \%$ \\
\hline Wave 9 & $1.9 \%$ & 0 & 0 & $2.6 \%$ & $3.2 \%$ & 0 & $2.1 \%$ \\
\hline Wave 10 & $1.8 \%$ & 0 & 0 & $2.6 \%$ & $3.6 \%$ & $1.0 \%$ & $2.0 \%$ \\
\hline
\end{tabular}




0

$0 \quad 2.5 \%$

$2.5 \%$
$2.1 \%$

Note. Analysis of the 1992 through 2014 HRS. Sample size = 8,247.

Table 6.

Summary of Marital Status Changes - Married to Widowed Before Retirement

\begin{tabular}{|c|c|c|c|c|c|c|c|}
\hline Wave & HRS & AHEAD & CODA & WB & EBB & MBB & Total \\
\hline Wave 2 & $8.5 \%$ & $23.4 \%$ & 0 & 0 & 0 & 0 & $8.8 \%$ \\
\hline Wave 3 & $8.4 \%$ & $24.0 \%$ & 0 & 0 & 0 & 0 & $8.8 \%$ \\
\hline Wave 4 & $8.3 \%$ & $24.0 \%$ & $16.7 \%$ & $5.3 \%$ & 0 & 0 & $8.2 \%$ \\
\hline Wave 5 & $8.3 \%$ & $24.0 \%$ & $16.7 \%$ & $5.3 \%$ & 0 & 0 & $8.3 \%$ \\
\hline Wave 6 & $8.3 \%$ & $22.1 \%$ & $16.7 \%$ & $5.3 \%$ & 0 & 0 & $8.2 \%$ \\
\hline Wave 7 & $8.2 \%$ & $23.4 \%$ & $15.3 \%$ & $4.9 \%$ & $2.8 \%$ & 0 & $7.5 \%$ \\
\hline Wave 8 & $8.1 \%$ & $22.1 \%$ & $16.7 \%$ & $4.9 \%$ & $2.9 \%$ & 0 & $7.4 \%$ \\
\hline Wave 9 & $8.1 \%$ & $21.4 \%$ & $15.3 \%$ & $5.1 \%$ & $2.9 \%$ & 0 & $7.4 \%$ \\
\hline Wave 10 & $7.9 \%$ & $20.1 \%$ & $15.3 \%$ & $4.9 \%$ & $3.2 \%$ & $0.5 \%$ & $7.1 \%$ \\
\hline Wave 11 & $7.5 \%$ & $19.5 \%$ & $15.3 \%$ & $4.9 \%$ & $3.4 \%$ & $0.5 \%$ & $6.8 \%$ \\
\hline Wave 12 & $7.1 \%$ & $17.5 \%$ & $12.5 \%$ & $4.9 \%$ & $3.1 \%$ & $0.5 \%$ & $6.4 \%$ \\
\hline
\end{tabular}

Note. Analysis of the 1992 through 2014 HRS. Sample size $=8,247$.

Table 7.

Summary of Marital Status Changes - Remained Married Before Retirement

\begin{tabular}{|c|c|c|c|c|c|c|c|}
\hline Wave & HRS & AHEAD & CODA & WB & EBB & MBB & Total \\
\hline Wave 1 & $79.5 \%$ & $60.1 \%$ & 0 & 0 & 0 & 0 & $77.7 \%$ \\
\hline Wave 2 & $76.8 \%$ & $62.3 \%$ & 0 & 0 & 0 & 0 & $76.5 \%$ \\
\hline Wave 3 & $76.3 \%$ & $61.0 \%$ & 0 & 0 & 0 & 0 & $75.8 \%$ \\
\hline Wave 4 & $75.5 \%$ & $61.0 \%$ & $66.7 \%$ & $82.5 \%$ & 0 & 0 & $76.2 \%$ \\
\hline Wave 5 & $73.6 \%$ & $61.0 \%$ & $65.3 \%$ & $82.3 \%$ & 0 & 0 & $74.6 \%$ \\
\hline Wave 6 & $72.9 \%$ & $60.4 \%$ & $66.7 \%$ & $83.7 \%$ & 0 & 0 & $74.3 \%$ \\
\hline
\end{tabular}




$\begin{array}{cccccccc}\text { Wave } 7 & 71.1 \% & 56.5 \% & 66.7 \% & 83.6 \% & 72.5 \% & 0 & 72.7 \% \\ \text { Wave } 8 & 68.3 \% & 53.2 \% & 68.1 \% & 83.4 \% & 70.1 \% & 0 & 70.3 \% \\ \text { Wave } 9 & 65.6 \% & 46.8 \% & 63.9 \% & 81.9 \% & 70.8 \% & 0 & 68.1 \% \\ \text { Wave } 10 & 62.1 \% & 38.3 \% & 61.1 \% & 81.1 \% & 81.8 \% & 89.4 \% & 67.0 \% \\ \text { Wave } 11 & 58.6 \% & 31.8 \% & 55.6 \% & 78.4 \% & 81.0 \% & 87.4 \% & 63.9 \% \\ \text { Wave } 12 & 53.5 \% & 23.4 \% & 48.6 \% & 75.5 \% & 80.1 \% & 83.1 \% & 59.5 \%\end{array}$

Note. Analysis of the 1992 through 2014 HRS. Sample size $=8,247$.

Table 8.

Summary of Marital Status Changes - Never Married Before Retirement

\begin{tabular}{|c|c|c|c|c|c|c|c|}
\hline Wave & HRS & AHEAD & CODA & WB & EBB & MBB & Total \\
\hline Wave 1 & $3.1 \%$ & 0 & 0 & 0 & 0 & 0 & $3.0 \%$ \\
\hline Wave 2 & $2.8 \%$ & $7.1 \%$ & 0 & 0 & 0 & 0 & $3.0 \%$ \\
\hline Wave 3 & $2.9 \%$ & $7.1 \%$ & 0 & 0 & 0 & 0 & $3.0 \%$ \\
\hline Wave 4 & $2.8 \%$ & $7.1 \%$ & $4.2 \%$ & $1.7 \%$ & 0 & 0 & $2.7 \%$ \\
\hline Wave 5 & $2.6 \%$ & $5.2 \%$ & $5.6 \%$ & $1.6 \%$ & 0 & 0 & $2.5 \%$ \\
\hline Wave 6 & $2.6 \%$ & $6.5 \%$ & $5.6 \%$ & $1.6 \%$ & 0 & 0 & $2.6 \%$ \\
\hline Wave 7 & $2.6 \%$ & $5.8 \%$ & $4.2 \%$ & $1.6 \%$ & $3.0 \%$ & 0 & $2.6 \%$ \\
\hline Wave 8 & $2.6 \%$ & $4.5 \%$ & $4.2 \%$ & $1.6 \%$ & $2.7 \%$ & 0 & $2.5 \%$ \\
\hline Wave 9 & $2.5 \%$ & $4.5 \%$ & $4.2 \%$ & $1.6 \%$ & $2.4 \%$ & 0 & $2.4 \%$ \\
\hline Wave 10 & $2.2 \%$ & $4.5 \%$ & $4.2 \%$ & $1.6 \%$ & $3.2 \%$ & $1.9 \%$ & $2.3 \%$ \\
\hline Wave 11 & $2.1 \%$ & $3.9 \%$ & $4.2 \%$ & $1.4 \%$ & $3.0 \%$ & $1.9 \%$ & $2.2 \%$ \\
\hline Wave 12 & $2.0 \%$ & $3.2 \%$ & $2.8 \%$ & $1.3 \%$ & $3.4 \%$ & $1.9 \%$ & $2.1 \%$ \\
\hline
\end{tabular}

Note. Analysis of the 1992 through 2014 HRS. Sample size $=8,247$. 


\subsubsection{Health Status Changes}

Sample characteristics of the RAND HRS respondents' health changes are reported in Table 9 through Table 15. Each table lists the percentages of respondents who were diagnosed with a certain disease before retirement. The results displayed in each table are discussed in this section.

Table 9 reports the percentages of respondents who were diagnosed with diabetes before retirement. The total percentages of respondents diagnosed with diabetes increased steadily from Wave 1 to Wave 12 , with $6.0 \%$ of all respondents in Wave 1 diagnosed with diabetes before retirement, $14.3 \%$ in Wave 7, and 20.6\% in Wave 12. In other words, more than one-fifth of the sample's respondents were diagnosed with diabetes by the time the sample reached Wave 12. For the initial HRS cohort, the number of respondents diagnosed with diabetes increased from $6.1 \%$ in Wave 1 to $19.1 \%$ in Wave 12. Compared to this cohort, the $\mathrm{WB}, \mathrm{EBB}$, and $\mathrm{MBB}$ cohorts had higher percentages of respondents with diabetes upon each cohort's first participation in the survey, with $6.4 \%$, $10.4 \%$, and $24.2 \%$, respectively. At Wave 12 , almost a quarter of the respondents from each of these three cohorts—WB (25.6\%), EBB (24.9\%), and MBB (27.5\%)—had been diagnosed with diabetes.

Table 10 focuses on respondents diagnosed with cancer before retirement. The percentages were lower in each wave than they were for diabetes, but like with diabetes, the trend in cancer diagnoses showed steadily increasing percentages. The total proportion of respondents diagnosed with cancer before retirement increased gradually from Wave 1 to Wave 12, starting at $3.6 \%$ in Wave 1, rising to $9.8 \%$ by Wave 7 , and reaching $13.9 \%$ by Wave 12 . The CODA cohort included the highest proportion of 
respondents diagnosed with cancer before retirement $-20.8 \%$ in Wave 10 . The increasing percentages of cancer diagnoses were found in all six cohorts (e.g., 3.6\% in Wave 1 and $14.5 \%$ in Wave 12 for the initial HRS cohort; $0.6 \%$ in Wave 1 and $9.1 \%$ in Wave 12 for the AHEAD cohort).

Table 11 reports the results of respondents who were diagnosed with lung disease before retirement. Similar to the trends for diabetes and cancer, the total number of respondents who were diagnosed with lung disease regularly increased over time (e.g., $2.7 \%$ in Wave $1,3.9 \%$ in Wave $4,5.9 \%$ in Wave $7,8.0 \%$ in Wave 10 , and $8.6 \%$ in Wave 12). This pattern of increasing proportions in the overall sample was consistent with the trends in each cohort.

Table 12 summarizes the data concerning respondents who were diagnosed with a stroke before retirement. No matter which wave was evaluated, the overall total percentage of respondents who were diagnosed with a stroke was below $10 \%$, with the highest percentage of $7.2 \%$ appearing in Wave 12 and the lowest of $1.0 \%$ in Wave 1 . The initial HRS cohort is a good example to observe the increasing pattern of stroke diagnoses; in this cohort, $1.0 \%$ of the respondents reported a stroke diagnosis in Wave 1 , $4.5 \%$ reported such a diagnosis in Wave 7 , and $7.3 \%$ did so in Wave 12 .

Heart problems are covered in Table 13. In the two most recent waves, one out of every five respondents was diagnosed with heart disease before retirement. In Wave 11, $20.7 \%$ of total respondents reported being diagnosed with heart disease. In that same wave, two cohorts had more than $20 \%$ of respondents with heart disease, including $22.0 \%$ of the initial HRS cohort and $31.9 \%$ of the CODA cohort. In Wave 12, the total percentage with a heart disease diagnosis before retirement was $21.4 \%$, while three 
cohorts had more than a fifth of their respondents reporting heart disease diagnoses: $22.2 \%$ of the initial HRS cohort, $25.0 \%$ of CODA, and $21.9 \%$ of WB.

Trends in respondents' mental health status changes are illustrated in Tables 14 and 15 . Table 14 shows the proportion of respondents who reported that they were experiencing problems with depression before retirement. Of the total sample, the percentage reporting depression started at only $1.0 \%$ in Wave 1, but jumped to $11.9 \%$ by Wave 2, decreased to $10.7 \%$ in Wave 3, and fluctuated after that, increasing to the highest percentage (12.6\%) in Wave 4 and ending up at $7.3 \%$ in Wave 12 . When evaluating the proportions within a particular cohort and comparing them across all six, one can see that the largest percentage of respondents who reported depression before retirement was $18.1 \%$, which was recorded for Wave 8 of the CODA cohort. Table 15 summarizes the health status changes concerning psychiatric problems. The number of respondents who were diagnosed with a psychiatric problem before retirement steadily increased from wave to wave, rising from $3.6 \%$ in Wave 1 to $13.4 \%$ in Wave 12 as more respondents reported having psychiatric problems.

It is interesting to note that, by and large, the trends in health status changes showed steady increases in the proportions of respondents who were reporting health problems. These patterns are not surprising given that aging is generally associated with a greater risk for illnesses. Still, it is interesting that the trends in marital status changes had more ups and downs whereby health status changes generally demonstrated steady upward trajectories. 
ㄱable 9.

Summary of Health Status Changes - Diagnosed with Diabetes Before Retirement

\begin{tabular}{|c|c|c|c|c|c|c|c|}
\hline Wave & HRS & AHEAD & CODA & WB & EBB & MBB & Total \\
\hline Wave 1 & $6.1 \%$ & $2.6 \%$ & 0 & 0 & 0 & 0 & $6.0 \%$ \\
\hline Wave 2 & $7.0 \%$ & $7.8 \%$ & 0 & 0 & 0 & 0 & $7.1 \%$ \\
\hline Wave 3 & $8.3 \%$ & $8.4 \%$ & 0 & 0 & 0 & 0 & $8.3 \%$ \\
\hline Wave 4 & $9.7 \%$ & $9.1 \%$ & $5.6 \%$ & $6.4 \%$ & 0 & 0 & $9.1 \%$ \\
\hline Wave 5 & $11.2 \%$ & $10.4 \%$ & $6.9 \%$ & $8.0 \%$ & 0 & 0 & $10.6 \%$ \\
\hline Wave 6 & $13.6 \%$ & $14.9 \%$ & $9.7 \%$ & $10.7 \%$ & 0 & 0 & $13.2 \%$ \\
\hline Wave 7 & $15.3 \%$ & $14.3 \%$ & $8.3 \%$ & $12.6 \%$ & $10.4 \%$ & 0 & $14.3 \%$ \\
\hline Wave 8 & $16.9 \%$ & $14.9 \%$ & $11.1 \%$ & $15.1 \%$ & $11.7 \%$ & 0 & $16.0 \%$ \\
\hline Wave 9 & $17.9 \%$ & $15.6 \%$ & $8.3 \%$ & $18.0 \%$ & $13.9 \%$ & 0 & $17.4 \%$ \\
\hline Wave 10 & $18.8 \%$ & $15.6 \%$ & $9.7 \%$ & $21.9 \%$ & $20.0 \%$ & $24.2 \%$ & $19.4 \%$ \\
\hline Wave 11 & $19.1 \%$ & $14.9 \%$ & $8.3 \%$ & $23.7 \%$ & $22.2 \%$ & $28.0 \%$ & $20.2 \%$ \\
\hline Wave 12 & $19.1 \%$ & $13.6 \%$ & $6.9 \%$ & $25.6 \%$ & $24.9 \%$ & $27.5 \%$ & $20.6 \%$ \\
\hline
\end{tabular}

Note. Analysis of the 1992 through 2014 HRS. Sample size $=8,247$. 
Table 10.

Summary of Health Status Changes - Diagnosed with Cancer Before Retirement

\begin{tabular}{|c|c|c|c|c|c|c|c|}
\hline Wave & HRS & AHEAD & CODA & WB & EBB & MBB & Total \\
\hline Wave 1 & $3.6 \%$ & $0.6 \%$ & 0 & 0 & 0 & 0 & $3.6 \%$ \\
\hline Wave 2 & $4.5 \%$ & $9.1 \%$ & 0 & 0 & 0 & 0 & $4.6 \%$ \\
\hline Wave 3 & $5.4 \%$ & $10.4 \%$ & 0 & 0 & 0 & 0 & $5.5 \%$ \\
\hline Wave 4 & $6.6 \%$ & $11.7 \%$ & $6.9 \%$ & $3.5 \%$ & 0 & 0 & $6.2 \%$ \\
\hline Wave 5 & $8.1 \%$ & $13.6 \%$ & $6.9 \%$ & $4.5 \%$ & 0 & 0 & $7.7 \%$ \\
\hline Wave 6 & $9.9 \%$ & $14.9 \%$ & $6.9 \%$ & $5.7 \%$ & 0 & 0 & $9.3 \%$ \\
\hline Wave 7 & $11.1 \%$ & $16.9 \%$ & $9.7 \%$ & $7.3 \%$ & $2.5 \%$ & 0 & $9.8 \%$ \\
\hline Wave 8 & $12.4 \%$ & $18.2 \%$ & $15.3 \%$ & $8.6 \%$ & $3.5 \%$ & 0 & $11.0 \%$ \\
\hline Wave 9 & $13.2 \%$ & $16.9 \%$ & $16.7 \%$ & $10.1 \%$ & $4.4 \%$ & 0 & $11.9 \%$ \\
\hline Wave 10 & $14.7 \%$ & $14.3 \%$ & $20.8 \%$ & $11.7 \%$ & $5.8 \%$ & $7.2 \%$ & $13.2 \%$ \\
\hline Wave 11 & $14.8 \%$ & $12.3 \%$ & $19.4 \%$ & $13.7 \%$ & $7.6 \%$ & $9.7 \%$ & $13.8 \%$ \\
\hline Wave 12 & $14.5 \%$ & $9.1 \%$ & $16.7 \%$ & $14.7 \%$ & $10.3 \%$ & $10.6 \%$ & $13.9 \%$ \\
\hline
\end{tabular}

Note. Analysis of the 1992 through 2014 HRS. Sample size $=8,247$.

\section{Table 11.}

Summary of Health Status Changes - Diagnosed with Lung Disease Before Retirement

\begin{tabular}{|c|c|c|c|c|c|c|c|}
\hline Wave & HRS & AHEAD & CODA & WB & EBB & $\mathrm{MBB}$ & Total \\
\hline Wave 1 & $2.7 \%$ & $0.6 \%$ & 0 & 0 & 0 & 0 & $2.7 \%$ \\
\hline Wave 2 & $3.3 \%$ & $1.9 \%$ & 0 & 0 & 0 & 0 & $3.3 \%$ \\
\hline Wave 3 & $3.8 \%$ & $1.9 \%$ & 0 & 0 & 0 & 0 & $3.7 \%$ \\
\hline Wave 4 & $4.4 \%$ & $3.2 \%$ & $6.9 \%$ & $1.3 \%$ & 0 & 0 & $3.9 \%$ \\
\hline Wave 5 & $4.8 \%$ & $2.6 \%$ & $6.9 \%$ & $2.1 \%$ & 0 & 0 & $4.4 \%$ \\
\hline Wave 6 & $5.7 \%$ & $5.2 \%$ & $9.7 \%$ & $3.0 \%$ & 0 & 0 & $5.3 \%$ \\
\hline Wave 7 & $6.8 \%$ & $4.5 \%$ & $8.3 \%$ & $4.2 \%$ & $2.2 \%$ & 0 & $5.9 \%$ \\
\hline Wave 8 & $7.6 \%$ & $5.2 \%$ & $9.7 \%$ & $5.2 \%$ & $2.5 \%$ & 0 & $6.7 \%$ \\
\hline
\end{tabular}




\begin{tabular}{cccccccr} 
Wave 9 & $8.3 \%$ & $5.8 \%$ & $12.5 \%$ & $6.0 \%$ & $3.0 \%$ & 0 & $7.4 \%$ \\
Wave 10 & $8.7 \%$ & $4.5 \%$ & $12.5 \%$ & $7.1 \%$ & $4.9 \%$ & $7.7 \%$ & $8.0 \%$ \\
Wave 11 & $9.0 \%$ & $9.1 \%$ & $11.1 \%$ & $8.2 \%$ & $6.0 \%$ & $9.2 \%$ & $8.6 \%$ \\
Wave 12 & $8.6 \%$ & $7.1 \%$ & $9.7 \%$ & $8.8 \%$ & $7.5 \%$ & $12.1 \%$ & $8.6 \%$ \\
\hline
\end{tabular}

Note. Analysis of the 1992 through 2014 HRS. Sample size = 8,247.

\section{Table 12.}

Summary of Health Status Changes - Diagnosed with a Stroke Before Retirement

\begin{tabular}{|c|c|c|c|c|c|c|c|}
\hline Wave & HRS & AHEAD & CODA & WB & EBB & MBB & Total \\
\hline Wave 1 & $1.0 \%$ & 0 & 0 & 0 & 0 & 0 & $1.0 \%$ \\
\hline Wave 2 & $1.5 \%$ & 0 & 0 & 0 & 0 & 0 & $1.4 \%$ \\
\hline Wave 3 & $1.8 \%$ & $1.9 \%$ & 0 & 0 & 0 & 0 & $1.8 \%$ \\
\hline Wave 4 & $2.4 \%$ & $3.9 \%$ & $2.8 \%$ & $1.2 \%$ & 0 & 0 & $2.2 \%$ \\
\hline Wave 5 & $3.4 \%$ & $3.9 \%$ & $2.8 \%$ & $1.6 \%$ & 0 & 0 & $3.1 \%$ \\
\hline Wave 6 & $3.9 \%$ & $9.1 \%$ & $5.6 \%$ & $2.6 \%$ & 0 & 0 & $3.8 \%$ \\
\hline Wave 7 & $4.5 \%$ & $11.0 \%$ & $5.6 \%$ & $2.9 \%$ & $1.7 \%$ & 0 & $4.1 \%$ \\
\hline Wave 8 & $5.3 \%$ & $9.7 \%$ & $6.9 \%$ & $3.6 \%$ & $2.1 \%$ & 0 & $4.8 \%$ \\
\hline Wave 9 & $5.9 \%$ & $9.7 \%$ & $8.3 \%$ & $4.2 \%$ & $2.9 \%$ & 0 & $5.4 \%$ \\
\hline Wave 10 & $6.8 \%$ & $11.7 \%$ & $9.7 \%$ & $5.8 \%$ & $4.3 \%$ & $1.0 \%$ & $6.3 \%$ \\
\hline Wave 11 & $7.2 \%$ & $11.0 \%$ & $11.1 \%$ & $6.8 \%$ & $5.6 \%$ & $2.9 \%$ & $6.9 \%$ \\
\hline Wave 12 & $7.3 \%$ & $9.1 \%$ & $9.7 \%$ & $7.2 \%$ & $6.3 \%$ & $4.3 \%$ & $7.2 \%$ \\
\hline
\end{tabular}

Note. Analysis of the 1992 through 2014 HRS. Sample size = 8,247.

Table 13.

Summary of Health Status Changes - Diagnosed with Heart Disease Before Retirement

\begin{tabular}{cccccccc}
\hline Wave & HRS & AHEAD & CODA & WB & EBB & MBB & Total \\
\hline Wave 1 & $6.7 \%$ & 0 & 0 & 0 & 0 & 0 & $0.5 \%$ \\
Wave 2 & $8.0 \%$ & $7.8 \%$ & 0 & 0 & 0 & 0 \\
Wave 3 & $9.6 \%$ & $13.6 \%$ & 0 & 0 & 0 & 0
\end{tabular}




\begin{tabular}{|c|c|c|c|c|c|c|c|}
\hline Wave 4 & $11.1 \%$ & $16.2 \%$ & $6.9 \%$ & $4.8 \%$ & 0 & 0 & $10.1 \%$ \\
\hline Wave 5 & $12.5 \%$ & $18.8 \%$ & $9.7 \%$ & $6.1 \%$ & 0 & 0 & $11.6 \%$ \\
\hline Wave 6 & $15.1 \%$ & $21.4 \%$ & $13.9 \%$ & $8.1 \%$ & 0 & 0 & $14.1 \%$ \\
\hline Wave 7 & $17.0 \%$ & $23.4 \%$ & $18.1 \%$ & $10.4 \%$ & $6.3 \%$ & 0 & $15.0 \%$ \\
\hline Wave 8 & $18.8 \%$ & $22.1 \%$ & $20.8 \%$ & $13.3 \%$ & $7.6 \%$ & 0 & $16.9 \%$ \\
\hline Wave 9 & $19.8 \%$ & $21.4 \%$ & $25.0 \%$ & $14.2 \%$ & $9.8 \%$ & 0 & $18.0 \%$ \\
\hline Wave 10 & $21.1 \%$ & $20.1 \%$ & $29.2 \%$ & $17.8 \%$ & $13.2 \%$ & $11.6 \%$ & $19.6 \%$ \\
\hline Wave 11 & $22.0 \%$ & $17.5 \%$ & $31.9 \%$ & $19.8 \%$ & $14.9 \%$ & $13.0 \%$ & $20.7 \%$ \\
\hline Wave 12 & $22.2 \%$ & $16.9 \%$ & $25.0 \%$ & $21.9 \%$ & $17.8 \%$ & $14.5 \%$ & $21.4 \%$ \\
\hline
\end{tabular}

Note. Analysis of the 1992 through 2014 HRS. Sample size = 8,247.

Table 14.

Summary of Health Status Changes - Reported Depressed Before Retirement

\begin{tabular}{|c|c|c|c|c|c|c|c|}
\hline Wave & HRS & AHEAD & CODA & WB & EBB & MBB & Total \\
\hline Wave 1 & $1.2 \%$ & $0.6 \%$ & 0 & 0 & 0 & 0 & $1.0 \%$ \\
\hline Wave 2 & $12.0 \%$ & $8.4 \%$ & 0 & 0 & 0 & 0 & $11.9 \%$ \\
\hline Wave 3 & $10.7 \%$ & $11.0 \%$ & 0 & 0 & 0 & 0 & $10.7 \%$ \\
\hline Wave 4 & $13.3 \%$ & $9.1 \%$ & $9.7 \%$ & $9.6 \%$ & 0 & 0 & $12.6 \%$ \\
\hline Wave 5 & $11.6 \%$ & $11.0 \%$ & $8.3 \%$ & $12.0 \%$ & 0 & 0 & $11.6 \%$ \\
\hline Wave 6 & $11.5 \%$ & $16.2 \%$ & $9.7 \%$ & $12.7 \%$ & 0 & 0 & $11.8 \%$ \\
\hline Wave 7 & $10.7 \%$ & $13.6 \%$ & $13.9 \%$ & $12.5 \%$ & $8.0 \%$ & 0 & $10.8 \%$ \\
\hline Wave 8 & $10.5 \%$ & $10.4 \%$ & $18.1 \%$ & $11.6 \%$ & $11.7 \%$ & 0 & $10.9 \%$ \\
\hline Wave 9 & $8.1 \%$ & $9.1 \%$ & $15.3 \%$ & $9.4 \%$ & $10.0 \%$ & 0 & $8.6 \%$ \\
\hline Wave 10 & $7.0 \%$ & $4.5 \%$ & $8.3 \%$ & $7.0 \%$ & $11.8 \%$ & $8.2 \%$ & $7.5 \%$ \\
\hline Wave 11 & $7.3 \%$ & $5.8 \%$ & $15.3 \%$ & $8.2 \%$ & $8.4 \%$ & $14.0 \%$ & $6.4 \%$ \\
\hline Wave 12 & $6.8 \%$ & $5.2 \%$ & $12.5 \%$ & $5.9 \%$ & $10.1 \%$ & $15.0 \%$ & $7.3 \%$ \\
\hline
\end{tabular}

Note. Analysis of the 1992 through 2014 HRS. Sample size $=8,247$. 
œ Table 15.

Summary of Health Status Changes - Diagnosed with a Psychiatric Problem Before Retirement

\begin{tabular}{|c|c|c|c|c|c|c|c|}
\hline Wave & HRS & AHEAD & $\mathrm{CODA}$ & WB & EBB & MBB & Total \\
\hline Wave 1 & $3.7 \%$ & $0.6 \%$ & 0 & 0 & 0 & 0 & $3.6 \%$ \\
\hline Wave 2 & $4.7 \%$ & $9.1 \%$ & 0 & 0 & 0 & 0 & $4.8 \%$ \\
\hline Wave 3 & $5.8 \%$ & $9.1 \%$ & 0 & 0 & 0 & 0 & $5.9 \%$ \\
\hline Wave 4 & $6.9 \%$ & $10.4 \%$ & $5.6 \%$ & $5.7 \%$ & 0 & 0 & $6.8 \%$ \\
\hline Wave 5 & $7.8 \%$ & $9.7 \%$ & $6.9 \%$ & $7.5 \%$ & 0 & 0 & $7.7 \%$ \\
\hline Wave 6 & $8.7 \%$ & $11.0 \%$ & $8.3 \%$ & $9.6 \%$ & 0 & 0 & $8.9 \%$ \\
\hline Wave 7 & $9.8 \%$ & $11.7 \%$ & $8.3 \%$ & $11.8 \%$ & $9.1 \%$ & 0 & $10.0 \%$ \\
\hline Wave 8 & $10.7 \%$ & $12.3 \%$ & $11.1 \%$ & $14.2 \%$ & $12.2 \%$ & 0 & $11.4 \%$ \\
\hline Wave 9 & $11.2 \%$ & $11.7 \%$ & $12.5 \%$ & $15.3 \%$ & $13.9 \%$ & 0 & $12.1 \%$ \\
\hline Wave 10 & $11.4 \%$ & $13.0 \%$ & $15.3 \%$ & $16.9 \%$ & $17.4 \%$ & $12.6 \%$ & $12.9 \%$ \\
\hline Wave 11 & $11.6 \%$ & $11.7 \%$ & $18.1 \%$ & $17.2 \%$ & $19.3 \%$ & $18.4 \%$ & $13.4 \%$ \\
\hline Wave 12 & $11.4 \%$ & $11.7 \%$ & $15.3 \%$ & $16.8 \%$ & $20.7 \%$ & $21.7 \%$ & $13.4 \%$ \\
\hline
\end{tabular}

Note. Analysis of the 1992 through 2014 HRS. Sample size = 8,247. 


\subsubsection{Financial Status Changes}

Tables 16 and 17 summarize respondents' information on positive income shocks and negative income shocks before retirement. Note that neither table has a row where Wave 1 percentages are reported. The reason for these missing rows lies in the very definition of income shock. As explained previously in Chapter 4, income shock was defined in this study as a greater than $12 \%$ change (positive or negative) of household income between two consecutive waves. Since no data came before Wave 1, it was impossible to evaluate how Wave 1 differed from the year prior.

From wave to wave, Table 16 shows similar percentages of the total sample's respondents who experienced a positive income shock before retirement. On average, about a quarter of the respondents in each wave experienced a positive income shock, which indicated they had a more than $12 \%$ positive change in their annual income when comparing the given wave to the wave immediately preceding it. In fact, in two waves, almost a third of the respondents experienced such an income shock (31.4\% in Wave 5 and $30.9 \%$ in Wave 8). The highest percentage of respondents who had a positive income shock was at Wave 5 with $31.4 \%$, and the lowest percentage appeared at Wave 4, with $23.2 \%$ of respondents demonstrating a positive income shock.

Per Table 17, in all survey waves, approximately one-fifth to one-fourth of the total respondents experienced a negative income shock before retirement. For example, $18.2 \%$ of all respondents had a negative income shock in Wave 2. The percentages fluctuated wave to wave, increasing to $26.9 \%$ in Wave 6 , staying somewhat steady until the peak of $29.4 \%$ in Wave 10 , and ending at $24.1 \%$ in Wave 12 . All six cohorts-HRS, AHEAD, CODA, WB, EBB, and MBB — showed changes consistent with the overall 
percentages. In the more recent waves (i.e., Waves 8 through 12), younger cohorts (WB, $\mathrm{EBB}$, and $\mathrm{MBB}$ ) more frequently experienced negative income shocks when compared to the older cohorts (HRS, AHEAD, and CODA). For example, in Wave 12, 21.1\% of respondents from the initial HRS cohort experienced a negative income shock, as did $13.0 \%$ of AHEAD and $18.1 \%$ of CODA; however, a full $28.0 \%$ of the WB cohort in Wave 12 experienced a negative income shock before retirement, as did $37.5 \%$ of EBB and $39.6 \%$ of $\mathrm{MBB}$.

Table 18 summarizes the mean and median wealth of each cohort in each wave. The mean of wealth increased steadily from Wave 1 to Wave 8 and decreased from Wave 8 to Wave 12 . The mean of the total sample started at $\$ 211,926.6$ in Wave 1, increased to $\$ 252,652.8$ in Wave 2, and continued to increase until it reached the highest amount of $\$ 554,519.3$ in Wave 8. The mean then slowly decreased, declining to $\$ 533,957.0$ in Wave 9 and ending at $\$ 550,862.1$ in Wave 12. The EBB cohort had the highest starting mean wealth of $\$ 407,138.6$ (in Wave 7), and the initial HRS cohort had the lowest starting mean wealth of $\$ 211,398.8$ (in Wave 1). In the most recent Wave 12 , the CODA cohort accumulated the highest amount of mean wealth, \$776,328.0. In addition, as the youngest cohort, the MBB cohort's wealth averages in Wave $10(\$ 300,192.6)$, Wave 11 $(\$ 273,677.4)$, and Wave $12(\$ 315,645.1)$ were the lowest among all six cohorts used in this study. 
Table 16.

Summary of Financial Status Changes - Positive Income Shock Before Retirement

\begin{tabular}{|c|c|c|c|c|c|c|c|}
\hline Wave & HRS & AHEAD & CODA & WB & EBB & MBB & Total \\
\hline Wave 2 & $37.4 \%$ & $7.1 \%$ & 0 & 0 & 0 & 0 & $26.4 \%$ \\
\hline Wave 3 & $37.9 \%$ & $35.1 \%$ & 0 & 0 & 0 & 0 & $27.3 \%$ \\
\hline Wave 4 & $32.0 \%$ & $37.7 \%$ & 0 & 0 & 0 & 0 & $23.2 \%$ \\
\hline Wave 5 & $34.8 \%$ & $31.2 \%$ & $40.3 \%$ & $43.2 \%$ & 0 & 0 & $31.4 \%$ \\
\hline Wave 6 & $31.7 \%$ & $33.1 \%$ & $25.0 \%$ & $33.4 \%$ & 0 & 0 & $27.8 \%$ \\
\hline Wave 7 & $32.0 \%$ & $30.5 \%$ & $31.9 \%$ & $35.8 \%$ & 0 & 0 & $28.4 \%$ \\
\hline Wave 8 & $30.5 \%$ & $29.2 \%$ & $31.9 \%$ & $35.6 \%$ & $35.3 \%$ & 0 & $30.9 \%$ \\
\hline Wave 9 & $29.1 \%$ & $20.8 \%$ & $26.4 \%$ & $34.9 \%$ & $31.9 \%$ & 0 & $29.3 \%$ \\
\hline Wave 10 & $23.0 \%$ & $18.2 \%$ & $23.6 \%$ & $32.5 \%$ & $23.7 \%$ & 0 & $23.8 \%$ \\
\hline Wave 11 & $23.9 \%$ & $18.8 \%$ & $29.2 \%$ & $32.7 \%$ & $34.1 \%$ & $28.0 \%$ & $26.3 \%$ \\
\hline Wave 12 & $24.0 \%$ & $15.6 \%$ & $26.4 \%$ & $32.5 \%$ & $30.7 \%$ & $29.5 \%$ & $25.9 \%$ \\
\hline
\end{tabular}

Note. Analysis of the 1992 through 2014 HRS. Sample size $=8,247$.

Table 17.

Summary of Financial Status Changes - Negative Income Shock Before Retirement

\begin{tabular}{|c|c|c|c|c|c|c|c|}
\hline Wave & HRS & AHEAD & CODA & WB & EBB & MBB & Total \\
\hline Wave 2 & $25.8 \%$ & $1.3 \%$ & 0 & 0 & 0 & 0 & $18.2 \%$ \\
\hline Wave 3 & $26.6 \%$ & $36.4 \%$ & 0 & 0 & 0 & 0 & $19.4 \%$ \\
\hline Wave 4 & $30.7 \%$ & $37.0 \%$ & 0 & 0 & 0 & 0 & $22.3 \%$ \\
\hline Wave 5 & $29.9 \%$ & $31.8 \%$ & $26.4 \%$ & $21.9 \%$ & 0 & 0 & $24.9 \%$ \\
\hline Wave 6 & $30.7 \%$ & $42.9 \%$ & $38.9 \%$ & $30.1 \%$ & 0 & 0 & $26.9 \%$ \\
\hline Wave 7 & $28.7 \%$ & $32.5 \%$ & $30.6 \%$ & $28.3 \%$ & 0 & 0 & $25.0 \%$ \\
\hline Wave 8 & $27.8 \%$ & $30.5 \%$ & $27.8 \%$ & $31.4 \%$ & $23.8 \%$ & 0 & $27.2 \%$ \\
\hline Wave 9 & $26.3 \%$ & $28.6 \%$ & $29.2 \%$ & $33.3 \%$ & $25.6 \%$ & 0 & $26.6 \%$ \\
\hline Wave 10 & $28.8 \%$ & $22.1 \%$ & $29.2 \%$ & $35.2 \%$ & $34.6 \%$ & 0 & $29.4 \%$ \\
\hline Wave 11 & $24.1 \%$ & $18.2 \%$ & $19.4 \%$ & $31.2 \%$ & $35.6 \%$ & $42.5 \%$ & $26.6 \%$ \\
\hline Wave 12 & $21.1 \%$ & $13.0 \%$ & $18.1 \%$ & $28.0 \%$ & $37.5 \%$ & $39.6 \%$ & $24.1 \%$ \\
\hline
\end{tabular}


Note. Analysis of the 1992 through 2014 HRS. Sample size = 8,247.

Table 18.

Summary of Financial Status Changes - Wealth (Mean and Median)

\begin{tabular}{|c|c|c|c|c|c|c|c|c|}
\hline Wave & Mean/median & HRS & AHEAD & CODA & WB & EBB & MBB & Total \\
\hline \multirow[b]{2}{*}{ Wave 1} & Mean & $\$ 211,398.8$ & $\$ 352,343.7$ & 0 & 0 & 0 & 0 & $\$ 211,926.6$ \\
\hline & Median & $\$ 103,500.0$ & $\$ 106,250.0$ & 0 & 0 & 0 & 0 & $\$ 103,500.0$ \\
\hline \multirow[b]{2}{*}{ Wave 2} & Mean & $\$ 248,788.8$ & $\$ 390,638.3$ & 0 & 0 & 0 & 0 & $\$ 252,652.8$ \\
\hline & Median & $\$ 125,000.0$ & $\$ 159,000.0$ & 0 & 0 & 0 & 0 & $\$ 126,000.0$ \\
\hline \multirow[b]{2}{*}{ Wave 3} & Mean & $\$ 286,526.9$ & $\$ 476,505.2$ & 0 & 0 & 0 & 0 & $\$ 291,744.1$ \\
\hline & Median & $\$ 135,500.0$ & $\$ 170,000.0$ & 0 & 0 & 0 & 0 & $\$ 136,750.0$ \\
\hline \multirow[b]{2}{*}{ Wave 4} & Mean & $\$ 336,893.5$ & $\$ 462,264.1$ & $\$ 349,700.1$ & $\$ 276,275.0$ & 0 & 0 & $\$ 329,857.0$ \\
\hline & Median & $\$ 151,500.0$ & $\$ 198,750.0$ & $\$ 132,000.0$ & $\$ 121,000.0$ & 0 & 0 & $\$ 145,200.0$ \\
\hline \multirow[b]{2}{*}{ Wave 5} & Mean & $\$ 396,884.6$ & $\$ 446,593.8$ & $\$ 415,131.3$ & $\$ 352,298.5$ & 0 & 0 & $\$ 390,765.5$ \\
\hline & Median & $\$ 168,900.0$ & $\$ 195,000.0$ & $\$ 148,000.0$ & $\$ 151,000.0$ & 0 & 0 & $\$ 166,500.0$ \\
\hline \multirow[b]{2}{*}{ Wave 6} & Mean & $\$ 381,231.3$ & $\$ 495,537.1$ & $\$ 418,085.7$ & $\$ 346,654.2$ & 0 & 0 & $\$ 378,233.2$ \\
\hline & Median & $\$ 182,000.0$ & $\$ 236,450.0$ & $\$ 166,600.0$ & $\$ 172,000.0$ & 0 & 0 & $\$ 181,000.0$ \\
\hline \multirow[b]{2}{*}{ Wave 7} & Mean & $\$ 451,132.6$ & $\$ 520,274.5$ & $\$ 613,780.1$ & $\$ 427,249.5$ & $\$ 407,138.6$ & 0 & $\$ 445,931.1$ \\
\hline & Median & $\$ 207,000.0$ & $\$ 230,250.0$ & $\$ 205,500.0$ & $\$ 207,500.0$ & $\$ 185,750.0$ & 0 & $\$ 203,000.0$ \\
\hline \multirow[b]{2}{*}{ Wave 8} & Mean & $\$ 554,702.2$ & $\$ 555,047.3$ & $\$ 556,448.6$ & $\$ 570,919.9$ & $\$ 526,013.5$ & 0 & $\$ 554,519.3$ \\
\hline & Median & $\$ 248,700.0$ & $\$ 269,500.0$ & $\$ 215,000.0$ & $\$ 254,300.0$ & $\$ 223,750.0$ & 0 & $\$ 248,100.0$ \\
\hline
\end{tabular}




\begin{tabular}{ccccccccc}
\hline Wave & Mean/median & HRS & AHEAD & CODA & WB & EBB & MBB & Total \\
\hline \multirow{2}{*}{ Wave 9 } & Mean & $\$ 519,450.4$ & $\$ 733,030.9$ & $\$ 560,476.0$ & $\$ 577,822.9$ & $\$ 527,522.8$ & 0 & $\$ 533,957.0$ \\
& Median & $\$ 248,000.0$ & $\$ 259,750.0$ & $\$ 210,000.0$ & $\$ 266,750.0$ & $\$ 218,500.0$ & 0 & $\$ 246,600.0$ \\
\multirow{2}{*}{ Wave 10 } & Mean & $\$ 489,297.1$ & $\$ 415,369.1$ & $\$ 764,640.3$ & $\$ 530,271.8$ & $\$ 565,591.3$ & $\$ 300,192.6$ & $\$ 500,880.8$ \\
& Median & $\$ 228,800.0$ & $\$ 183,500.0$ & $\$ 171,000.0$ & $\$ 248,250.0$ & $\$ 207,000.0$ & $\$ 127,000.0$ & $\$ 226,800.0$ \\
\multirow{2}{*}{ Wave 11 } & Mean & $\$ 492,507.8$ & $\$ 457,782.1$ & $\$ 753,896.3$ & $\$ 618,458.2$ & $\$ 551,172.7$ & $\$ 273,677.4$ & $\$ 515,486.6$ \\
& Median & $\$ 224,000.0$ & $\$ 127,500.0$ & $\$ 225,500.0$ & $\$ 246,000.0$ & $\$ 221,500.0$ & $\$ 109,800.0$ & $\$ 223,000.0$ \\
\multirow{2}{*}{ Wave 12 } & & & & & & & & \\
& Mean & $\$ 520,048.1$ & $\$ 514,550.2$ & $\$ 776,328.0$ & $\$ 684,823.9$ & $\$ 573,405.8$ & $\$ 315,645.1$ & $\$ 550,862.1$ \\
& Median & $\$ 225,000.0$ & $\$ 175,000.0$ & $\$ 166,000.0$ & $\$ 260,000.0$ & $\$ 220,000.0$ & $\$ 125,500.0$ & $\$ 226,560.5$ \\
\hline
\end{tabular}

Note. Analysis of the 1992 through 2014 HRS. Sample size = 8,247. 


\subsection{Sample Characteristics Concerning Demographics, Economics, and Respondents' Expectations}

The previous section described the characteristics of the sample relating to the major life-changing events that affect retirement time and are the focus of this dissertation: marital, health, and financial status changes. In this section, the focus shifts to considerations besides life-changing events-specifically, the same considerations previously described in Section 2.2. As a reminder, the following considerations unrelated to life-changing events affect retirement time: demographic characteristics, economic factors, and the respondents' expectations and preferences. They are reported in Table 19. As shown in the table, within the total sample size of 8,247 respondents to the RAND HRS, the majority of respondents were from the initial HRS cohort $(5,796)$, the WB cohort $(1,154)$, and the EBB cohort $(864)$. The remaining three cohorts made up a relatively small portion of the total sample: 154 respondents from AHEAD, 72 from CODA, and 207 from MBB.

Next, Table 19 covers the demographic characteristics that affect retirement time. As explained in Chapter 2, they are age, gender, race/ethnicity, education, number of children, and occupation. First, the mean age of the respondents was 54.2 for the initial HRS cohort, 67.9 for the AHEAD cohort, 67.7 for CODA, 52.3 for WB, 53.5 for EBB, and 53.2 for MBB cohort. When the total sample was assessed, it was found that the average age was 54.2 years old. As expected by the very definition of the AHEAD cohort, it had the highest average age (67.9), and MBB had the lowest average age (53.2) among all six cohorts. 
Overall, female respondents accounted for more than half $(54.9 \%)$ of the total sample, the rest $(45.1 \%)$ of the respondents were male. Each of the six cohorts had more female respondents than male respondents. More than half of the cohorts were pretty close to a fifty-fifty distribution of males and females, including the initial HRS cohort (45.0\% male and $55.0 \%$ female), WB (44.5\% male and $55.5 \%$ female), EBB $(49.0 \%$ male and 51.0\% female), and MBB (49.3\% male and 50.7\% female). The AHEAD cohort (33.8\% male and $66.2 \%$ female) and CODA cohort (29.2\% male and $70.8 \%$ female) had 2 times more female respondents than male respondents.

The overwhelming majority of respondents were White, with the overall percentage of White respondents at $78.9 \%$. The percentages were higher in the initial HRS cohort (80.7\%), AHEAD (86.4\%), CODA (90.3\%), and WB (81.7\%). In other words, all the cohorts except for EBB (65.9\%) and MBB (58.0\%) had proportions of White respondents that were higher than the sample's overall percentage of Whites. The percentages of respondents who identified either as Black or as being in the "other" category of the RAND HRS survey were higher in younger cohorts. For example, less than one-fifth of the sample's total respondents (16.5\%) were Black, but among those respondents in the EBB and MBB cohorts, $23.3 \%$ and $28.5 \%$, respectively, identified as Black. Similarly, the percentages of respondents who identified as other races were more than 2 times higher within the $\mathrm{EBB}$ and $\mathrm{MBB}$ cohorts $(10.8 \%$ and $13.5 \%$, respectively) than in the overall sample, in which only $4.5 \%$ of the respondents identified as other races. 
б Table 19.

Summary of Respondents' Characteristics Besides Life-Changing Events (Demographics, Economics, and Expectations)

\begin{tabular}{|c|c|c|c|c|c|c|c|}
\hline Category/characteristic & HRS & AHEAD & CODA & WB & EBB & MBB & Total \\
\hline \multicolumn{8}{|l|}{ Sample size } \\
\hline Number of respondents & 5,796 & 154 & 72 & 1,154 & 864 & 207 & 8,247 \\
\hline \multicolumn{8}{|c|}{ Demographic characteristics } \\
\hline Age & $54.2(4.8)$ & $67.9(8.7)$ & $67.7(7.1)$ & $52.3(3.2)$ & $53.5(3.7)$ & $53.2(4.1)$ & $54.2(5.2)$ \\
\hline \multicolumn{8}{|l|}{ Gender } \\
\hline \multicolumn{8}{|l|}{ Race/ethnicity } \\
\hline White & $80.7 \%$ & $86.4 \%$ & $90.3 \%$ & $81.7 \%$ & $65.9 \%$ & $58.0 \%$ & $78.9 \%$ \\
\hline Black & $15.7 \%$ & $11.7 \%$ & $5.6 \%$ & $14.6 \%$ & $23.3 \%$ & $28.5 \%$ & $16.5 \%$ \\
\hline Other & $3.6 \%$ & $1.9 \%$ & $4.2 \%$ & $3.7 \%$ & $10.8 \%$ & $13.5 \%$ & $4.5 \%$ \\
\hline \multicolumn{8}{|l|}{ Education } \\
\hline Number of children & $4.0(1.9)$ & $3.8(2.4)$ & $4.0(2.3)$ & $3.0(1.5)$ & $3.0(1.6)$ & $3.0(1.7)$ & $3.0(1.9)$ \\
\hline \multicolumn{8}{|l|}{ Occupation } \\
\hline Managerial & $14.2 \%$ & $1.9 \%$ & $15.3 \%$ & $15.9 \%$ & $10.2 \%$ & 0 & $13.5 \%$ \\
\hline Professional & $15.8 \%$ & $3.2 \%$ & $16.7 \%$ & $18.2 \%$ & $14.6 \%$ & 0 & $15.4 \%$ \\
\hline Sales & $7.7 \%$ & 0 & $9.7 \%$ & $8.1 \%$ & $7.9 \%$ & 0 & $7.5 \%$ \\
\hline Service & $13.0 \%$ & $1.9 \%$ & $18.1 \%$ & $11.4 \%$ & $10.8 \%$ & 0 & $12.0 \%$ \\
\hline Other & $49.3 \%$ & $92.9 \%$ & $40.3 \%$ & $46.4 \%$ & $56.6 \%$ & $100.0 \%$ & $51.7 \%$ \\
\hline
\end{tabular}




\begin{tabular}{lccccccc}
\hline Category/characteristic & HRS & AHEAD & CODA & WB & EBB & MBB & Total \\
\hline $\begin{array}{l}\text { Economic characteristics } \\
\text { Income }\end{array}$ & & & & & & & \\
$\quad$ Mean & $\$ 54,850.2$ & $\$ 56,791.5$ & $\$ 56,511.9$ & $\$ 79,730.1$ & $\$ 96,028.6$ & $\$ 92,119.4$ & $\$ 63,610.1$ \\
$\quad$ Median & $\$ 44,000.0$ & $\$ 36,792.0$ & $\$ 38,227.5$ & $\$ 61,912$ & $\$ 65,275.0$ & $\$ 63,880.0$ & $\$ 48,000.0$ \\
$\quad$ Wealth & & & & & & & \\
$\quad$ Mean & $\$ 215,814.8$ & $\$ 426,424.3$ & $\$ 338,594.4$ & $\$ 280,283.9$ & $\$ 391,129.5$ & $\$ 299,576.3$ & $\$ 249,259.8$ \\
$\quad$ Median & $\$ 103,850.0$ & $\$ 162,000.0$ & $\$ 130,000.0$ & $\$ 122,000.0$ & $\$ 174,600.0$ & $\$ 128,000.0$ & $\$ 111,500.0$
\end{tabular}

Pension ownership

No pension

DB only

DC only

DB and DC

Homeownership

Yes

No

$(4.2 \%$

$\begin{array}{ccccccc}43.2 \% & 92.9 \% & 56.9 \% & 38.5 \% & 41.4 \% & 49.8 \% & 43.6 \% \\ 35.6 \% & 2.6 \% & 12.5 \% & 28.6 \% & 28.9 \% & 28.0 \% & 32.9 \% \\ 19.4 \% & 3.9 \% & 25.0 \% & 25.7 \% & 27.0 \% & 20.8 \% & 20.9 \% \\ 1.8 \% & 0.6 \% & 5.6 \% & 7.2 \% & 2.7 \% & 1.4 \% & 2.7 \%\end{array}$

Health insurance coverage in retirement

Yes

No

$53.0 \%$

$33.1 \%$

$36.1 \%$

$58.8 \%$

$52.5 \%$

$44.0 \%$

$53.0 \%$

$47.0 \%$

$66.9 \%$

$63.9 \%$

$41.2 \%$

$47.5 \%$

$56.0 \%$

$47.0 \%$

$54.1 \%$

$5.2 \%$

$4.2 \%$

$29.8 \%$

$45.9 \%$

$94.8 \%$

$95.8 \%$

$33.0 \%$

$28.5 \%$

$46.5 \%$

Respondents' expectations and preferences

Expect to receive inheritance

Yes

$43.7 \%$

$13.6 \%$

$56.3 \%$

$86.4 \%$

$18.1 \%$

$70.2 \%$

$67.0 \%$

$71.5 \%$

$53.5 \%$

Expect to leave bequest

Yes

$43.5 \%$

$56.5 \%$

$5.8 \%$

$94.2 \%$

$53.4 \%$

$38.2 \%$

$61.8 \%$

0
$100.0 \%$

$42.6 \%$

$81.9 \% \quad 46.6 \%$

0

$\begin{array}{cc}0 & 0 \\ 100.0 \% & 100.0 \%\end{array}$

0
$100.0 \%$

0

$100.0 \%$

$30.7 \%$

No

(n)




\begin{tabular}{|c|c|c|c|c|c|c|c|}
\hline Category/characteristic & HRS & AHEAD & CODA & WB & EBB & MBB & Total \\
\hline \multicolumn{8}{|c|}{ Whether current job involves lots of stress } \\
\hline No & $40.8 \%$ & $77.3 \%$ & $45.8 \%$ & $37.1 \%$ & $37.4 \%$ & $36.2 \%$ & $40.5 \%$ \\
\hline Less than 1 year & $14.0 \%$ & $3.9 \%$ & $15.3 \%$ & $10.9 \%$ & $11.9 \%$ & 0 & $12.9 \%$ \\
\hline 1 to 5 years & $42.5 \%$ & $6.5 \%$ & $52.8 \%$ & $27.7 \%$ & $24.3 \%$ & 0 & $36.9 \%$ \\
\hline 5 to 10 years & $30.4 \%$ & $3.2 \%$ & $13.9 \%$ & $37.9 \%$ & $32.3 \%$ & 0 & $30.2 \%$ \\
\hline Not sure/unknown & $5.2 \%$ & $85.7 \%$ & $11.1 \%$ & $9.6 \%$ & $18.5 \%$ & $100.0 \%$ & $11.2 \%$ \\
\hline
\end{tabular}

Note. In this table, the numbers in parentheses in the rows for age and number of children describe standard deviation. 
In terms of education, for the total sample that included all 12 waves and six cohorts, an overall average of $17.9 \%$ of respondents had not completed high school, $36.9 \%$ obtained a high school diploma, $23.0 \%$ had some college education, and $22.2 \%$ had earned a bachelor's degree or graduate or professional degree. Most of the respondents had earned at least a high school education. For respondents who did not complete high school, the percentage was $21.1 \%$ in the initial HRS cohort, $19.5 \%$ in AHEAD, $22.2 \%$ in CODA, $10.1 \%$ in $\mathrm{WB}, 9.5 \%$ in $\mathrm{EBB}$, and $5.8 \%$ in $\mathrm{MBB}$. The percentage who obtained a high school degree was the highest in the MBB cohort $(40.1 \%)$ and lowest in the EBB cohort $(30.1 \%)$. For respondents who had some college education, the percentage was the lowest in the CODA cohort (18.0\%) and highest in MBB (33.8\%). Compared with the overall percentage $(22.2 \%)$ of those respondents who have a bachelor's degree or graduate or professional degree (i.e., are in the "college and above" category), the percentages were lower only in the initial HRS cohort (19.9\%) and the MBB cohort (20.3\%). The percentages were higher in AHEAD (24.0\%), CODA (25.0\%), WB (27.9\%), and EBB (29.5\%).

Overall, across the six cohorts, each respondent has an average of three children. On average, respondents in the $\mathrm{WB}, \mathrm{EB}$, and $\mathrm{MBB}$ cohorts reported having an average of three children. The averages for the other three cohorts were slightly higher, about four children. In short, older cohorts had more children than younger cohorts did.

The majority (51.7\%) of the sample's overall respondents reported working in an occupation that fell in the "other" category, meaning these respondents did not work in managerial, professional, sales, or service occupations. As previously mentioned in Chapter 4, "other" included farmers, members of the armed forces, and operators. The 
percentages of respondents in the "other" category differed substantially from cohort to cohort (49.3\% in HRS, 92.9\% in AHEAD, 40.3\% in CODA, 46.4\% in WB, 56.6\% in $\mathrm{EBB}$, and $100.0 \%$ in $\mathrm{MBB})$.

After the "other" category, the next-highest proportion of total respondents reported working in a professional occupation. More than one-tenth (15.4\%) of respondents had professional occupations. When comparing cohorts, the percentage in this category was highest in the WB cohort (18.2\%) and lowest in AHEAD (3.2\%). On average, $13.5 \%$ of the overall sample's respondents reported working in a managerial position. The corresponding percentages were higher in the initial HRS cohort (14.2\%), CODA (15.3\%), and WB (15.9\%). The AHEAD cohort had only 1.9\% of respondents working in managerial positions. The MBB cohort had no respondents working in managerial, professional, sales, or service occupations-all MMB respondents reported working in an occupation that fell within the "other" category. The overall average percentage (12.0\%) of respondents working in a service occupation was slightly above one-tenth. The percentage of respondents who had sales occupations was less than onetenth for the total sample (7.5\%) as well as all six cohorts: $7.7 \%$ in the initial HRS cohort, 9.7\% in CODA, $8.1 \%$ in $\mathrm{WB}$, and $7.9 \%$ in EBB while neither AHEAD nor MBB had any respondents in sales occupations.

Moving on from demographic characteristics, Table 18 reports economic characteristics, listing the sample-wide and cohort-specific mean and median incomes and mean and median wealth along with the percentages of respondents who owned pensions, owned homes, and had retiree health insurance plans offered by their 
employers. In the total sample, the mean income was $\$ 63,610.1$, and the mean wealth was $\$ 249,259.8$.

An average of $43.6 \%$ of all respondents had no pension ownership. On average, $32.9 \%$ of all respondents had DB plans only. A little more than one-fifth (20.9\%) of the respondents had DC plans only. The percentage of the total sample that had both DC and DB plans was much lower (2.7\%) than the other three categories. The percentages of the respondents who did not have any retirement plans (neither DB nor DC) were higher than the overall total (43.6\%) in the AHEAD (92.9\%), CODA (56.9\%), and MBB (49.8\%) cohorts but lower in HRS (43.2\%), WB (38.5\%), and EBB (41.4\%) cohorts. In the majority of cohorts, approximately one-third of the respondents had DB plans only (35.6\% in $\mathrm{HRS}, 28.6 \%$ in $\mathrm{WB}, 28.9 \%$ in $\mathrm{EBB}$, and $28.0 \%$ in MBB). On the contrary, both AHEAD (2.6\%) and CODA (12.5\%) had much lower percentages of respondents with DB plans only. The trend for the percentages of respondents who had only DC plans was similar to the trend for DB plans: In five out of six cohorts, roughly a fifth of the cohort's respondents had DC plans only (19.4\% in HRS, $25.0 \%$ in CODA, $25.7 \%$ in WB, $27.0 \%$ in EBB, and $20.8 \%$ in MBB). Yet, one had a much lower percentage (3.9\% in AHEAD). Within each cohort, the percentage of respondents that had both DC and DB plans was quite low. The lowest percentage was $0.6 \%$ in the AHEAD cohort, and the highest was $7.2 \%$ in the WB cohort.

More than half (53.0\%) of the total sample's respondents were homeowners. The percentages were similar within the initial HRS cohort (53.0\%), the WB cohort (58.8\%), as well as the EBB cohort (52.5\%). On the other hand, the percentages of respondents 
who owned homes were less than half in AHEAD (33.1\%), CODA (36.1\%), and MBB $(44.0 \%)$, meaning these three cohorts had more renters than homeowners.

Among the total sample of respondents, more than half $(53.5 \%)$ did not have access to employer-provided health insurance coverage during retirement. Most of the AHEAD cohort (94.8\%) and CODA cohort (95.8\%) did not have such health insurance in retirement; more than two-thirds of the respondents did not have such health insurance in WB (70.2\%) and MBB (71.5\%). The overall percentage of those respondents who had employer-provided health insurance in retirement was $46.5 \%$; among the corresponding cohort-specific percentages, the percentage was highest in the initial HRS cohort, at $54.1 \%$, and lowest in the CODA cohort, at $4.2 \%$.

Thus far, the data in Table 18 have described demographic and economic characteristics that, while unrelated to major life-changing events, may still affect retirement time. Table 18 also reports on respondents' expectations and preferences that may affect retirement time. The majority $(57.4 \%)$ of the overall sample did not expect to receive any inheritance. More than $80 \%$ of respondents from three cohorts did not expect any inheritance: $86.4 \%$ in the AHEAD cohort, $81.9 \%$ in the CODA cohort, and $100.0 \%$ in the MBB cohort. Corresponding percentages were much lower in the initial HRS cohort (56.3\%), WB (46.6\%), and EBB (61.8\%). For respondents who expected to receive an inheritance, the top two highest cohort-specific percentages were in the HRS (43.7\%) and WB (53.4\%) cohorts, and the two lowest percentages were in AHEAD $(13.6 \%)$ and CODA $(18.1 \%)$.

More than two-thirds $(69.3 \%)$ of the overall sample's respondents did not expect to leave any bequest. In particular, none of the respondents $(0 \%)$ in the CODA, WB, 
EBB, and MBB cohorts expected to leave a bequest. The initial HRS cohort (43.5\%) and the AHEAD cohort (5.8\%) were the only two that had respondents who expected to leave some sort of bequest, with the initial HRS cohort having a much higher percentage of respondents expecting to leave a bequest than any of the other six cohorts.

The majority $(59.5 \%)$ of respondents in the total sample experienced lots of stress in their jobs. In all but one of the cohorts, roughly half of the respondents reported experiencing high levels of stress (e.g., $54.2 \%$ in the CODA cohort and $63.8 \%$ in the MBB cohort). On the other hand, in the AHEAD cohort, only $22.7 \%$ reported experiencing lots of stress. In the overall sample, $40.5 \%$ of respondents said they did not have lots of stress in their current jobs. The percentage was lowest in the MBB cohort (36.2\%) and highest in the AHEAD cohort (77.3\%).

Another preference that each respondent reported on was the financial planning horizon (i.e., the number of years that a respondent wanted his or her financial assets to last). The largest percentage of respondents (36.9\% of the total sample) reported that they had a financial planning horizon of 1 to 5 years. The corresponding cohort-specific percentage was highest $(52.8 \%)$ in the CODA cohort and lowest $(6.5 \%)$ in the AHEAD cohort. When assessing the total sample, the second-highest percentage $(30.2 \%)$ of respondents said their financial planning horizons fell in the range of 5 to 10 years. Corresponding percentages remained similar within cohorts (e.g., 30.4\% in the initial HRS cohort, $37.9 \%$ in the WB cohort, and $32.3 \%$ in the EBB cohort). The third-highest percentage $(12.9 \%)$ of total respondents reported financial planning horizons of less than 1 year. The longest financial planning horizon (i.e., longer than 10 years) was associated with $8.9 \%$ of the overall sample; the WB cohort had the highest percentage (13.9\%) of 
respondents with financial planning horizons greater than 10 years. Not surprisingly, the AHEAD cohort, which includes respondents born before 1924, had the lowest percentage $(0.6 \%)$ of respondents who had financial planning horizons longer than 10 years.

\subsection{Summary of Retirement Timing by Sample Characteristics}

The two previous sections of this chapter focused on describing the characteristics of the sample-Section 5.2 concentrated on life-changing-event characteristics, while Section 5.3 described the non-life-changing-event characteristics. Section 5.4 now shifts to descriptions of how retirement times related to the various characteristics from Sections 5.2 and 5.3. In other words, this section answers the question, "How did the sample characteristics match up with the respondents who chose early, delayed, or ontime retirement (when compared to the anticipated retirement years they reported in the HRS survey)?” Table 20 summarizes respondents' retirement timing by sample characteristics.

In order to better understand this table, it is helpful to provide an example of how to interpret it: The data are clustered in three categories (early retirement, delayed retirement, and on-time retirement). For example, the cells in the tables' first few rows include data about the marital status changes, and the first column of data concerns those respondents who took early retirement. Included in this subset were respondents who, before retirement, changed from not married to married (4.2\% of this group), married to widowed $(6.6 \%)$, or married to divorced $(2.6 \%)$ as well as respondents who remained married $(83.3 \%)$ or never married $(3.4 \%)$. Note that these percentages add up to $100 \%$ (ignoring rounding discrepancies), meaning that this group's marital status changes were evaluated on their own. Similarly, those respondents who delayed their retirement were 


\section{$\&$ Table 20.}

Summary of Retirement Timing by Sample Characteristics

\begin{tabular}{|c|c|c|c|}
\hline Variable & $\begin{array}{c}\text { Early retirement } \\
(\mathrm{n}=3,801)\end{array}$ & $\begin{array}{c}\text { Delayed retirement } \\
(\mathrm{n}=3,264)\end{array}$ & $\begin{array}{c}\text { On-time retirement } \\
(\mathrm{n}=1,182)\end{array}$ \\
\hline \multicolumn{4}{|l|}{ Life-changing events } \\
\hline \multicolumn{4}{|l|}{ Marital status changes } \\
\hline Not married to married & $4.2 \%$ & $3.2 \%$ & $2.1 \%$ \\
\hline Married to widowed & $6.6 \%$ & $11.0 \%$ & $5.8 \%$ \\
\hline Married to divorced & $2.6 \%$ & $2.0 \%$ & $2.7 \%$ \\
\hline Remained married & $83.3 \%$ & $81.0 \%$ & $86.6 \%$ \\
\hline Never married & $3.4 \%$ & $2.8 \%$ & $2.7 \%$ \\
\hline \multicolumn{4}{|l|}{ Positive income shock } \\
\hline Yes & $34.4 \%$ & $39.6 \%$ & $33.2 \%$ \\
\hline No & $65.6 \%$ & $60.4 \%$ & $66.8 \%$ \\
\hline \multicolumn{4}{|l|}{ Negative income shock } \\
\hline Yes & $52.5 \%$ & $46.1 \%$ & $52.3 \%$ \\
\hline No & $47.5 \%$ & $53.9 \%$ & $47.7 \%$ \\
\hline \multicolumn{4}{|c|}{ Whether diagnosed with diabetes before retirement } \\
\hline Yes & $19.6 \%$ & $21.0 \%$ & $16.8 \%$ \\
\hline No & $80.4 \%$ & $79.0 \%$ & $83.2 \%$ \\
\hline \multicolumn{4}{|c|}{ Whether diagnosed with cancer before retirement } \\
\hline Yes & $11.0 \%$ & $15.3 \%$ & $10.0 \%$ \\
\hline No & $89.0 \%$ & $84.7 \%$ & $90.0 \%$ \\
\hline \multicolumn{4}{|c|}{ Whether diagnosed with lung disease before retirement } \\
\hline Yes & $9.2 \%$ & $8.2 \%$ & $7.0 \%$ \\
\hline No & $90.8 \%$ & $91.8 \%$ & $93.0 \%$ \\
\hline
\end{tabular}




\begin{tabular}{|c|c|c|c|}
\hline Variable & $\begin{array}{l}\text { Early retirement } \\
(\mathrm{n}=3,801)\end{array}$ & $\begin{array}{c}\text { Delayed retirement } \\
(\mathrm{n}=3,264)\end{array}$ & $\begin{array}{l}\text { On-time retirement } \\
(\mathrm{n}=1,182)\end{array}$ \\
\hline \multicolumn{4}{|c|}{ Whether diagnosed with a stroke before retirement } \\
\hline Yes & $6.4 \%$ & $6.1 \%$ & $4.4 \%$ \\
\hline No & $93.6 \%$ & $93.9 \%$ & $95.6 \%$ \\
\hline \multicolumn{4}{|c|}{ Whether diagnosed with heart disease before retirement } \\
\hline Yes & $18.7 \%$ & $22.1 \%$ & $16.9 \%$ \\
\hline No & $81.3 \%$ & $77.9 \%$ & $83.1 \%$ \\
\hline \multicolumn{4}{|c|}{ Reported depressed before retirement } \\
\hline Yes & $15.0 \%$ & $10.9 \%$ & $12.4 \%$ \\
\hline No & $85.0 \%$ & $89.1 \%$ & $87.6 \%$ \\
\hline \multicolumn{4}{|c|}{ Whether diagnosed with a psychiatric problem before retirement } \\
\hline Yes & $17.0 \%$ & $11.8 \%$ & $8.3 \%$ \\
\hline No & $83.0 \%$ & $88.2 \%$ & $91.7 \%$ \\
\hline \multicolumn{4}{|c|}{ Demographic Characteristics } \\
\hline Age & $53.3(5.25)$ & $54.7(5.04)$ & $55.8(5.07)$ \\
\hline \multicolumn{4}{|l|}{ Gender } \\
\hline Male & $44.1 \%$ & $43.2 \%$ & $50.9 \%$ \\
\hline Female & $55.9 \%$ & $56.8 \%$ & $49.1 \%$ \\
\hline \multicolumn{4}{|c|}{ Race/ethnicity } \\
\hline White & $78.5 \%$ & $79.3 \%$ & $79.6 \%$ \\
\hline Black & $16.3 \%$ & $16.9 \%$ & $16.0 \%$ \\
\hline Other & $5.2 \%$ & $3.8 \%$ & $4.4 \%$ \\
\hline
\end{tabular}




\begin{tabular}{|c|c|c|c|}
\hline Variable & $\begin{array}{l}\text { Early retirement } \\
\quad(\mathrm{n}=3,801)\end{array}$ & $\begin{array}{c}\text { Delayed retirement } \\
(\mathrm{n}=3,264)\end{array}$ & $\begin{array}{c}\text { On-time retirement } \\
(\mathrm{n}=1,182)\end{array}$ \\
\hline Less than high school & $17.9 \%$ & $17.7 \%$ & $18.7 \%$ \\
\hline Some college & $24.0 \%$ & $22.4 \%$ & $21.4 \%$ \\
\hline College and above & $21.6 \%$ & $22.5 \%$ & $22.8 \%$ \\
\hline \multicolumn{4}{|l|}{ Occupation } \\
\hline Professional & $14.3 \%$ & $16.7 \%$ & $15.1 \%$ \\
\hline Sales & $8.0 \%$ & $7.2 \%$ & $6.3 \%$ \\
\hline Service & $12.0 \%$ & $12.3 \%$ & $11.1 \%$ \\
\hline Other & $53.6 \%$ & $48.2 \%$ & $55.2 \%$ \\
\hline \multicolumn{4}{|l|}{ Economic characteristics } \\
\hline \multicolumn{4}{|l|}{ Income } \\
\hline \multicolumn{4}{|l|}{ Wealth } \\
\hline Mean & $\$ 227,652.9$ & $\$ 241,791.1$ & $\$ 271,047.6$ \\
\hline Median & $\$ 117,616.7$ & $\$ 141,296.7$ & $\$ 126,066.7$ \\
\hline \multicolumn{4}{|l|}{ Pension ownership } \\
\hline No pension & $48.1 \%$ & $41.9 \%$ & $33.6 \%$ \\
\hline DB only & $30.1 \%$ & $33.9 \%$ & $39.0 \%$ \\
\hline DC only & $19.5 \%$ & $21.3 \%$ & $24.1 \%$ \\
\hline $\mathrm{DB}$ and $\mathrm{DC}$ & $2.3 \%$ & $2.9 \%$ & $3.3 \%$ \\
\hline
\end{tabular}




\begin{tabular}{|c|c|c|c|}
\hline Variable & $\begin{array}{l}\text { Early retirement } \\
(\mathrm{n}=3,801)\end{array}$ & $\begin{array}{c}\text { Delayed retirement } \\
(\mathrm{n}=3,264)\end{array}$ & $\begin{array}{c}\text { On-time retirement } \\
(\mathrm{n}=1,182)\end{array}$ \\
\hline \multicolumn{4}{|l|}{ Homeownership } \\
\hline Yes & $52.2 \%$ & $54.6 \%$ & $51.1 \%$ \\
\hline No & $47.8 \%$ & $45.4 \%$ & $48.9 \%$ \\
\hline \multicolumn{4}{|c|}{ Health insurance coverage in retirement } \\
\hline Yes & $42.5 \%$ & $48.9 \%$ & $52.9 \%$ \\
\hline No & $57.5 \%$ & $51.1 \%$ & $47.1 \%$ \\
\hline \multicolumn{4}{|c|}{ Respondents' expectations and preferences } \\
\hline \multicolumn{4}{|c|}{ Expect to receive inheritance } \\
\hline Yes & $41.6 \%$ & $44.7 \%$ & $39.8 \%$ \\
\hline No & $58.4 \%$ & $55.3 \%$ & $60.2 \%$ \\
\hline \multicolumn{4}{|l|}{ Expect to leave bequest } \\
\hline Yes & $27.0 \%$ & $35.0 \%$ & $30.7 \%$ \\
\hline No & $73.0 \%$ & $65.0 \%$ & $69.3 \%$ \\
\hline \multicolumn{4}{|c|}{ Whether current job involves lots of stress } \\
\hline Yes & $58.3 \%$ & $60.0 \%$ & $61.7 \%$ \\
\hline No & $41.7 \%$ & $40.0 \%$ & $38.3 \%$ \\
\hline \multicolumn{4}{|c|}{ Financial planning horizon } \\
\hline Less than 1 year & $12.3 \%$ & $13.5 \%$ & $12.7 \%$ \\
\hline 1 to 5 years & $34.5 \%$ & $39.2 \%$ & $38.1 \%$ \\
\hline 5 to 10 years & $29.5 \%$ & $31.5 \%$ & $29.1 \%$ \\
\hline Longer than 10 years & $9.5 \%$ & $8.1 \%$ & $9.0 \%$ \\
\hline Not sure/unknown & $14.2 \%$ & $7.7 \%$ & $11.1 \%$ \\
\hline
\end{tabular}


evaluated as a separate group. Like the early retirement subset, the delayed retirement group changed from not married to married before retirement (3.2\% of this group), married to widowed (11.0\%), or married to divorced (2.0\%), or they remained married $(81.0 \%)$ or never married (2.8\%). Those respondents who retired on time were also evaluated separately.

Of the three categories of major life-changing events that may impact retirement timing, the first to be reported in Table 20 is marital status changes. Regardless of whether a respondent chose early, delayed, or on-time retirement, it was highly likely that the respondent was married and remained married before retirement. In other words, the highest percentage of respondents in all three categories of retirement timing had a marital status of "remained married": $83.3 \%$ in the early retirement group, $81.0 \%$ in the delayed retirement group, and $86.6 \%$ in the on-time retirement group. Only a couple of small percentage changes were notable across the table: First, the percentage of respondents who lost a spouse and delayed retirement (11.0\%) was higher than that of early retirement respondents $(6.6 \%)$ and on-time retirement respondent $(5.8 \%)$ who were widowed. Second, the highest percentage of respondents who changed from not married to married before retirement was in the early retirement group (4.2\%), rather than being in the subsets who delayed retirement (3.2\%) or retired on time (2.1\%).

In Table 20, the second category of life-changing events is financial status changes. Of the respondents in the subset who chose to retire early, more than a third (34.4\%) experienced positive income shocks. The percentage of respondents experiencing positive income shocks and retiring later than their planned retirement times was $39.6 \%$. Of the respondents who retired as planned, roughly one-third (33.2\%) had a 
positive income shock, and approximately two-thirds (66.8\%) did not. More than half of respondents in the early retirement group (52.5\%) and on-time retirement group $(52.3 \%)$ experienced negative income shocks.

When assessing the third category of life-changing events—respondents' changes in health status - the data raised questions as to whether health status changes influence retirement timing. The data in Table 20 hint at two trends, though these are not conclusive nor fully confirmed by the data. First, a higher proportion of the people who delayed retirement were diagnosed with a physical health problem. In contrast, a higher proportion of the people who retired early reported a mental condition.

A higher percentage of those who delayed their retirement (21.0\%) were diagnosed with diabetes, compared to those who retired early (19.6\%) and on time (16.8\%). Similarly, the percentage of people who delayed retirement and were diagnosed with cancer was $15.3 \%$, which was higher than the percentages of those who were diagnosed with cancer and retired early $(11.0 \%)$ or retired on time $(10.0 \%)$. Less than a tenth $(6.4 \%)$ of the respondents who chose to retire earlier than their planned retirement time were diagnosed with a stroke, but, unlike for diabetes and cancer, this percentage was higher than in the delayed retirement subset $(6.1 \%)$. The percentage of respondents who were diagnosed with heart disease and delayed retirement $(22.1 \%)$ was much higher than the percentages for those who chose to retire early $(18.7 \%)$ and on time $(16.9 \%)$. For mental health status changes, the subset of respondents who retired early had a higher percentage reporting that they were depressed: $15.0 \%$ of them reported that they were depressed, while $85.0 \%$ said that they were not depressed. The percentages were lower for the other two subsets: For the group that chose to delay retirement, $10.9 \%$ reported 
that they were depressed, and $89.1 \%$ said that they were not. For the group that retired on time, $12.4 \%$ reported that they were depressed. Similar results were found for the respondents who were diagnosed with a psychiatric problem $(17.0 \%$ had a psychiatric problem in the early retirement group, $11.8 \%$ in the delayed retirement group, and $8.3 \%$ in the on-time retirement group).

Like life-changing events, demographic characteristics seemed to impact respondents' retirement timing. The average age of respondents who retired earlier than they had planned was 53.3 years old. The average ages of both delayed (54.7 years) and on-time (55.8 years) retirement respondents were older than the early retirement respondents. More than half of the respondents who chose to delay their retirement or retire early were females; $55.9 \%$ of the early retirement group was female, as was $56.8 \%$ of the delayed retirement group. Within the subset of respondents who retired on time, well over the majority $(79.6 \%)$ were White respondents. The same was true of the early and delayed retirement subsets, which had $78.5 \%$ and $79.3 \%$ White respondents, respectively. The delayed retirement subset had a higher percentage of respondents with higher education. Compared to only $17.7 \%$ of respondents who delayed retirement and had less than a high school education, $22.4 \%$ of these respondents had some college education, and $22.5 \%$ of the same subset had a college or graduate degree.

When examining the occupation variable, the results showed that the early retirement subset had a higher percentage of respondents who classified themselves in the "professional" or "other" categories. Table 20 reports that, within the early retirement column, $14.3 \%$ fell in the professional category, and 53.6\% fell in the "other" category. 
Lower percentages applied to the managerial (12.0\%), sales $(8.0 \%)$, and service $(12.0 \%)$ categories.

Economic characteristics are reported in Table 20 next. The average income for respondents who retired early, delayed retirement, and retired on time was very close. Early retirement respondents had $\$ 56,010.4$ in average income, delayed retirement respondents had $\$ 55,620.5$ in average income, and on-time retirement respondents had $\$ 61,334.6$. On average, respondents who retired on time had the highest amount of average wealth $(\$ 271,047.6$ mean wealth, compared to $\$ 227,652.9$ for those who retired early and \$241,791.1 for those who delayed retirement). For pension ownership, of those respondents who delayed their retirement, $41.9 \%$ of them did not have any retirement plans, $33.9 \%$ of them only had DB plans, $21.3 \%$ only had DC plans, and $2.9 \%$ had both DB and DC plans. Furthermore, the data on economic characteristics raised a question as to whether access to employer-provided retiree health insurance plans prompted a greater proportion of individuals to delay their retirement. For example, Table 20 reports that $48.9 \%$ of the delayed retirement respondents had access to health insurance coverage in retirement. Compare that to only $42.5 \%$ of the respondents who took early retirement and $52.9 \%$ of the respondents who retired on time.

As with other characteristics, the data suggested that, perhaps, respondents' expectations and preferences impacted retirement timing. The delayed retirement subset had a higher percentage of respondents who expected to receive an inheritance in the future: $44.7 \%$ of the delayed retirement respondents expected to receive an inheritance, compared to $41.6 \%$ of the early retirement respondents and $39.8 \%$ of on-time retirement respondents. More respondents who delayed retirement (35.0\%) expected to leave a 
bequest too, compared to $27.0 \%$ in the early retirement subset and $30.7 \%$ among the ontime retirement respondents.

Furthermore, respondents who retired early were more likely to have a financial planning horizon that was longer than 10 years. In the group of respondents who took early retirement, $9.5 \%$ had a financial planning horizon of more than 10 years, compared to $8.1 \%$ of the delayed retirement respondents and $9.0 \%$ of the on-time retirement respondents. The early retirement respondents also had the highest percentage of people who were not sure about their financial planning horizons. For example, $14.2 \%$ of the early retirees fell into the "not sure/unknown" category when asked about their financial planning horizons, compared to $7.7 \%$ among respondents who delayed retirement and $11.1 \%$ among respondents who chose on-time retirement.

\subsection{Linear Mixed Results}

This final section of the chapter shares the results of the linear mixed regression analysis that was performed as part of the current research. The first step in conducting the regression analysis was to assess whether there might be collinearity concerns. A multicollinearity test was conducted to identify the possible significant multicollinearities between independent variables. The results of all independent variables' variance inflation were less than 10 , and the tolerances of all independent variables were greater than 0.1, indicating that there was no collinearity issue (Miles, 2005).

Table 21 displays the results of the linear mixed regression. This paragraph and the next few describe only the results in Table 21 that had $p$ values less than $.05, .01$, or .001, all suggesting that the null hypothesis could be rejected. The first category of life-changing events in Table 21 is marital status changes. Controlling for other factors, 
compared to those who remained married (i.e., the reference category), the regression analysis found that respondents who had a marital status change from married to widowed delayed their retirement by 1.8 years (21.6 months) later than their planned retirement year.

The second category of life-changing events is financial status changes. For respondents who had positive income shocks, they tended to retire 0.4 years ( 4.8 months) later than their planned retirement year when compared to those who did not experience any income shocks.

The third category is health status changes. Compared with respondents who were not diagnosed with diabetes, those who received a diabetes diagnosis delayed their retirement by 0.5 years ( 6 months). Similarly, respondents diagnosed with cancer and heart disease retired 1.0 year (12 months) and 0.9 years (10.8 months) later, respectively, than their planned retirement year. Both mental health variables included in this dissertation were significantly associated with respondents' retirement timing. Compared to those who did not report depression, respondents who reported that they were depressed retired 0.8 years (9.6 months) earlier than their planned retirement year. Respondents who were diagnosed with a psychiatric problem retired 1.0 year (12 months) earlier than their planned retirement year. These findings are consistent with prior literature (Jokela et al., 2010).

As with life-changing events, some characteristics unrelated to life-changing events were significantly associated with retirement timing. Among the demographic characteristics, Table 21 first reports on age. A 1-year increase from the mean age (54.2) led to a delay in retirement of 0.3 years (3.6 months) beyond the planned retirement year. 
In terms of the occupation variable, respondents in the "sales" and "other" categories retired 1.0 year (12 months) and 0.6 years $(7.2$ months $)$ earlier than their expected retirement year, respectively, when compared to those who were in a managerial occupation (i.e., the reference category).

Other significant characteristics relate to economics. Wealth was significantly associated with retiring later than planned. Compared to respondents whose wealth fell in the first quartile (i.e., the reference category), the respondents with wealth in the second, third, and fourth quartiles retired 0.8 years ( 9.6 months), 0.9 years (10.8 months), and 0.5 years (6.0 months) later than their planned retirement year. Pension ownership was also positively associated with retirement timing. Respondents who had only DB pension plans, only DC plans, and DB and DC plans, respectively, were found to have delayed retirement by 0.9 years (10.8 months), 0.7 years ( 8.4 months), and 1.1 years $(13.2$ months) beyond their planned retirement year when compared to those without any pension plans (i.e., the reference group). Respondents who had access to an employerprovided retiree health insurance plan retired 0.5 years ( 6 months) later than their planned retirement year. Respondents who expected to receive inheritance retired 0.5 years (6 months) later than their planned retirement year.

Among the characteristics related to respondents' expectations and preferences, bequests and financial planning horizons were found to be significant in the regression analysis. Respondents who expected to leave a bequest to a loved one(s) delayed retirement 0.8 years (9.6 months) beyond their planned retirement year when compared to those who did not expect to leave any bequest. Respondents who expected to receive any inheritance delated retirement 0.5 years ( 6 months) beyond their planned retirement year 
when compared to those who did not expect to receive any inheritance. Compared to respondents whose financial planning horizon was less than 1 year, respondents who were not sure or did not know their financial planning horizon retired 2.7 years $(32.4$ months) earlier than their planned retirement year. In addition, those who had a financial planning horizon longer than 10 years retired early by 0.7 years ( 8.4 months).

Compared to male respondents (i.e., the reference category), female respondents retired 0.6 years (7.2 months) later than their planned retirement year. Education was found to be negatively associated with the gap between planned and actual retirement years. Compared to respondents with less than a high school degree (i.e., the reference category), those who were in either the "some college" or "college and above" category (i.e., had an undergraduate or graduate degree) retired 0.7 years (8.4 months) earlier than their planned retirement year.

For the most part, the findings from the linear regression contradict the hypotheses set forth at the beginning of this study. Hypotheses 1a and 1b were not supported by the results. Respondents who had positive income shocks retired later than their planned retirement years. Negative income shock was not found to be significant. Hypothesis 2 was not supported; a respondent's wealth change was found to be not significant in the linear regression analysis. Hypothesis 3 was supported, significant relationship existed among respondents who were widowed. The regression showed a significant positive relationship, with widowed respondents retiring 1.8 years later than planned.

Hypothesis 4 was partially supported. Respondents who were diagnosed with mental health conditions (reported depressed or diagnosed with psychiatric problems) 
retired earlier than their planned retirement year, meaning a significant negative correlation was found between retirement timing and the mental health variables. However, the opposite was revealed for three of the physical conditions under investigation: diabetes, cancer, and heart disease. While retirement timing had a negative relationship with mental health conditions, it had a positive relationship with these three physical illnesses, meaning all of them were found to delay respondents' retirement, rather than inducing early retirement. 
$\stackrel{n}{=}$ Table 21.

Linear Mixed Regression Analysis of Life-Changing Events

\begin{tabular}{|c|c|c|c|c|c|}
\hline Variables & Estimate & SE & P-value & Tolerance & $\begin{array}{l}\text { Variance } \\
\text { inflation } \\
\text { factors }\end{array}$ \\
\hline Intercept & $-1.789 * * *$ & 0.512 & 0.0005 & & \\
\hline \multicolumn{6}{|c|}{ — Time-varying variables — } \\
\hline \multicolumn{6}{|l|}{ Life-changing events } \\
\hline \multicolumn{6}{|l|}{ Marital status changes (reference category = remained married) } \\
\hline Not married to married & -0.311 & 0.338 & 0.3568 & 0.956 & 1.046 \\
\hline Married to widowed & $1.842 * * *$ & 0.390 & $<.0001$ & 0.941 & 1.063 \\
\hline Married to divorced & -0.445 & 0.522 & 0.3934 & 0.973 & 1.028 \\
\hline Never married & -0.292 & 0.487 & 0.5492 & 0.929 & 1.077 \\
\hline Positive income shock & $0.404 *$ & 0.188 & 0.0311 & 0.443 & 2.257 \\
\hline Negative income shock & -0.133 & 0.184 & 0.4694 & 0.436 & 2.291 \\
\hline Wealth change & 0.001 & 0.002 & 0.4694 & 0.994 & 1.006 \\
\hline Whether diagnosed with diabetes before retirement & $0.479 * *$ & 0.157 & 0.0024 & 0.937 & 1.067 \\
\hline Whether diagnosed with cancer before retirement & $0.992 * * *$ & 0.184 & $<.0001$ & 0.988 & 1.012 \\
\hline Whether diagnosed with lung disease before retirement & -0.061 & 0.223 & 0.7849 & 0.946 & 1.057 \\
\hline Whether diagnosed with a stroke before retirement & 0.224 & 0.260 & 0.3896 & 0.966 & 1.035 \\
\hline Whether diagnosed with heart disease before retirement & $0.857 * * *$ & 0.157 & $<.0001$ & 0.932 & 1.073 \\
\hline Reported depressed before retirement & $-0.805 * * *$ & 0.189 & $<.0001$ & 0.909 & 1.100 \\
\hline Whether diagnosed with a psychiatric problem before retirement & $-1.036 * * *$ & 0.186 & $<.0001$ & 0.897 & 1.115 \\
\hline \multicolumn{6}{|l|}{ Demographic characteristics } \\
\hline Age & $0.278 * * *$ & 0.013 & $<.0001$ & 0.828 & 1.208 \\
\hline
\end{tabular}




\begin{tabular}{lcccc} 
Estimate & SE & P-value & Tolerance & $\begin{array}{c}\text { Variance } \\
\text { inflation } \\
\text { factors }\end{array}$ \\
\hline 0.056 & 0.032 & 0.0783 & 0.931 & 1.074 \\
-0.211 & 0.234 & 0.3664 & 0.516 & 1.937 \\
$-0.985^{* * *}$ & 0.282 & 0.0005 & 0.665 & 1.505 \\
-0.246 & 0.266 & 0.3539 & 0.489 & 2.044 \\
$-0.622^{* *}$ & 0.204 & 0.0023 & 0.354 & 2.828
\end{tabular}

\section{Economic characteristics}

Income (reference category $=1$ st quartile)

2nd quartile

3rd quartile

4th quartile

Wealth (reference category $=1$ st quartile)

2nd quartile

3rd quartile

4th quartile

Pension ownership (reference category $=$ no pension)

$$
\begin{aligned}
& \text { DB only } \\
& \text { DC only } \\
& \text { DB and DC }
\end{aligned}
$$

Homeownership

Health insurance coverage in retirement

Respondents' expectations and preferences

Expect to receive inheritance

Expect to leave bequest

$\begin{array}{lllll}0.026 & 0.185 & 0.8866 & 0.573 & 1.745 \\ -0.094 & 0.203 & 0.6434 & 0.474 & 2.111 \\ 0.238 & 0.233 & 0.3069 & 0.364 & 2.749 \\ & & & & \\ 0.806^{* * *} & 0.184 & <.0001 & 0.580 & 1.725 \\ 0.906^{* * *} & 0.197 & <.0001 & 0.505 & 1.979 \\ 0.487^{*} & 0.215 & 0.0232 & 0.425 & 2.354 \\ & & & & \\ 0.879^{* * *} & 0.160 & <.0001 & 0.648 & 1.543 \\ 0.684^{* * *} & 0.170 & <.0001 & 0.769 & 1.301 \\ 1.068^{* *} & 0.390 & 0.0061 & 0.926 & 1.080 \\ 0.106 & 0.130 & 0.4168 & 0.873 & 1.146 \\ 0.525^{* * *} & 0.135 & <.0001 & 0.815 & 1.228 \\ & & & & \\ 0.496^{* * * *} & 0.134 & 0.0002 & 0.842 & 1.187 \\ 0.828^{* * *} & 0.138 & <.0001 & 0.913 & 1.095\end{array}$




\begin{tabular}{|c|c|c|c|c|c|}
\hline Variables & Estimate & SE & P-value & Tolerance & $\begin{array}{c}\text { Variance } \\
\text { inflation } \\
\text { factors }\end{array}$ \\
\hline Whether current job involves lots of stress & 0.173 & 0.131 & 0.1864 & 0.892 & 1.122 \\
\hline Not sure/unknown & $-2.670 * * *$ & 0.259 & $<.0001$ & 0.512 & 1.633 \\
\hline 1 to 5 years & -0.074 & 0.200 & 0.7101 & 0.576 & 1.736 \\
\hline 5 to 10 years & -0.104 & 0.208 & 0.6171 & 0.570 & 1.755 \\
\hline Longer than 10 years & variables - & & & & \\
\hline \multicolumn{6}{|l|}{ Gender $($ reference category $=$ male $)$} \\
\hline Female & $0.562 * * *$ & 0.131 & $<.0001$ & 0.864 & 1.157 \\
\hline \multicolumn{6}{|l|}{ Race/ethnicity (reference category = White) } \\
\hline Black & 0.143 & 0.179 & 0.4224 & 0.835 & 1.197 \\
\hline College and above & $-0.740 * *$ & 0.251 & 0.0032 & 0.341 & 2.936 \\
\hline
\end{tabular}

Note. $* p<.05 ; * * p<.01 ; * * p<.001$. Analysis of the 1992 through 2014 HRS. Sample size $=8,247$. 


\section{Chapter 6: Discussion}

This study used data from the 1992 to 2014 HRS to investigate whether lifechanging events significantly affect individuals' retirement timing. The analysis examined three types of life-changing events: changes in marital, health, and financial status. Other factors affecting individuals' retirement timing were also analyzed. The first section of this chapter discusses the findings, summarizing the results and explaining whether they are consistent with other research in the field. The second section covers the limitations and implications of this dissertation.

\subsection{Summary and Conclusions}

\subsubsection{Life-Changing Events}

This discussion begins by focusing on the first of the three categories of major life-changing events: changes in marital status. The descriptive analysis found that more than half of the HRS respondents were married and remained so before retirement (Table 7). A small percentage of respondents experienced changes in their marital status, shifting from not married to married or married to divorced (Tables 4 and 5). The percentage of people who lost spouses before retirement changed slightly over time but remained between $6.0 \%$ and $8.0 \%$ (Table 6). The percentage of respondents who never married before retirement remained steady, hovering at 2.0\% (Table 8).

The data suggest that individuals who delay retirement are more likely to be widowed than individuals who choose early or on-time retirement. Descriptive results showed that $11.0 \%$ of the respondents who delayed retirement became widowed beforehand, compared to $6.6 \%$ of the respondents who took early retirement and $5.8 \%$ of the respondents who chose on-time retirement (Table 20). Also, regression analysis found 
that respondents whose status changed from married to widowed delayed their retirement by 1.8 years (21.6 months) later than their planned retirement year (Table 21). These results were significant and are consistent with prior research, which has reported that widowed individuals remain in the workplace longer than married individuals to increase their retirement income. People who are widowed in their 50s appear more likely to work after age 65 (Au, Mitchell, \& Phillips, 2005).

While the findings regarding marital status are consistent with the literature, they support this study's relevant hypothesis, Hypothesis 3: changing marital status from married to divorced or widowed will induce retirement delay. In terms of the descriptive analysis, $11.0 \%$ of the respondents who delayed retirement changed from married to widowed (Table 20). Smaller percentages of respondents changed from married to widowed in the subset of respondents who took early retirement $(6.6 \%)$ and the subset who retired on time $(5.8 \%)$. Like the descriptive analysis, the regression analysis supports the hypothesis. A change from not married to married was found to be significant (Table 21).

Discussed next is the second category of life-changing events: changes to health status. The descriptive analysis showed that the proportion of respondents diagnosed with a life-threatening disease - including diabetes, cancer, lung disease, stroke, and heart disease - gradually increased over time (Tables 9-13). In the last two waves of the HRS data (Wave 11 and Wave 12), over one-fifth of respondents were diagnosed with diabetes and heart disease. In terms of mental health, the variable whether diagnosed with a psychiatric problem before retirement had a trend similar to those concerning diagnoses of physical illnesses — namely, the percentage of respondents diagnosed with a 
psychiatric problem steadily increased over time (Table 15). That was not the case for the proportions of people who reported that they were feeling depressed (Table 14). The percentages from Wave 1 to Wave 12 fluctuated, rising to their highest in Waves 4 to 8 . So, while some health status changes were less predictable, most followed the trend of more and more respondents reporting physical and/or mental health issues as time progressed from wave to wave. These findings are to be expected because people's overall health conditions decrease both physically and mentally as they grow older (Case \& Deaton, 2005; Yashin et al., 2007).

The data partially support the hypothesis related to health status (Hypothesis 4). As a reminder, the hypothesis was this: Individuals confronted with declining health will be induced to retire early when compared to individuals in good health. The literature review suggested that this hypothesis would be a good one to test. Many studies (e.g., Calvo et al., 2012; Dave et al., 2008; Jokela et al., 2010; Paradise et al., 2012; Rice et al., 2011) have found that a decline in health condition - either mental or physical — is correlated with a decrease in the age at which a person retires. However, this study's linear regression analysis only partially agrees with the previous literature and, thus, Hypothesis 4. Findings concerning mental health were found to be significant and supported the hypothesis. Respondents who reported that they were depressed retired 0.8 years (9.6 months) earlier than their planned retirement year. Similarly, respondents who were diagnosed with a psychiatric problem retired 1.0 year (12 months) earlier than their planned retirement year. (See Table 21.) Several previous studies found that poor mental health conditions increased the likelihood of early retirement because workplace stress worsens employees' mental health conditions (Dave et al., 2008; Calvo et al., 2012; 
McGarry, 2004). On the other hand, the findings concerning physical health do not support the hypothesis. Of the five physical conditions studied, three of them yielded significant results: diabetes, cancer, and heart disease. All of them contradict Hypothesis 4; respondents who were diagnosed with any of these three illnesses retired later than they had planned, rather than earlier.

An avenue for future research would be to spend more time examining why the current findings partially contradict previous studies. Could it be that not enough studies have examined the differences in the effects on retirement timing between mental and physical illnesses — or between extremely costly and relatively less expensive illnesses? Treating diabetes, cancer, or heart disease is often very costly and imposes a very high financial burden on individuals. It may make sense that such illnesses prompt individuals to retire later. This study's results actually seem to be consistent with the notion that working longer increases retirement incomes, making healthcare costs more affordable. Johnson, Penner, and Toohey (2008) reported that individuals beyond age 65 who expect high healthcare costs in their later life retire 1 year later than those with low healthcare costs.

Changes in financial status comprise the third and last category of life-changing events. Over a quarter of the HRS respondents studied, on average, experienced positive income shocks from Wave 1 through Wave 12. This finding is consistent with the overall upward trend of household income during the period studied (Federal Reserve Bank of St. Louis, 2016). Positive income shock was found to be positively significantly associated with retirement timing—respondents who had positive income shocks tended to retire 0.4 years ( 4.8 months) later than their planned retirement year (Table 21). 
Consistent with research by Pozzebon and Mitchell (1989), the increased wage of a positive income shock results in higher leisure costs and prompts individuals to relocate their demand from leisure to consumption, creating a substitution effect that causes individuals to postpone retirement.

While the results concerning positive income shock agree with the literature, they do not support the relevant hypothesis, Hypothesis 1a: Positive income shock will induce early retirement. In fact, the findings showed the exact opposite than what was predicted in the hypothesis. As explained in Chapter 3, there are contradicting theories regarding income shock and its effects on retirement timing. The substitution effect theory (Kalemli-Ozcan \& Weil, 2010) says that there is a positive correlation between income and retirement timing: If income goes up, the age at which a person retires goes up because a higher-income earner focuses on the bigger opportunity cost of missing out on the earnings from a high-paying job (Pozzebon \& Mitchell, 1989). On the other hand, the income effect theory (Coile, 2004) says there is a negative correlation between the two: If income goes up, the preferred retirement time goes down because people treat leisure as a normal good (Coile, 2004; Damman et al., 2011; Farnham \& Sevak, 2007). This study’s results support the substitution effect theory, even though, as it is written, Hypothesis 1a favors the income effect theory.

Two other hypotheses put forward in this study relate to financial status changes: Hypothesis $1 b$ : Negative income shock will induce retirement delay. Hypothesis 2: Individuals who have positive wealth changes will be more likely to retire early. 
The relevant results of the linear regression analysis do not support these hypotheses and are not statistically significant (Table 21). A fruitful path for future research might be to examine further the competing ideas advanced by the income effect and substitution effect theories and to see if the substitution effect consistently swamps the income effect when people experience drastic financial changes, or shocks.

\subsubsection{Non-Life-Changing Characteristics}

Like life-changing events, several characteristics that are not associated with a life change also play into retirement decision-making. They include people's demographic and economic characteristics as well as their expectations for and preferences on retirement. This study examined them all so as not to ignore the non-life-changing factors that influence retirement timing.

First, the findings demonstrated that two demographic characteristics have some significant associations with retirement timing: age and occupation. In the sample of all 12 HRS waves studied, the descriptive analysis found that a majority of respondents either retired early or delayed retirement. The average actual retirement age for those who retired early (60.4 years old; see Table 3 ) was approximately 7 years less than those who delayed retirement (67.0 years old). Respondents who retired on time did so at an average age of 62.8 years old. The linear regression analysis found that age was positively correlated with retirement timing, meaning that older respondents were more likely to delay retirement beyond their planned retirement dates. A 1-year increase from the sample's mean age ( 54.2 years) led to a delay in retirement of 0.3 years (Table 21). This finding is consistent with previous research (Zappalà et al., 2008) that said that older employees were more likely to postpone their expected retirement than were younger 
workers. The researchers surmised that older workers who were close to retirement had a better understanding of whether their actual financial situation was adequate for retirement.

The other statistically significant demographic characteristics relate to a person's occupation. Findings suggest that individuals who work in sales tend to retire early, indicating a significant negative association between a sales occupation and retirement time. The same is true for workers who fall in the study's "other" category (farmers, members of the armed forces, machine operators, etc.). Compared with individuals with a managerial job, sample HRS respondents who worked in sales or in an occupation in the "other" category retired earlier than their planned retirement years. Specifically, the regression found that respondents in the "sales" and "other" categories retired 1.0 year (12 months) and 0.6 years (7.2 months) earlier than planned, respectively (Table 21).

These findings are consistent with what other studies have found. Individuals who have sales occupations usually have heavy workloads and greater demands on their time at work; salespeople also have to spend more time and resources on building and maintaining client relationships (Bacharach \& Bamberger 1992; Mulki, Jaramillo, \& Locander, 2008). Workers in this category are more likely to trade their consumption for leisure and retire early because leisure becomes more and more valuable as they get older (Lévesque \& Minniti, 2006). Blue-collar workers and members of the armed forces comprise the "other" occupation category. Compared with white-collar employees, who often work in less physically demanding jobs, blue-collar workers tend to retire early because of their diminishing competence in meeting their jobs' demands(Streib \& Schneider, 1971). According to the Military Compensation official website 
(https://militarypay.defense.gov/; managed by the U.S. Department of Defense), service members can retire after 20 years of service and receive retiree payments.

This study examined other demographic characteristics that were found to be statistically insignificant. These factors were the number of children a respondent had and whether the respondent worked in a professional or service occupation.

Economic characteristics—-such as wealth, pension ownership, and employerprovided retiree health insurance — are all strongly and positively associated with retirement timing. Compared with HRS respondents whose total wealth fell in the first quartile, the results showed that sample individuals whose total wealth were in higher quartiles significantly delayed their retirement beyond their planned retirement year. Wealthier individuals have different spending patterns and lifestyles compared to people with less wealth. Wealthier individuals spend most of their money on luxurious lifestyles, meaning that a higher proportion of their spending is on goods and services that are sometimes classified as "necessary luxuries," such as designer clothes and leisure activities, but a significant amount still goes to insurance, financial services, and healthcare (A.T. Kearney, 2012). In order to maintain their desired lifestyle, they work longer and retire later than their planned retirement years. Munnell and Sass (2008) found that working two more years beyond the normal retirement year had a significant impact on the preservation of retirement wealth for American workers. These kinds of results in the relevant literature are consistent with this dissertation's findings that greater wealth was associated with delayed retirement.

Pension ownership is another economic characteristic that has a significant positive association with retirement timing. The results of this study showed that 
individuals who had either DB or DC pension plans, or had both DB and DC plans, significantly delayed their retirement compared to their counterparts without any pension plans. For example, HRS respondents with a DC plan, such as a typical 401(k) plan, delayed their retirement by 0.7 years beyond their planned retirement time (Table 21). These results align with the literature. Studies have found that people who have pension plans delay retirement to boost their wealth (Butrica et al., 2009; Friedberg \& Webb, 2005). For DC plans, individuals can make contributions to their employer-sponsored accounts when they are employed; once they leave their jobs, they can no longer make contributions (Bodie, Marcus, \& Merton, 1988; Poterba, Rauh, Venti, \& Wise, 2007). By delaying retirement year, individuals have more time to make contributions to their DC plans and increase their retirement wealth. For DB plans, retirement benefits are determined by a formula, which includes years of service, wages, or salary, and a certain percentage. Increasing the number of service years by delaying retirement is one of the most efficient ways to boost DB plan benefits (Bodie et al., 1988; Poterba, Rauh, Venti, \& Wise, 2007).

The other economic characteristic that is statistically related to retirement time is health insurance coverage in retirement, meaning whether an employee has access to employer-provided retiree health insurance. The results showed that, compared to respondents who did not have access to employer-provided retiree health insurance plans, those who did have access chose to delay their retirement by 0.5 years (Table 21). This result is supported by existing research by Johnson et al. (2008), which found that a person's out-of-pocket spending for an employer-provided retiree health insurance plan substantially delays retirement. The researchers stated that retirement was delayed 
because of (a) the monthly insurance premiums for that are required before age 65 and (b) the anticipated out-of-pocket costs charged after 65 .

While the Johnson et al. study (2008) aligns with the findings presented herein, the findings contradict the prevailing wisdom shared in much of the relevant literature. One study (Karoly \& Rogowski, 1994) said that access to continued employer-provided health insurance coverage after retirement increased the likelihood of retirement before age 65. Another study (Blau \& Gilleskie, 1997) found that, when employer-provided retiree health insurance is available, the rate of exiting the workforce increased by two percentage points per year, on average, if the employee and employer shared the cost of coverage. The exit rate increased by six percentage points if the company paid the entire cost. A third and final study (Nyce, Schieber, Shoven, Slavov, \& Wise, 2011) reported that access to employer-provided retiree health benefits increased the probability of retiring at age 62 by 3.7 percentage points (a $21.2 \%$ increase) and the probability of exiting the workforce at age 63 by 5.1 percentage points (a $32.2 \%$ increase). More modest effects occurred under the age of 62 .

Future research to extend this dissertation's work should examine why the results of this study contradict the published literature. It would be interesting to pay particular attention to married couples and investigate how retirement timing varies depending upon which spouse, if there is only one, has access to employer-provided retiree health insurance. For example, if a younger wife has access to the couple's retiree health plan, perhaps her older husband might delay retirement to ensure that he is covered under the policy before exiting the workforce. So many of this study's sample HRS respondents were married (e.g., $59.5 \%$ of the total sample in Wave 12). In the future, it might be 
useful to examine a set of variables related to the owners (i.e., married employees) and dependents (e.g., spouses) of retiree health plans as well as the plans' eligibility criteria and the correlations to spouses' retirement timing.

Other financial characteristics evaluated in this study were income and homeownership. Neither produced statistically significant results.

In this section on non-life-changing factors affecting retirement time, the discussion has covered demographics and economic characteristics. The last category is the respondents' expectations and preferences related to retirement. Of the variables assessed, expecting to leave a bequest and people's preferences about their financial planning horizons are the two significant variables related to retirement timing. They will be discussed in the next two paragraphs. Respondents' expectations about whether they would receive an inheritance were not significantly correlated to retirement time; nor was respondents' feelings about whether their currents jobs involved lots of stress. They will not be discussed in this section.

In the regression model, compared with people who did not expect to leave bequests to loved ones, those who expected to leave a bequest significantly delayed retirement by 0.8 years beyond their anticipated retirement time. These findings are consistent with a previous study, which stated that individuals who planned to leave a bequest tended to delay retirement to accumulate more wealth (Smith, 1995). Also, a more recent study proved that individuals who expect to leave luxury goods to their household members upon their death are more likely to continue to work beyond full retirement age (De Nardi \& Yang, 2014). Compared with people who did not expect to receive any inheritance, those who expected to receive any inheritance delayed retirement 
by 0.5 years beyond their anticipated retirement time. There were very few people from this study who expected to receive inheritance and actually received it. Most people who expected to receive inheritance did not actually receive any inheritance. As a result, it does not make much meaningful sense in this study.

An individual's financial planning horizon was found to be a significant determinant of retirement timing, with a negative statistical correlation. Compared to individuals with a financial planning horizon of less than 1 year, those who did not know or were not sure about their horizons retired 2.7 years earlier than their planned retirement year (Table 21). Similarly, individuals with a financial planning horizon of more than 10 years were statistically likely to retire 0.7 years earlier than planned. These findings align with the literature. The financial planning horizon helps an individual financially prepare for the transition from working status to retirement and plan for an earlier retirement time (Reitzes, Mutran, \& Fernandez, 1996). Published research has shown that people who have longer financial planning horizons tend to have realistic expectations and achievable goals that they can accomplish within the horizon's period (Taylor \& Doverspike, 2003). As mentioned above, this study found that people retire earlier than planned when they are not sure about their financial planning horizon. Taylor and Doverspike's research (2003) helps to explain this result-meaning, these nonplanners are unlikely to have realistic goals to instruct them to keep working for their desired future. The absence of a plan means nothing stands in their way to keep them from retiring 2.7 years earlier than they had initially hoped.

The last two characteristics to discuss are gender and education. The findings suggest that female individuals retire at later years than they planned when compared to 
males. Previous studies have indicated that females are more likely to extend their employment time than males. On average, women choose to retire later because they have insufficient funds in their retirement accounts due to their longer life expectancy and lower lifetime incomes when compared to males (Bardasi \& Jenkins, 2002; Yabiku, 2000). Level of education was found to have a negatively statistical association with retirement timing. Individuals with some college education, as well as with a bachelor's degree or above, retired earlier than they planned, compared to their counterparts with less than a high school education. The literature supports these findings. Financial literacy increases greatly and significantly with a person's level of education (Lusardi \& Mitchell, 2007). Individuals with stronger financial literacy better prepare for retirement and tend to retire early, because the management of retirement wealth and portfolio choice requires sophisticated knowledge (Alessie, Van Rooij, \& Lusardi, 2011; Van Rooij, Lusardi, \& Alessie, 2012).

This dissertation's research included three types of major life-changing events: (1) marital status change; (2) health status change; and (3) financial change. Via linear regression analysis, this study found that some life events included within the three categories are statistically significant to individuals' retirement time. In other words, this study set out to answer the question, "Do major life-changing events affect people's preferred retirement timing?" The answer is, yes, some do. Both the descriptive and regression analyses yielded results that support this conclusion.

Many different variables were found to have a positive statistical correlation to retirement time, meaning that, as the variable increases, so too does the age at which the person retires. For example, people who have been widowed tend to work longer than 
their preferred retirement timing. Likewise, people work longer if they experience a positive income shock; have greater amounts of wealth; have DB and/or DC pension plans; have access to employer-provided retiree health insurance; expect to make a bequest; have aged more; are female; or have certain physical illnesses (diagnoses of diabetes, cancer, or heart disease). In total, 14 different variables (shown in Table 21) had a statistically significant positive correlation to retirement timing.

On the other hand, people with a mental illness (experience feelings of depression or receive a diagnosis of a psychological problem) tend to choose early retirement. So too do people who work in sales; have a blue-collar or military occupation; are unsure about their financial planning horizon; have a horizon of more than 10 years; have some college education; or have earned a bachelor's degree or higher. In total, eight variables had a significant negative correlation to retirement timing.

Perhaps the biggest takeaway from this research is that myriad events and characteristics influence retirement behavior. The human experience is, at once, a journey that we all share and unique to every individual. Different individuals experience different life-changing events, some that fall into the three categories studied in this dissertation and others outside its scope. For experts in the retirement planning field, as well as for individuals seeking a map with which to plan their future, the best advice is to understand the trends and assess individual risk in the face of those trends.

\subsection{Limitation and Implications}

There is a limitation of this dissertation, and future studies need to address and overcome it. The limitation of this study is that, if a person experienced more than one life-changing event, the sequence in which the events occurred was not measured. The 
comparative timing might affect the retirement age because of people's varied reactions to the events. Future studies should examine how the sequence of different types of lifechanging events affect individuals' retirement timing.

This study only included three categories of major life-changing events, which is a tip of the iceberg when it comes to studies on life events. As explained in Chapter 1, Holmes and Rahe's study (1967) included 43 life events that concerned residence, group and peer relationships, religion, and recreation in addition to the three life events addressed in this dissertation (marital, health, and financial status changes). But their study also recognized that marital status changes, financial changes, and health changes were ranked at the top as priorities above the other life events concerning education, religion, recreation, and group and peer relationships (Holmes \& Rahe, 1967). That is why the three categories were chosen for this study. Future studies can continue to investigate the effects of different life-changing events on retirement decision-making by including more events and examining how they are associated with individuals' retirement timing. As Holmes and Rahe (1967) mentioned, life events connect to major areas of dynamic significance in the social structure of the American way of life. Many of them are socially recognized and consonant with American values, which is a big influencer on retirement timing.

This study has implications for individuals planning for their futures and for the financial professionals who are helping them. This study can help households identify which type(s) of life-changing events might influence the time at which they retire. At the same time, the results can provide individuals with a more detailed perspective on how other factors, such as gender and level of education, affect retirement time. For instance, 
from the regression analysis, it was possible to draw the conclusions that people delayed retirement if they changed their marital status from married to widowed; experienced positive income shocks; or were diagnosed with diabetes, cancer, or heart disease. On the other hand, individuals who were diagnosed with mental diseases tended to retire early. As a result, after such events occur, people can gain an understanding of what others in similar predicaments have done and plan better for when to retire.

Further, financial professionals can use results to educate pre-retirees about how life-changing events influence retirement planning, particularly pre-retirees' planned retirement time, and discuss strategies to overcome and prepare for such events. Financial advisors also can also use the results to work closely with clients who have experienced life-changing events to make suitable adjustments to their retirement timing and other financial goals. Particularly in the case of clients who are not fully prepared for retirement, financial professionals can help them determine a reasonable retirement age as well as implement proper investment strategies and research investment products that provide adequate retirement income. Financial professionals also can help clients who experience major life-changing events to rebalance their investment portfolios in order to maintain the desired level of asset allocation and meet their financial needs. Along with financial advisors, the companies that design and deliver financial products aimed at saving for retirement should also take these life-changing events into consideration.

When people get older, along with losing earning power and experiencing declining health, they become more vulnerable to the social and economic changes in society. At the same time, they become more susceptible to the negative consequences of changes in their own marital, health, and financial status. Professional curiosity should no 
doubt inspire retirement researchers and professionals to learn more about what affects retirement timing and related decisions. However, researchers should be motivated not only by curiosity but also by an obligation to protect and serve this vulnerable population. As touched on throughout this dissertation, a multidisciplinary approach, involving financial, medical, and psychological professionals, is needed to meet this obligation and make quality research possible. Older adults have contributed to society for decades. Society must help to ensure that they can retire with honor later in their lives and enjoy their retirement life. 


\section{BIBLIOGRAPHY}

Aaron, H. J., \& Callan, J. M. (2011, May). Who retires early? (CRR Working Paper No. 2011-10). Chestnut Hill, MA: Center for Retirement Research at Boston College.

Alessie, R., Van Rooij, M., \& Lusardi, A. (2011). Financial literacy and retirement preparation in the Netherlands. Journal of Pension Economics \& Finance, 10(4), 527-545. doi:10.1017/S1474747211000461

An, M. Y., Christensen, B. J., \& Gupta, N. D. (2004). Multivariate mixed proportional hazard modelling of the joint retirement of married couples. Journal of Applied Econometrics, 19(6), 687-704. doi:10.1002/jae.783

Anderson, K. H., Burkhauser, R. V., \& Quinn, J. F. (1986). Do retirement dreams come true? The effect of unanticipated events on retirement plans. ILR Review, 39(4), 518-526. doi:10.2307/2523244

Ando, A., \& Modigliani, F. (1963). The "life cycle" hypothesis of saving: Aggregate implications and tests. The American Economic Review, 53(1), 55-84.

Anspach, D. (2019, March 12). Average retirement age in the United States. The Balance. Retrieved from https://www.thebalance.com/average-retirement-age-inthe-united-states-2388864

Ashforth, B. (2001). Role transitions in organizational life: An identity-based perspective. Mahwah, NJ: Erlbaum.

A.T. Kearney [consulting firm]. (2012). Consumer wealth and spending: The $\$ 12$ trillion opportunity. Seoul, Korea: A.T. Kearney. 
Atchley, R. C. (1982). The process of retirement: Comparing women and men. In M. Szinovacz (Ed.), Women's retirement: Policy implications of recent research (pp. 153-168). Beverly Hills, CA: Sage.

Atchley, R. C. (1989). A continuity theory of normal aging. The Gerontologist, 29, 183190. doi:10.1093/geront/29.2.183

Atchley, R. C. (1999). Continuity and adaptation in aging: Creating positive experiences. Baltimore, MD: The Johns Hopkins University Press.

Au, A., Mitchell, O. S., \& Phillips, J. W. (2005). Saving shortfalls and delayed retirement (Working Paper No. WP 2005-094). Ann Arbor, MI: University of Michigan Retirement Research Center.

Bacharach, S., \& Bamberger, P. (1992). Causal models of role stressor antecedents and consequences: The importance of occupational differences. Journal of Vocational Behavior, 41(1), 13-34. doi:10.1016/0001-8791(92)90036-Y

Banks, J., Breeze, E., Lessof, C., \& Nazroo, J. (Eds.). (2006). Retirement, health and relationships of the older population in England: The 2004 English Longitudinal Study of Ageing. London, England: The Institute for Fiscal Studies.

Bardasi, E., \& Jenkins, S. P. (2002). Income in later life: Work history matters. Bristol, UK: Policy Press.

Bartel, A. P., \& Sicherman, N. (1993). Technological change and retirement decisions of older workers. Journal of Labor Economics, 11(1), 162-183.

Beehr, T. A., Glazer, S., Nielson, N. L., \& Farmer, S. J. (2000). Work and nonwork predictors of employees' retirement ages. Journal of Vocational Behavior, 57, 206-225. doi:10.1006/jvbe.1999.1736 
Biggs, A. G. (2016). The life cycle model, replacement rates, and retirement income adequacy (AEI Economics Working Paper No. 2016-11). Washington, DC: American Enterprise Institute for Public Policy Research.

Blau, D. M., \& Gilleskie, D. B. (1997). Retiree health insurance and the labor force behavior of older men in the 1990s (NBER Working Paper No. 5948). Retrieved from the National Bureau of Economic Research website: https://www.nber.org/papers/w5948

Blau, D. M., \& Gilleskie, D. B. (2006). Health insurance and retirement of married couples. Journal of Applied Econometrics, 21(7), 935-953. doi:10.1002/jae.921

Blekesaune, M., \& Skirbekk, V. (2012). Can personality predict retirement behaviour? A longitudinal analysis combining survey and register data from Norway. European Journal of Ageing, 9(3), 199-206. doi:10.1007/s10433-011-0212-6

Bodie, Z., Marcus, A. J., \& Merton, R. C. (1988). Defined benefit versus defined contribution pension plans: What are the real trade-offs? In Z. Bodie, J. B. Shoven, \& D. A. Wise (Eds.), Pensions in the US economy (pp. 139-162). Chicago, IL: University of Chicago Press.

Bossé, R., Aldwin, C. M., Levenson, M. R., \& Workman-Daniels, K. (1991). How stressful is retirement? Findings from the Normative Aging Study. Journal of Gerontology, 46(1), 9-14.

Bound, J., Schoenbaum, M., \& Waidmann, T. (1996). Race differences in labor force attachment and disability status. The Gerontologist, 36(3), 311-321. doi:10.1093/geront/36.3.311 
Bound, J., Stinebrickner, T., \& Waidmann, T. (2010). Health, economic resources and the work decisions of older men. Journal of Econometrics, 156(1), 106-129.

Brown, J. E., Saad-Lessler, J., \& Oakley, D. (2018). Retirement in America:

Out of reach for working Americans? Retrieved from the National Institute on Retirement Security website: https://www.nirsonline.org/reports/retirement-inamerica-out-of-reach-for-most-americans/

Burbidge, J. B., \& Robb, A. L. (1980). Pensions and retirement behaviour. The Canadian Journal of Economics, 13(3), 421-437. doi:10.2307/134702

Burke, P. J. (1991). Identity processes and social stress. American Sociological Review, 56, 836-849. doi:10.2307/2096259

Butler, M., Huguenin, O., \& Teppa, F. (2005). Why forcing people to save for retirement may backfire (CESifo Working Paper Series No. 1458; University of St. Gallen Economics Discussion Paper No. 9). Retrieved from the SSRN website: https://papers.ssrn.com/sol3/papers.cfm?abstract_id=710945

Burtless, G. (1986). Social security, unanticipated benefit increases, and the timing of retirement. The Review of Economic Studies, 53(5), 781-805. doi: $10.2307 / 2297719$

Butrica, B. A., Iams, H. M., \& Smith, K. E. (2007). Understanding baby boomers' retirement prospects. In B. Madrian, O. S. Mitchell, \& B. J. Soldo (Eds.), Redefining retirement: How will boomers fare? (pp. 70-91). New York, NY: Oxford University Press. doi:10.1093/acprof:oso/9780199230778.001.0001 
Butrica, B. A., Iams, H. M., Smith, K. E., \& Toder, E. J. (2009). The disappearing defined benefit pension and its potential impact on the retirement incomes of baby boomers. Social Security Bulletin, 69(3), 1-27.

Calvo, E., Sarkisian, N., \& Tamborini, C. R. (2012). Causal effects of retirement timing on subjective physical and emotional health. The Journals of Gerontology, Series B: Psychological Sciences and Social Sciences, 68(1), 73-84. doi:10.1093/geronb/gbs097

Carnegie, A. (1891). The advantages of poverty. The Nineteenth Century and After: A Monthly Review, 29(169), 367-385.

Carter, M. A. T., \& Cook, K. (1995). Adaptation to retirement: Role changes and psychological resources. The Career Development Quarterly, 44, 67-82. doi:10.1002/j.2161-0045.1995.tb00530.x

Case, A., \& Deaton, A. S. (2005). Broken down by work and sex: How our health declines. In D. A. Wise (Ed.), Analyses in the economics of aging (pp. 185-212). Chicago, IL: University of Chicago Press.

Chan, S., \& Stevens, A. H. (1999a). Employment and retirement following a late-career job loss. The American Economic Review, 89(2), 211-216.

Chan, S., \& Stevens, A. H. (1999b). Job loss and retirement behavior of older men (No. w6920). Cambridge, MA: National Bureau of Economic Research.

Coile, C. (2004). Retirement incentives and couples' retirement decisions. Topics in Economic Analysis \& Policy, 4(1), 1-30. doi:10.2202/1538-0653.1277

Coile, C., \& Gruber, J. (2000). Social Security and retirement (No. w7830). Cambridge, MA: National Bureau of Economic Research. 
Conde-Ruiz, J. I., Galasso, V., \& Profeta, P. (2013). The role of income effects in early retirement. Journal of Public Economic Theory, 15(3), 477-505. doi:10.1111/jpet.12026

Coronado, J. L., \& Perozek, M. G. (2003). Wealth effects and the consumption of leisure: Retirement decisions during the stock market boom of the 1990s (FEDS Working Paper No. 2003-20). Retrieved from the SSRN website: https://papers.ssrn.com/sol3/papers.cfm?abstract_id=419721

Crimmins, E. M., Reynolds, S. L., \& Saito, Y. (1999). Trends in health and ability to work among the older working-age population. The Journals of Gerontology, Series B: Psychological Sciences and Social Sciences, 54B(1), S31-S40. doi:10.1093/geronb/54B.1.S31

Damman, M., Henkens, K., \& Kalmijn, M. (2011). The impact of midlife educational, work, health, and family experiences on men's early retirement. The Journals of Gerontology, Series B: Psychological Sciences and Social Sciences, 66B, 617627. doi:10.1093/geronb/gbr092

Dave, D., Rashad, I., \& Spasojevic, J. (2008). The effects of retirement on physical and mental health outcomes. Southern Economic Journal, 75, 497-523.

De Nardi, M., French, E., \& Jones, J. B. (2010). Why do the elderly save? The role of medical expenses. Journal of Political Economy, 118(1), 39-75. doi:10.1086/651674

De Nardi, M., \& Yang, F. (2014). Bequests and heterogeneity in retirement wealth. European Economic Review, 72, 182-196. doi:10.1016/j.euroecorev.2014.09.004 
De Preter, H., Van Looy, D., \& Mortelmans, D. (2014). Retirement timing of dual-earner couples in 11 European countries? A comparison of Cox and shared frailty models. Journal of Family and Economic Issues, 36, 396-407. doi:10.1007/s10834-014-9403-6

Dentinger, E., \& Clarkberg, M. (2002). Informal caregiving and retirement time among men and women: Gender and caregiving relationships in late midlife. Journal of Family Issues, 23(7), 857-879. doi:10.1177/019251302236598

Denton, F. T., \& Spencer, B. G. (2009). What is retirement? A review and assessment of alternative concepts and measures. Canadian Journal on Aging/La Revue Canadienne du Vieillissement, 28(1), 63-76. doi:10.1017/S0714980809090047

Disney, R., Ratcliffe, A., \& Smith, S. (2010). Booms, busts and retirement timing (Working Paper No. 10/233). Bristol, UK: University of Bristol Centre for Market and Public Organisation

Dwyer, D. S., \& Mitchell, O. S. (1999). Health problems as determinants of retirement: Are self-rated measures endogenous? Journal of Health Economics, 18(2), 173193.

Earl, C., \& Taylor, P. (2015). Is workplace flexibility good policy? Evaluating the efficacy of age management strategies for older women workers. Work, Aging and Retirement, 1, 214-226. doi:10.1093/workar/wau012

Elder, G, H. (1995). The life-course paradigm: Historical, comparative, and developmental perspectives. In P. Moen, G. H. Elder Jr., \& K. Lusher (Eds.), Examining lives in context: Perspectives on the ecology of human development (pp. 101-140). Washington, DC: American Psychology Press. 
Farnham, M., \& Sevak, P. (2007). Housing wealth and retirement time (Working Paper No. WP 2007-172). Ann Arbor, MI: University of Michigan Retirement Research Center.

Federal Reserve Bank of St. Louis. (2016). The puzzle of real median household income [Web log post]. Retrieved from https://fredblog.stlouisfed.org/2016/12/thepuzzle-of-real-median-household-

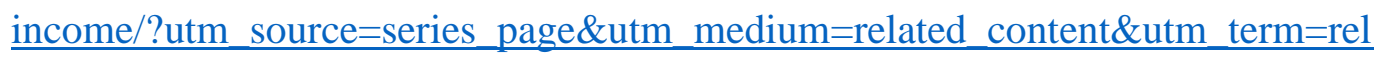
ated_resources\&utm_campaign=fredblog

Feeney, J., Dooley, C., Finucane, C., \& Kenny, R. A. (2015). Stressful life events and orthostatic blood pressure recovery in older adults. Health Psychology, 34(7), 765-774. doi:10.1037/hea0000194

Finch, N. (2014). Why are women more likely than men to extend paid work? The impact of work-family life history. European Journal of Ageing, 11, 31-39. doi:10.1007/s10433-013-0290-8

Fisher, G. G., Chaffee, D. S., \& Sonnega, A. (2016). Retirement time: A review and recommendations for future research. Work, Aging and Retirement, 2(2), 230261. doi:10.1093/workar/waw001

Friedberg, L., \& Webb, A. (2005). Retirement and the evolution of pension structure. Journal of Human Resources, 40(2), 281-308.

Fronstin, P., \& Adams, N. (2012). Employment-based retiree health benefits: Trends in access and coverage, 1997-2010 (Employee Benefit Research Institute Issue Brief No. 377). Retrieved from the SSRN website: https://papers.ssrn.com/sol3/papers.cfm?abstract_id=2166507 
Geisel, J. (2016, February 22). Fortune 500 continues to shed pension plans. Business Insurance. Retrieved from https://www.businessinsurance.com/article/20160222/NEWS03/160229986

Gibson, R. C. (1987). Reconceptualizing retirement for Black Americans. The Gerontologist, 27(6), 691-698. doi:10.1093/geront/27.6.691

Gibson, R. C. (1991). The subjective retirement of Black Americans. Journal of Gerontology, 46(4), S204-S209. doi:10.1093/geronj/46.4.S204

Gobeski, K, T. \& Beehr, T, A. (2009). How retirees work: Predictors of different types of bridge employment. Journal of Organizational Behaviors, 30, 401-425. doi:10.1002/job.547

Goda, G. S., Shoven, J. B., \& Slavov, S. N. (2012). Does stock market performance influence retirement intentions? Journal of Human Resources, 47, 1055-1081.

Gorodnichenko, Y., Song, J., \& Stolyarov, D. (2013). Macroeconomic determinants of retirement time (No. w19638). Cambridge, MA: National Bureau of Economic Research.

Goodstein, R. (2008). The effect of wealth on labor force participation of older men. (Unpublished manuscript, University of North Carolina at Chapel Hill). Retrieved from $\underline{\text { http://citeseerx.ist.psu.edu/viewdoc/download?doi=10.1.1.568.6839\&rep=rep1\&t }}$ ype $=$ pdf

Grosch, J. W., \& Pransky, G. (2009) Safety and health issues for an aging workforce. In S. Czaja \& J. Sharit (Eds.), Aging and work: Issues and implications in a 
changing landscape (pp. 334-358). Baltimore, MD: The Johns Hopkins University Press.

Gustman, A. L., \& Steinmeier, T. L. (2000). Retirement in dual-career families: A structural model. Journal of Labor Economics, 18(3), 503-545. doi:10.1086/209968

Hall, A., \& Johnson, T. R. (1980). The determinants of planned retirement age. Industrial and Labor Relations Review, 33(2), 241-254. doi:10.2307/2522453

Hanisch, K. A., \& Hulin, C. L. (1991). General attitudes and organizational withdrawal: An evaluation of a causal model. Journal of Vocational Behavior, 39, 110-128. doi:10.1016/0001-8791(91)90006-8

Hank, K. (2004). Effects of early life family events on women's late life labour market behaviour: An analysis of the relationship between childbearing and retirement in Western Germany. European Sociological Review, 20(3), 189-198.

Hayward, M. D. \& Grady, W. R. (1990). Work and retirement among a cohort of older men in the United States, 1966-1983. Demography, 27, 337-356.

Hayward, M. D., Hardy, M. A., \& Grady, W. R. (1989). Labor force withdrawal patterns among older men in the United States. Social Science Quarterly, 70, 425-448.

Henretta, J. C., O'Rand, A. M., \& Chan, C. G. (1993). Joint role investments and synchronization of retirement: A sequential approach to couples' retirement timing. Social Forces, 71(4), 981-1000. doi:10.2307/2580127

Hershey, D. A., Henkens, K., \& Van Dalen, H. P. (2007). Mapping the minds of retirement planners: A cross-cultural perspective. Journal of Cross-Cultural Psychology, 38, 361-382. doi:10.1177/0022022107300280 
Holtz-Eakin, D., Joulfaian, D., \& Rosen, H. S. (1993). The Carnegie conjecture: Some empirical evidence. The Quarterly Journal of Economics, 108(2), 413-435. doi:10.2307/2118337

Hough, R. L., Fairbank, D. T., \& Garcia, A. M. (1976). Problems in the ratio measurement of life stress. Journal of Health and Social Behavior, 17(1), 70-82. doi:10.2307/2136469

Hoffower, H. (2019, January 19). A woman who studied 600 millionaires says there's a misconception about wealth that just won't die. Business Insider. Retrieved from https://www.businessinsider.com/difference-between-wealth-net-worth-income2019-1

Holmes, T. H., \& Rahe, R. H. (1967). The social readjustment rating scale. Journal of Psychosomatic Research, 11(2), 213-218. doi:10.1016/0022-3999(67)90010-4

House, J. S., Kessler, R. C., \& Herzog, A. R. (1990). Age, socioeconomic status, and health. The Milbank Quarterly, 68, 383-411. doi:10.2307/3350111

Hurd, M. D. (1990). Research on the elderly: Economic status, retirement, and consumption and saving. Journal of Economic Literature, 28(2), 565-637.

Hurd, M., \& Boskin, M. (1984). The effect of social security on retirement in the early 1970s. The Quarterly Journal of Economics, 99(4), 767-790. doi: $10.2307 / 1883125$

Hurd, M. D., \& Rohwedder, S. (2010). The effects of the economic crisis on the older population (Working Paper No. WP 2010-231). Ann Arbor, MI: University of Michigan Retirement Research Center. 
Imbens, G. W., Rubin, D. B., \& Sacerdote, B. I. (2001). Estimating the effect of unearned income on labor earnings, savings, and consumption: Evidence from a survey of lottery players. American Economic Review, 91(4), 778-794. doi:10.1257/aer.91.4.778

Jackson, J. S., Chatters, L. M., \& Taylor, R. J. (1993). Aging in Black America. Newbury Park, CA: Sage.

Jaeger, M. M., \& Holm, A. (2004). How stressful is retirement? New evidence from a longitudinal, fixed-effects analysis (Working Paper No. 2004-19). Copenhagen, Denmark: University of Copenhagen Centre for Applied Microeconometrics.

Jex, S. M., \& Grosch, J. (2013). Retirement decision making. In M. Wang (Ed.), The Oxford handbook of retirement (pp. 267-279). New York, NY: Oxford University Press. doi:10.1093/oxfordhb/9780199746521.013.0106

Jokela, M., Ferrie, J. E., Gimeno, D., Chandola, T., Shipley, M. J., Head, J., . . . Kivimäki, M. (2010). From midlife to early old age: Health trajectories associated with retirement. Epidemiology, 21(3), 284-290.

doi:10.1097/EDE.0b013e3181d61f53

Johnson, R. W., Davidoff, A. J., \& Perese, K. (2003). Health insurance costs and early retirement decisions. Industrial and Labor Relations Review, 56, 716-729. doi: $10.2307 / 3590965$

Johnson, R. W., \& Favreault, M. (2001). Retiring together or working alone: The impact of spousal employment and disability on retirement decisions (CRR Working Paper No. 2001-01). Chestnut Hill, MA: Center for Retirement Research at Boston College. 
Johnson, R. W., Penner, R. G., \& Toohey, D. (2008). Do out-of-pocket health care costs delay retirement? (CRR Working Paper No. 2008-4). Chestnut Hill, MA: Center for Retirement Research at Boston College.

Kalemli-Ozcan, S., \& Weil, D. N. (2010). Mortality change, the uncertainty effect, and retirement. Journal of Economic Growth, 15(1), 65-91. doi:10.1007/s10887-010$9050-1$

Kapur, K., \& Rogowski, J. (2006). Love or money? Health insurance and retirement among married couples (NBER Working Paper No. 12273). Cambridge, MA: National Bureau of Economic Research.

Karoly, L. A., \& Jeannette A. R. (1998). Retiree health benefits and retirement behavior: Implications for health policy. Health Benefits and the Workforce, 2, 43-71.

Karoly, L. A., \& Rogowski, J. A. (1994). The effect of access to post-retirement health insurance on the decision to retire early. ILR Review, 48, 103-123. doi:10.1177/001979399404800108

Kim, H., \& DeVaney, S. A. (2005). The selection of partial or full retirement by older workers. Journal of Family and Economic Issues, 26(3), 371-394. doi:10.1007/s10834-005-5903-8

Kim, S., \& Feldman, D. C. (2000). Working in retirement: The antecedents of bridge employment and its consequences for quality of life in retirement. Academy of Management Journal, 43, 1195-1210. doi:10.2307/1556345

Lacomba, J. A., \& Lagos, F. (2006). Population aging and legal retirement age. Journal of Population Economics, 19(3), 507-519. doi:10.1007/s00148-005-0044-9 
Lévesque, M., \& Minniti, M. (2006). The effect of aging on entrepreneurial behavior. Journal of Business Venturing, 21(2), 177-194. doi:10.1016/j.jbusvent.2005.04.003

Levinson, D. J. (1986). A conception of adult development. American Psychologist, 41, 3-13. doi:10.1037/0003-066X.41.1.3

Lu, X., \& White, H. (2014). Robustness checks and robustness tests in applied economics. Journal of Econometrics, 178, 194-206.

Lumsdaine, R. L., \& Mitchell, O. S. (1999). New developments in the economic analysis of retirement. Handbook of Labor Economics, 3, 3261-3307. doi:10.1016/S15734463(99)30040-7

Lusardi, A. (2002). Preparing for retirement: The importance of planning costs. In Proceedings: Annual Conference on Taxation and Minutes of the Annual Meeting of the National Tax Association (Vol. 95, pp. 148-154). Washington, DC: National Tax Association.

Lusardi, A., \& Mitchell, O. S. (2007). Baby boomer retirement security: The roles of planning, financial literacy, and housing wealth. Journal of Monetary Economics, 54(1), 205-224.

Matthews, A. M., \& Brown, K. (1987). Retirement as a critical life event: The differential experiences of women and men. Research on Aging, 9(4), 548-571. doi:10.1177/0164027587094004

Matthews, A. M., Brown, K. H., Davis, C. K., \& Denton, M. A. (1982). A crisis assessment technique for the evaluation of life events: Transition to retirement as 
an example. Canadian Journal on Aging/La Revue canadienne du vieillissement, 1(3-4), 28-39. doi:10.1017/S071498080001360X

Matthews, R. A., \& Fisher, G. G. (2013). Family, work, and the retirement process: A review and new directions. In M. Wang (Ed.), The Oxford handbook of retirement (pp. 354-370). New York, NY: Oxford University Press.

doi:10.1093/oxfordhb/9780199746521.013.0123

McArdle, F., Stark, I., Levinson, Z., \& Neuman, T. (2012). How does the benefit value of Medicare compare to the benefit value of typical large employer plans? A 2012 update (Issue Brief). Retrieved from the Kaiser Family Foundation website: https://www.kff.org/wp-content/uploads/2013/01/7768-02.pdf

McDonald, L. (1996). Transitions into retirement: A time for retirement final report. Human Resources Development, Canada.

McGarry, K. (2004). Health and retirement: Do changes in health affect retirement expectations? The Journal of Human Resources, 39, 624-648. doi:10.2307/3558990

McNamara, T. K., \& Williamson, J. B. (2004). Race, gender, and the retirement decisions of people ages 60 to 80: Prospects for age integration in employment. The International Journal of Aging and Human Development, 59(3), 255-286. doi:10.2190/GE24-03MX-U34P-AMNH

Mein, G., Martikainen, P., Stansfeld, S. A., Brunner, E. J., Fuhrer, R., \& Marmot, M. G. (2000). Predictors of early retirement in British civil servants. Age and Ageing, 29, 529-536. doi:10.1093/ageing/29.6.529

Merton, R. K. (1957). Social theory and social structure. Glencoe, IL: Free Press. 
Meyer, A. (1951). The life chart and the obligation of specifying positive data in psychopathological diagnosis. The collected papers of Adolf Meyer, 3, 52-56.

Miles, J. (2005). Tolerance and variance inflation factor. In B. S. Everitt \& D. C. Howell (Eds.), Encyclopedia of statistics in behavioral science (pp. 2055-2056). Hoboken, NJ: John Wiley and Sons.

Miller, M. (2018, June 21). Companies need older workers: Here is why. Reuters. Retrieved from https://www.reuters.com/article/us-world-workolderworkers/companies-need-older-workers-here-is-why-idUSKBN1JH15F

Mitchell, O. S., \& Fields, G. S. (1984). The economics of retirement behavior. Journal of Labor Economics, 2(1), 84-105. doi:10.1086/298024

Moen, P. (1996). A life course perspective on retirement, gender, and well-being. Journal of Occupational Health Psychology, 1, 131-144.

Moen, P., Dempster-McClain, D., \& Williams, R. W., Jr. (1992). Successful aging: A life-course perspective on women's multiple roles and health. American Journal of Sociology, 97(6), 1612-1638. doi:10.1086/229941

Mulki, J. P., Jaramillo, J. F., \& Locander, W. B. (2008). Effect of ethical climate on turnover intention: Linking attitudinal- and stress theory. Journal of Business Ethics, 78(4), 559-574. doi:10.1007/s10551-007-9368-6

Munnell, A. H., Muldoon, D., \& Sass, S. A. (2009). Recessions and older workers (Issue Brief No. 9-2). Chestnut Hill, MA: Center for Retirement Research at Boston College.

Munnell, A. H., \& Sass, S. A. (2008). The decline of career employment (Issue Brief 814). Chestnut Hill, MA: Center for Retirement Research at Boston College. 
Neuman, T., Cubanski, J., Huang, J., \& Damico, A. (2015, Jan 14). The rising cost of living longer: Analysis of Medicare spending by age for beneficiaries in traditional Medicare. Retrieved from https://www.kff.org/medicare/report/therising-cost-of-living-longer-analysis-of-medicare-spending-by-age-forbeneficiaries-in-traditional-medicare/

Nyce, S., Schieber, S., Shoven, J. B., Slavov, S., \& Wise, D. A. (2011). Does retiree health insurance encourage early retirement? (NBER Working Paper No. 17703). Retrieved from the National Bureau of Economic Research website: https://www.nber.org/papers/w17703

Olesen, S. C., Butterworth, P., \& Rodgers, B. (2012). Is poor mental health a risk factor for retirement? Findings from a longitudinal population survey. Social Psychiatry and Psychiatric Epidemiology, 47, 735-744. doi:10.1007/s00127-011-0375-7

Palmer, L., Bhargava, V., \& Hong, G. S. (2006). Will adoption and life events among older adults. Financial Services Review, 15(4), 281-295.

Paradise, M. B., Naismith, S. L., Davenport, T. A., Hickie, I. B., \& Glozier, N. S. (2012). The impact of gender on early ill-health retirement in people with heart disease and depression. Australian and New Zealand Journal of Psychiatry, 46, 249-256. doi:10.1177/0004867411427807

Parnes, H. S., \& Nestel, G. (1974). Early retirement. In H. S. Parnes, A. Adams, P. Andrisani, A. Kohen, \& G. Nestel (Eds.), The retirement years: Five years in the work lives of middle-aged men (Vol. 4, pp. 153-196). Columbus, OH: Ohio University Center for Human Resources Research. 
Pavalko, E. K., Elder, G. H., Jr., \& Clipp, E. C. (1993). Worklives and longevity: Insights from a life course perspective. Journal of Health and Social Behavior, 34, 363380. doi:10.2307/2137373

Pellechio, A. J. (1979). Social Security financing and retirement behavior. The American Economic Review, 69(2), 284-287.

Pew Charitable Trust (2016). Employer-sponsored retirement plan access, uptake, and savings. Philadelphia, PA. Retrieved from https://www.pewtrusts.org/en/researchand-analysis/issue-briefs/2016/09/employer-sponsored-retirement-plan-accessuptake-and-savings

Pienta, A. M., \& Hayward, M. D. (2002). Who expects to continue working after age 62? The retirement plans of couples. The Journals of Gerontology, Series B: Psychological Sciences and Social Sciences, 57(4), S199-S208. doi:10.1093/geronb/57.4.S199

Poterba, J., Rauh, J., Venti, S., \& Wise, D. (2007). Defined contribution plans, defined benefit plans, and the accumulation of retirement wealth. Journal of public economics, 91(10), 2062-2086.

Pozzebon, S., \& Mitchell, O. S. (1989). Married women's retirement behavior. Journal of Population Economics, 2(1), 39-53. doi:10.1007/BF00599179

Pritchard, D., Petrilla, A., Hallinan, S., Taylor, D. H., Jr., Schabert, V. F., \& Dubois, R. W. (2016). What contributes most to high health care costs? Health care spending in high resource patients. Journal of Managed Care \& Specialty Pharmacy, 22(2), 102-109. doi:10.18553/jmcp.2016.22.2.102 
Quick, H. E., \& Moen, P. (1998). Gender, employment, and retirement quality: A life course approach to the differential experiences of men and women. Journal of Occupational Health Psychology, 3, 44-64. doi:10.1037/1076-8998.3.1.44

Quintini, G., \& Venn, D. (2013). Back to work: Re-employment, earnings and skill use after job displacement (Final Report). Retrieved from the Organisation for Economic Co-operation and Development website: https://www.oecd.org/employment/emp/Backtowork-report.pdf

Rabkin, J. G., \& Struening, E. L. (1976). Life events, stress, and illness. Science, 194(4269), 1013-1020. doi:10.1126/science.790570

Rahe, R. H. (1992). Van Gogh and the life chart. Integrative Physiological and Behavioral Science, 27(4), 323-335. doi:10.1007/BF02691167

Redfield, J., \& Stone, A. A. (1979). Individual viewpoints of stressful life events. Journal of Consulting and Clinical Psychology, 47(1), 147-154.

Reitzes, D. C., Mutran, E. J., \& Fernandez, M. E. (1996). Preretirement influences on postretirement self-esteem. The Journals of Gerontology, Series B: Social Sciences, 51B, S242-S249. doi:10.1093/geronb/51B.5.S242

Rice, N. E., Lang, I. A., Henley, W., \& Melzer, D. (2011). Common health predictors of early retirement: Findings from the English Longitudinal Study of Ageing. Age and Ageing, 40, 54-61. doi:10.1093/ageing/afq153

Rosow, I. (1967). Social integration of the aged. New York: Free Press.

Ruhm, C. J. (1991). Are workers permanently scarred by job displacements? The American Economic Review, 81(1), 319-324. 
Schmitt, N., \& McCune, J. T (1981). The relationship between job attitudes and the decision to retire. Academy of Management Journal, 24, 795-802. doi: $10.2307 / 256177$

Schulz, J. H. (1992). The economics of aging. Westport, CT: Auburn House.

Scopelliti, D. M. (2014). Housing: Before, during, and after the Great Recession. Retrieved from the U.S. Department of Labor, Bureau of Labor Statistics, website: https://www.bls.gov/spotlight/2014/housing/home.htm

Sefton, T., Evandrou, M., \& Falkingham, J. (2011). Family ties: women's work and family histories and their association with incomes in later life in the UK. Journal of Social Policy, 40(1), 41-69. doi:10.1017/S0047279410000255

Settersten, R. A., Jr., \& Hagestad, G. O. (1996). What's the latest? Cultural age deadlines for educational and work transitions. The Gerontologist, 36, 602-613. doi:10.1093/geront/36.5.602

Sevak, P. (2002). Wealth shocks and retirement time: Evidence from the nineties (Working Paper No. 2002-027). Ann Arbor, MI: University of Michigan Retirement Research Center.

Shanas, E. (1970). Health and adjustment in retirement. The Gerontologist, 10(1), 19-21. doi:10.1093/geront/10.1_Part_2.19

Shaw, L. B. (1984). Retirement plans of middle-aged married women. The Gerontologist, 24(2), 154-159. doi:10.1093/geront/24.2.154

Shultz, K. S., Morton, K. R., \& Weckerle, J. R. (1998). The influence of push and pull factors on voluntary and involuntary early retirees' retirement decision and 
adjustment. Journal of Vocational Behavior, 53, 45-57.

doi:10.1006/jvbe.1997.1610

Shultz, K. S., \& Wang, M. (2007). The influence of specific physical health conditions on retirement decisions. The International Journal of Aging and Human Development, 65(2), 149-161. doi:10.2190/AG.65.2.c

Shultz, K. S., \& Wang, M. (2011). Psychological perspectives on the changing nature of retirement. American Psychologist, 66(3), 170-179. doi:10.1037/a0022411

Singh, G., Kaur, D., \& Kaur, H. (1984). Presumptive stressful life events scale (PSLES) - A new stressful life events scale for use in India. Indian Journal of Psychiatry, 26(2), 107-114.

Smeaton, D., \& McKay, S. (2003). Working after state pension age: Quantitative analysis (Department for Work and Pensions Research Report No. 182). Norwich, UK: Corporate Document Services.

Smith, D. B., \& Moen, P. (1998). Spousal influence on retirement: His, her, and their perceptions. Journal of Marriage and Family, 60(3), 734-744. doi: $10.2307 / 353542$

Smith, J. P. (1995). Racial and ethnic differences in wealth in the Health and Retirement Study. Journal of Human resources, S158-S183.

Social Security Board of Trustees. (2017). The 2017 annual report of the Board of Trustees of the federal Old-Age and Survivors Insurance and federal Disability Insurance Trust Funds. Retrieved from https://www.ssa.gov/oact/tr/2017/tr2017.pdf 
Stevens, A. H. (1997). Persistent effects of job displacement: The importance of multiple job losses. Journal of Labor Economics, 15(1, Part 1), 165-188.

Streib, G. F, \& Schneider, C. J. (1971). Retirement in American society. Ithaca, NY: Cornell University Press.

Stock, J. H., \& Wise, D. A. (1990). Pensions, the option value of work, and retirement. Econometrica, 58(5), 1151-1180. doi:10.2307/2938304

Szinovacz, M. E. (2003). Contexts and pathways: Retirement as institution, process, and experience. In G. A. Adams \& T. A. Beehr (Eds.), Retirement: Reasons, processes, and results (pp. 6-52). New York, NY: Springer.

Szinovacz, M. E., DeViney, S., \& Davey, A. (2001). Influences of family obligations and relationships on retirement: Variations by gender, race, and marital status. The Journals of Gerontology, Series B: Psychological Sciences and Social Sciences, 56(1), S20-S27. doi:10.1093/geronb/56.1.S20

Szinovacz, M. E., Martin, L., \& Davey, A. (2013). Recession and expected retirement age: Another look at the evidence. The Gerontologist, 54(2), 245-257. doi:10.1093/geront/gnt010

Szinovacz, M., \& Washo, C. (1992). Gender differences in exposure to life events and adaptation to retirement. Journal of Gerontology, 47(4), S191-S196. doi:10.1093/geronj/47.4.S191

Taylor, M. A., \& Doverspike, D. (2003). Retirement planning and preparation. In G. A. Adams \& T. A. Beehr (Eds.), Retirement: Reasons, processes, and results (pp. 53-82). New York, NY: Springer Publishing Company. 
Taylor, M. A., \& Schaffer, M. (2013). Planning and adaptation to retirement: The postretirement environment, change management resources, and need-oriented factors as moderators. In M. Wang (Ed.), The Oxford handbook of retirement (pp. 249266). New York, NY: Oxford University Press.

Taylor, M. A., \& Shore, L. M. (1995). Predictors of planned retirement age: An application of Beehr's model. Psychology and Aging, 10, 76-83.

Topel, R. (1990, September). Specific capital and unemployment: Measuring the costs and consequences of job loss. In Carnegie-Rochester Conference Series on Public Policy (Vol. 33, pp. 181-214). North-Holland.

U.S. Department of Commerce, Census Bureau (2009). U.S. Population Projections: 2009 National Population Projections. Retrieved from https://www.census.gov/data/tables/2009/demo/popproj/2009-popprojcomptables.html

U.S. Department of Labor, Bureau of Labor Statistics. (2018). The Economics Daily: Labor force participation rate at 62.7 percent in September 2018, little changed over last 5 years. Retrieved from https://www.bls.gov/opub/ted/2018/labor-forceparticipation-rate-at-62-7-percent-in-september-2018-little-changed-over-last-5years.htm

Van Rooij, M. C., Lusardi, A., \& Alessie, R. J. (2012). Financial literacy, retirement planning and household wealth. The Economic Journal, 122(560), 449-478. van Solinge, H., \& Henkens, K. (2014). Work-related factors as predictors in the retirement decision-making process of older workers in the Netherlands. Ageing and Society, 34, 1551-1574. 
Wang, M. (2007). Profiling retirees in the retirement transition and adjustment process: Examining the longitudinal change patterns of retirees' psychological wellbeing. Journal of Applied Psychology, 92(2), 455-474.

Wang, M., Zhan, Y., Liu, S., \& Shultz, K. S. (2008). Antecedents of bridge employment: A longitudinal investigation. Journal of Applied Psychology, 93, 818-830. doi:10.1037/0021-9010.93.4.818

Wheaton, B. (1990). Life transitions, role histories, and mental health. American Sociological Review, 55, 209-223. doi:10.2307/2095627

Wheaton, F., \& Crimmins, E. M. (2013). The demography of aging and retirement. In M. Wang (Ed.), The Oxford handbook of retirement (pp. 22-41). New York, NY: Oxford University Press.

Yabiku, S. T. (2000). Family history and pensions: The relationships between marriage, divorce, children, and private pension coverage. Journal of Aging Studies, 14(3), 293-312. doi:10.1016/S0890-4065(00)08023-3

Yao, R., \& Cheng, G. (2017). Millennials' retirement saving behavior: Account ownership and balance. Family and Consumer Sciences Research Journal, 46(2), 110-128. doi:10.1111/fcsr.12241

Yao, R., \& Park, E. (2012). Market performance and the timing of retirement. Journal of Personal Finance, 11(1), 10-48.

Yashin, A. I., Arbeev, K. G., Kulminski, A., Akushevich, I., Akushevich, L., \& Ukraintseva, S. V. (2007). Health decline, aging and mortality: How are they related? Biogerontology, 8(3), 291-302. 
Zappalà, S., Depolo, M., Fraccaroli, F., Guglielmi, D., \& Sarchielli, G. (2008).

Postponing job retirement? Psychosocial influences on the preference for early or late retirement. The Career Development International, 13, 150-167. doi:10.1108/13620430810860558

Zickar, M. J. (2013). The evolving history of retirement within the United States. In M. Wang (Ed.), The Oxford handbook of retirement (pp. 10-21). New York, NY: Oxford University Press. 


\section{VITA}

Guopeng Cheng received his bachelor's degree in Personal Financial Planning in December 2012, master's degree in Personal Financial Planning in May 2015, and PhD in Personal Financial Planning in July 2019 from the University of Missouri-Columbia. He has presented his research at the 2017, 2018, and 2019 conferences of the American Council on Consumer Interests (ACCI). He received the 2017 ACCI travel scholarship and 2018 Consumer Movement Archives Applied Economics Student Paper Award. In addition, he published "Millennials' Retirement Saving Behavior: Account Ownership and Balance," coauthored with Dr. Rui Yao, in the Family and Consumer Sciences Research Journal in December 2017. This paper won the award for Best Paper in Personal Finance and Consumer Economics published in the journal that year. Guopeng gained his teaching and research experiences while he worked as a teaching and researching assistant in the Personal Financial Planning Department at the University of Missouri-Columbia from 2015 to 2019. Guopeng gained his financial planning industry experience through internships at State Farm Insurance Company, LPL Financial, and Pension Consultants, Inc. 